\title{
Control scheme for cathode airflow during load swings in a solid oxide fuel cell/gas turbine system
}

\author{
Megan Rae Gorrell \\ West Virginia University
}

Follow this and additional works at: https://researchrepository.wvu.edu/etd

\section{Recommended Citation}

Gorrell, Megan Rae, "Control scheme for cathode airflow during load swings in a solid oxide fuel cell/gas turbine system" (2012). Graduate Theses, Dissertations, and Problem Reports. 217.

https://researchrepository.wvu.edu/etd/217

This Thesis is protected by copyright and/or related rights. It has been brought to you by the The Research Repository @ WVU with permission from the rights-holder(s). You are free to use this Thesis in any way that is permitted by the copyright and related rights legislation that applies to your use. For other uses you must obtain permission from the rights-holder(s) directly, unless additional rights are indicated by a Creative Commons license in the record and/ or on the work itself. This Thesis has been accepted for inclusion in WVU Graduate Theses, Dissertations, and Problem Reports collection by an authorized administrator of The Research Repository @ WVU. For more information, please contact researchrepository@mail.wvu.edu. 


\title{
CONTROL SCHEME FOR CATHODE AIRFLOW DURING LOAD SWINGS IN A SOLID OXIDE FUEL CELL/GAS TURBINE SYSTEM
}

\author{
by \\ Megan Rae Gorrell \\ Thesis submitted to the \\ College of Engineering and Mineral Resources \\ at West Virginia University \\ in partial fulfillment of the requirements \\ for the degree of \\ Master of Science \\ in \\ Mechanical Engineering \\ Larry Banta, Ph.D., Chair \\ Ken Means, Ph.D. \\ David Tucker, Ph.D.
}

Department of Mechanical and Aerospace Engineering

Morgantown, West Virginia

2012

Keywords: Solid Oxide Fuel Cells (SOFC); Hybrid Fuel Cell Systems; SOFC/GT; HyPer; Control 


\title{
CONTROL SCHEME FOR CATHODE AIRFLOW DURING LOAD SWINGS IN A SOLID OXIDE FUEL CELL/GAS TURBINE SYSTEM
}

\section{Megan Rae Gorrell}

\begin{abstract}
Control and management of cathode airflow in a solid oxide fuel cell gas turbine hybrid power system was analyzed using the Hybrid Performance (HyPer) hardware simulation at the National Energy Technology Laboratory (NETL), U.S. Department of Energy. This work delves into previously unexplored operating practices for HyPer, via simultaneous manipulation of bypass valves and the electric load on the generator. The work is preparatory to the development of a Multi-Input, Multi-Output (MIMO) controller for HyPer. A factorial design of experiments was conducted to acquire data for 81 different combinations of the manipulated variables, which consisted of three air flow control valves and the electric load on the turbine generator. From this data the response surfaces for the cathode airflow and other operational parameters with respect to bypass valve positions or electric load were analyzed. The control of airflow through the cathode during system startup and during large load swings is of particular interest.

This work presents two algorithms for controlling air mass flow through the cathode. The first was an initial trajectory based on steepest ascent method to minimize valve movement. The second and more optimal trajectory determines the trajectories taking into account safe operation with the least penalty in efficiency particularly during load variations. This was achieved by identifying step changes during a load change where the load division between the solid oxide fuel cell and gas turbine are optimal. These load changes result in changes in cathode airflow. The hot air, cold air, and bleed air bypasses are used to achieve these cathode mass flow rates. The hot air bypass is the main method of variation in cathode airflow and is varied to its full range. The cold air bypass valve however, is held as close as possible to an identified efficient location of $20 \%$ open. To maintain stability the bleed air bypass is used only when the compressor flow reaches below a determined minimum of $2.02 \mathrm{~kg} / \mathrm{s}$. These criteria work to create an effective control scheme that showcases complex relationships in which load swings can be managed in the HyPer system.
\end{abstract}




\section{Acknowledgements}

First I want to thank Dr. Banta for all of his guidance throughout this project and my academic career at West Virginia University. I would like to thank him for introducing me to this project and giving me the opportunity to author two conference papers and present at the Fuel Cell Conference in Washington D.C. Also I want to thank him for allowing me to return to the project and helping me create this thesis. Working on this project though trying at times, has been a very rewarding experience.

I would also like to thank Dr. David Tucker, Alex Tsai, Bernardo Restrepo, and everyone at NETL for use of the facility as well as assistance throughout the testing and analysis phases of this work. A special thanks goes to William "Bill" Rosen for being my partner in crime in my academic endeavors and assisting me in the testing and beginning analysis of this work. I could not have done it without him and he is and always will be a great friend.

Dr. Means has also been instrumental in this work. I want to thank him for his willingness to fund me even though my thesis was on an unrelated project from my Graduate Research position. I thoroughly enjoyed working with him this year and helping with the Energy Star projects as well as the senior design projects. It has been a very fulfilling experience. I would also like to thank Cari CrumbakerKinnet for introducing me to Dr. Means when we worked on the New Vision solar panel project. She is an awesome friend and I owe her a lot.

Finally I would like to thank Doug for always being there for me. I could not have completed my master's degree without his love and support. He was also very helpful in proofreading this entire thesis, no easy feat, and helping me make it what it is today. I really want to thank all of my friends and family for their support through my college career and this master's thesis. Thanks mom for always pushing me to get it done. You're right it does feel really good now that it's all finished. 


\section{Table of Contents}

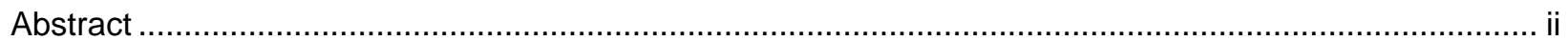

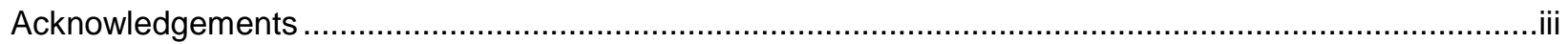

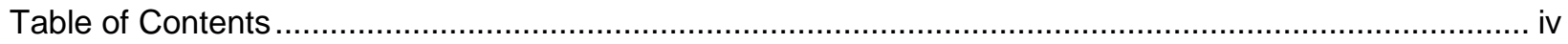

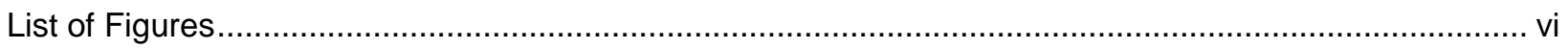

List of Tables

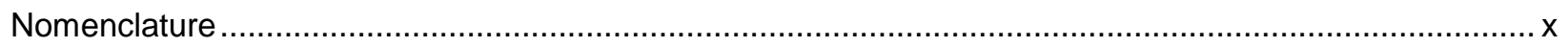

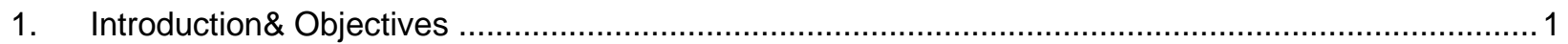

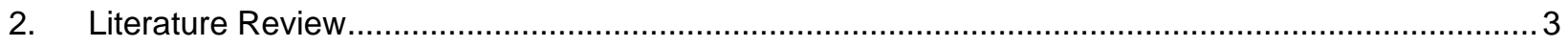

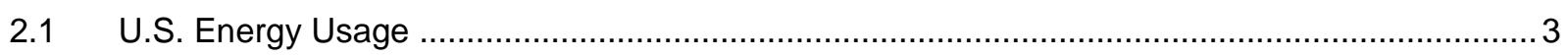

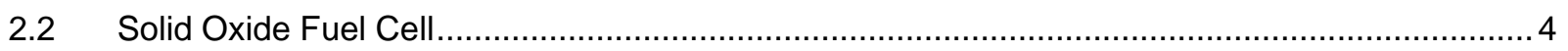

2.3 Solid Oxide Fuel Cell Gas Turbine Hybrids ............................................................................ 7

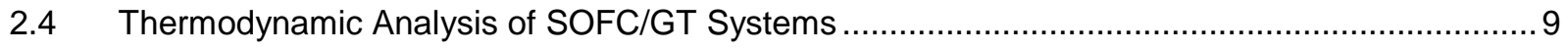

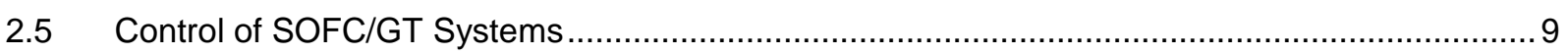

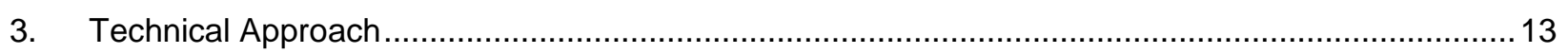

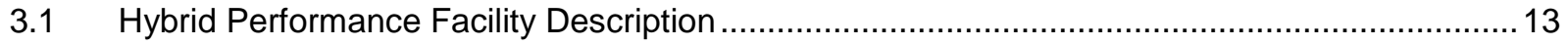

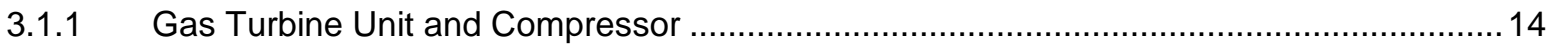

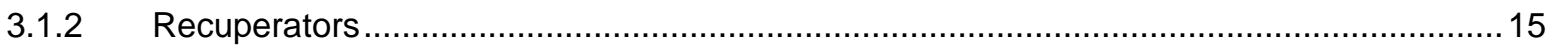

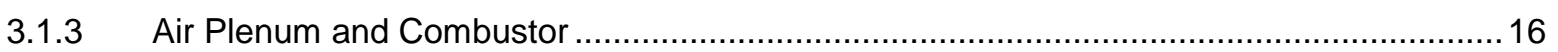

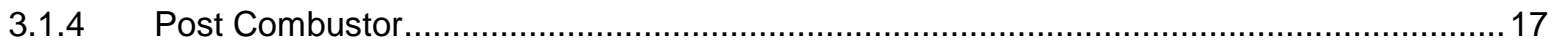

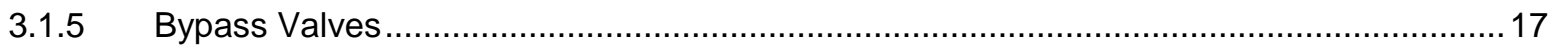

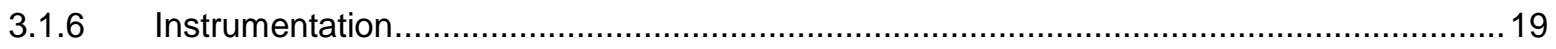

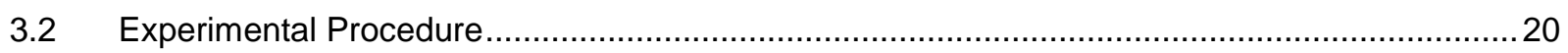

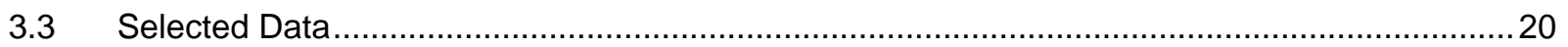

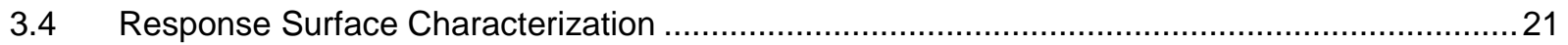

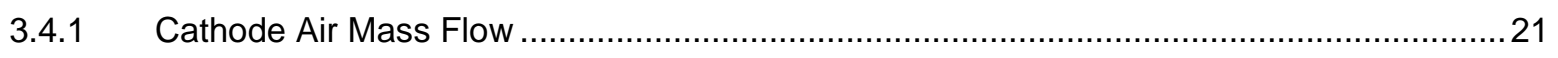

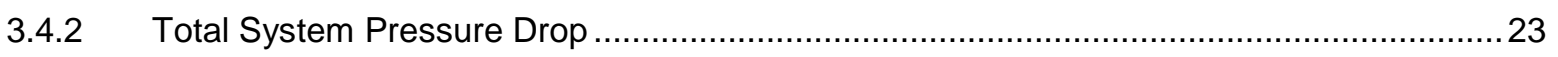

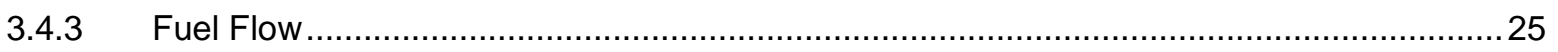

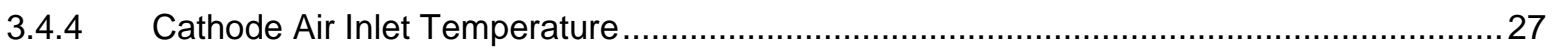

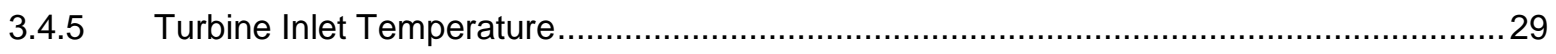

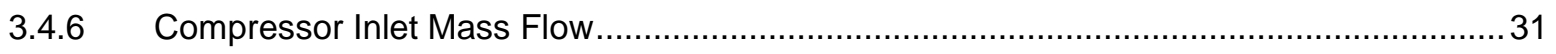

3.5 Load Division Strategy during Power Demand Step Changes .............................................. 32

3.5.1 Steady State Load Distribution and SOFC Mass Flow Rate ......................................... 34

3.5.2 Power Division and SOFC Mass Flow Rate in Response to a Load Change ....................35

3.6 Control Valve Trajectory for Cathode Airflow using Modified Steepest Ascent Method ..............36

3.7 Optimal Control of Cathode Airflow............................................................................................. 42 


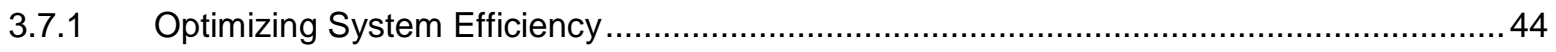

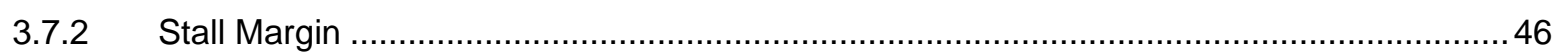

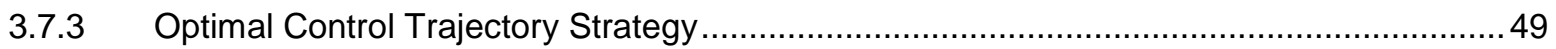

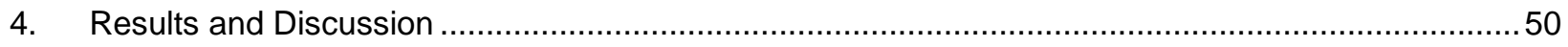

4.1 Test Cases to Showcase a Control Scheme over a Wide Range of Load Change Scenarios .. 50

4.1.1 Optimal Cathode Mass Flow Rate during a Total System Load Increase .........................51

4.1.1.1 Cathode Airflow Trajectory for Total System Load Increase from 100kw to $125 \mathrm{~kW} \ldots . . .51$

4.1.1.2 Cathode Airflow Trajectory for Total System Load Increase from 125kW to $200 \mathrm{~kW} . \ldots . .55$

4.1.1.3 Cathode Airflow Trajectory for Total System Load Increase from 100kW to $240 \mathrm{~kW} \ldots \ldots .59$

4.1.2 Optimal Cathode Mass Flow Rate during a Load Decrease ............................................ 63

4.1.2.1 Cathode Airflow Trajectory for Total System Load Decrease from 200kW to $140 \mathrm{~kW}$....63

4.1.2.2 Cathode Airflow Trajectory for Total System Load Decrease from $260 \mathrm{~kW}$ to $120 \mathrm{~kW} . . .67$

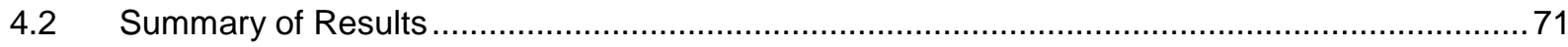

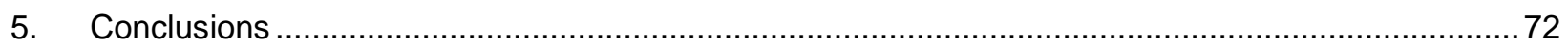

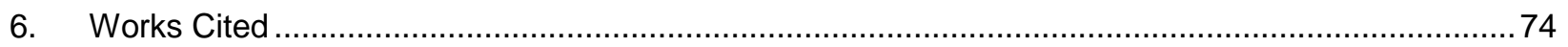

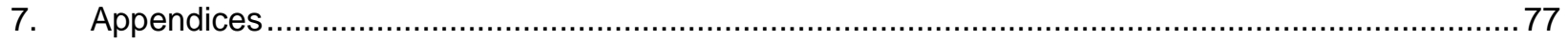

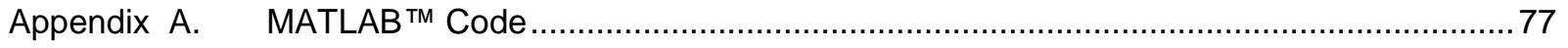

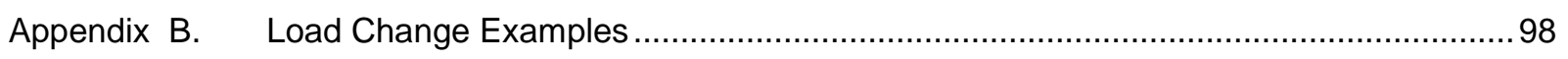

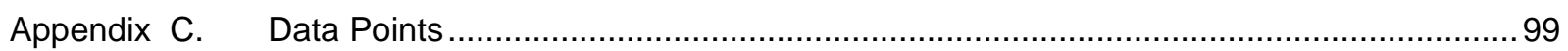




\section{List of Figures}

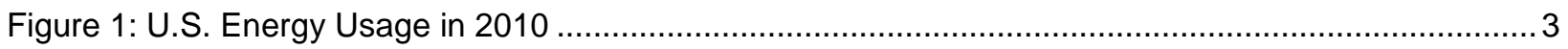

Figure 2: U.S. Electricity Generation Distribution by Fuel Source ........................................................ 4

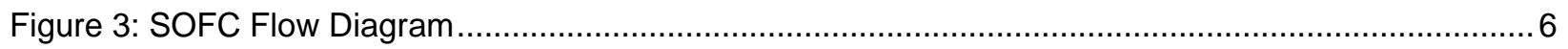

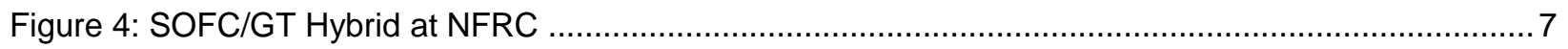

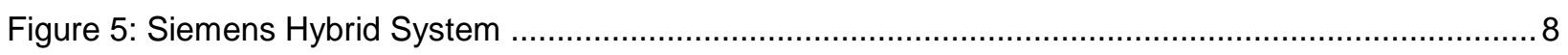

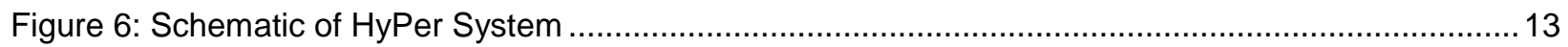

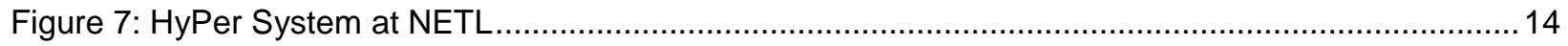

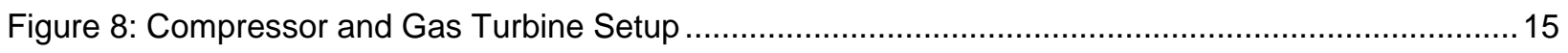

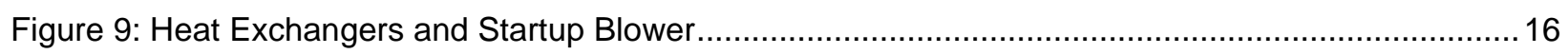

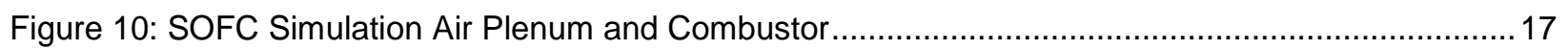

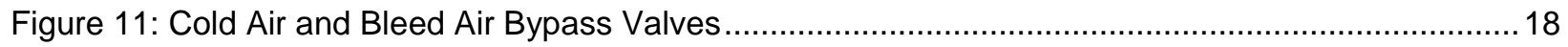

Figure 12: Hot Air Bypass Valve ............................................................................................. 18

Figure 13: Flow Diagram for the Hybrid Performance Facility at NETL ................................................ 19

Figure 14: Comparison of Experimentally Measured Cathode Air Mass Flow with Value Predicted by

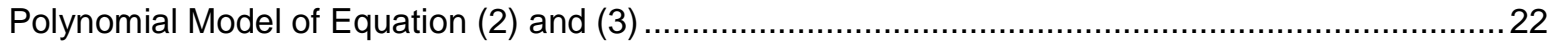

Figure 15: Cathode Mass Flow Rate as a Function of Hot Air and Cold Air Valve Positions ....................23

Figure 16: Comparison of Experimentally Measured System Pressure Drop with Value Predicted by

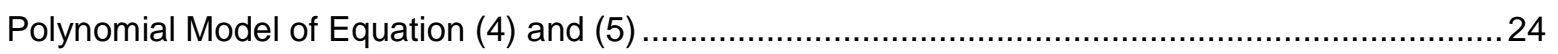

Figure 17: Total System Pressure Drop as a Function of Electric Load and Cold Air Valve Position .........25

Figure 18: Comparison of Experimentally Measured Fuel Flow with Value Predicted by Polynomial Model

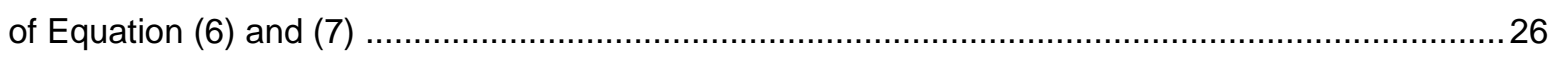

Figure 19: Fuel Flow as a Function of Electric Load and Cold Air Valve Position.....................................27

Figure 20: Comparison of Experimentally Measured Cathode Air Inlet Temperature with Value Predicted

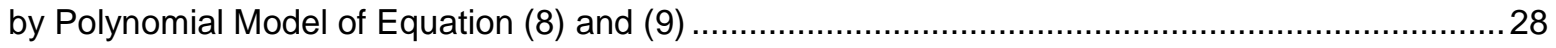

Figure 21: Cathode Inlet Temperature as a Function of Electric Load and Bleed Air Valve Position ........29

Figure 22: Comparison of Experimentally Measured Turbine Inlet Temperature with Value Predicted by

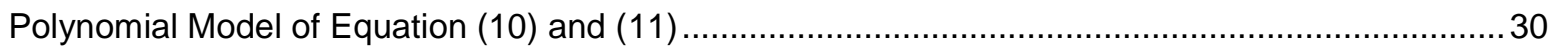

Figure 23: Turbine Inlet Temperature as a Function of Electric Load and Combined CA and BA bypass air

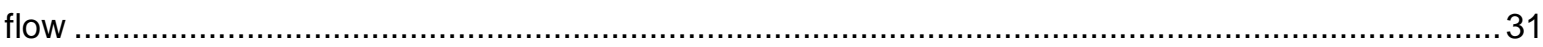

Figure 24: Comparison of Experimentally Measured Compressor Inlet Mass Flow with Value Predicted by

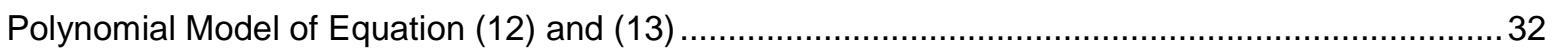

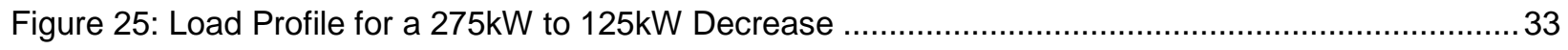

Figure 26: Steepest Accent Method Drives HA below 20\% Open for Certain Initial Conditions which Violates the Correlation Equation Boundaries ........................................................................ 37

Figure 27: Potential Function Reaction with Gradients along Operational Boundary .............................. 38 
Figure 28: Constrained Steepest Accent with HA in Bounds. 39

Figure 29: Comparison of Two Different Initial Cathode Airflow but Identical Final Cathode Airflow ..........40 Figure 30: Comparison of Identical Final Cathode Airflow Trajectories on the Response Surface of Cathode Airflow 41

Figure 31: Comparison of Identical Final Cathode Airflow Trajectories along the Contour of Simplified Cathode Airflow Response Surface ..... 41

Figure 32: Contour Map of Cathode Flow Rate with respect to HA and CA Valve Positions Contour lines are for constant air mass flow through the cathode, and are given in $\mathrm{kg} / \mathrm{s}$ 42

Figure 33: Contour Map of Cathode Flow Rate with respect to HA and CA Valve Positions Contour lines are for constant air mass flow through the cathode, and are given in $\mathrm{kg} / \mathrm{s}$ 43

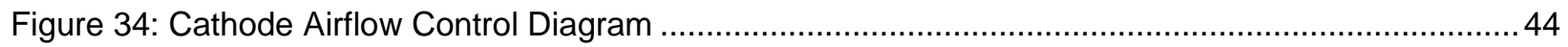

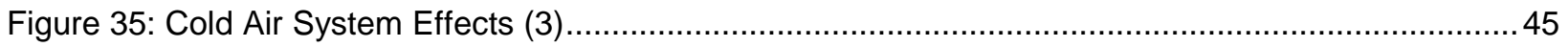

Figure 36: Cold Air Bypass Effect on Cathode Mass Flow Rate (F380) with Old Compressor (3) ............ 45

Figure 37: Cold Air Bypass Effect on Cathode Mass Flow Rate (F380) from Current Data...................... 46

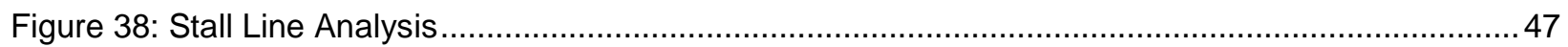

Figure 39: Cold Air Bypass Effect on Previous Compressor's Flow (3) ….......................................... 48

Figure 40: Cold Air Bypass Effect on Current Compressor's Flow ….................................................. 48

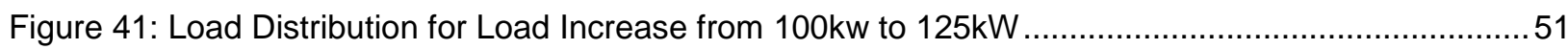

Figure 42: Cathode Mass Flow Rate and Valve Position Variation for a Total Load Increase from 100kW to $125 \mathrm{~kW}$ .52

Figure 43: Cathode Airflow Trajectory on the Response Surface of Cathode Airflow for a Total Load Increase from $100 \mathrm{~kW}$ to $125 \mathrm{~kW}$ .53

Figure 44: Cathode Airflow Trajectory along the Contour of Simplified Cathode Airflow Response Surface for a Total Load Increase from 100kW to $125 \mathrm{~kW}$. .54

Figure 45: Load Distribution for Load Increase from 125kw to $200 \mathrm{~kW}$. 55

Figure 46: Cathode Mass Flow Rate and Valve Position Variation for a Total Load Increase from 125kw to $200 \mathrm{~kW}$ .56

Figure 47: Cathode Airflow Trajectory on the Response Surface of Cathode Airflow for a Total Load Increase from $125 \mathrm{kw}$ to $200 \mathrm{~kW}$. 57

Figure 48: Cathode Airflow Trajectory along the Contour of Simplified Cathode Airflow Response Surface for a Total Load Increase from $125 \mathrm{kw}$ to $200 \mathrm{~kW}$..... .58

Figure 49: Load Distribution for Load Increase of $100 \mathrm{~kW}$ to $240 \mathrm{~kW}$ .59

Figure 50: Cathode Mass Flow Rate and Valve Position Variation for a Total Load Increase from 100kW to $240 \mathrm{~kW}$...... 60

Figure 51: Cathode Airflow Trajectory on the Response Surface of Cathode Airflow for a Total Load Increase from $100 \mathrm{~kW}$ to $240 \mathrm{~kW}$ 61 
Figure 52: Cathode Airflow Trajectory along the Contour of Simplified Cathode Airflow Response Surface

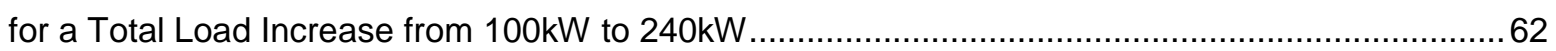

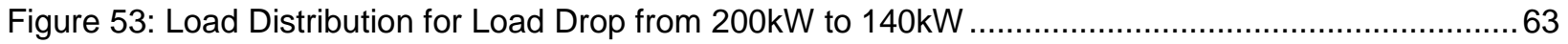

Figure 54: Cathode Mass Flow Rate and Valve Position Variation for a Total Load Drop from 200kW to $140 \mathrm{~kW}$ 64

Figure 55: Cathode Airflow Trajectory on the Response Surface of Cathode Airflow for a Total Load Drop from $200 \mathrm{~kW}$ to $140 \mathrm{~kW}$. 65

Figure 56: Cathode Airflow Trajectory along the Contour of Simplified Cathode Airflow Response Surface

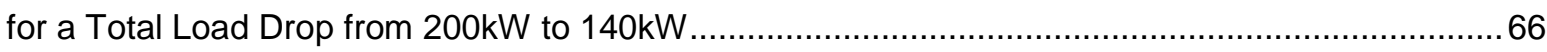

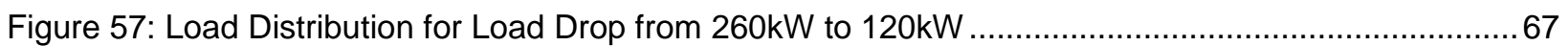

Figure 58: Cathode Mass Flow Rate and Valve Position Variation for a Total Load Drop from 260kW to $120 \mathrm{~kW}$ .68

Figure 59: Cathode Airflow Trajectory on the Response Surface of Cathode Airflow for a Total Load Drop from $260 \mathrm{~kW}$ to $120 \mathrm{~kW}$ 69

Figure 60: Cathode Airflow Trajectory along the Contour of Simplified Cathode Airflow Response Surface for a Total Load Drop from $260 \mathrm{~kW}$ to $120 \mathrm{~kW}$. 70 


\section{List of Tables}

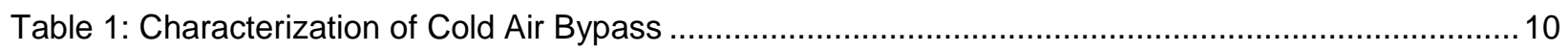

Table 2: Characterization of Hot Air By-pass ............................................................................... 11

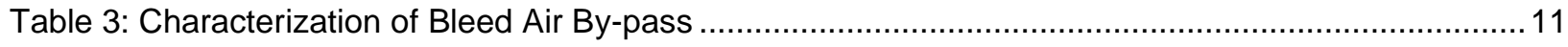

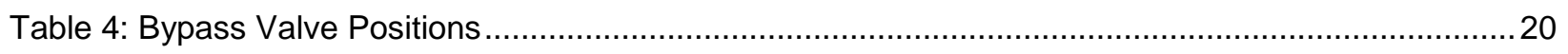

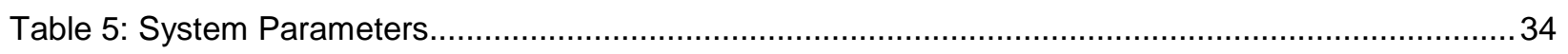

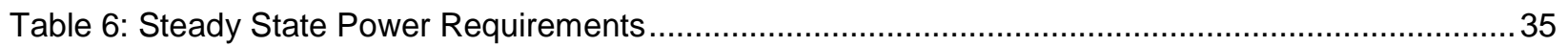

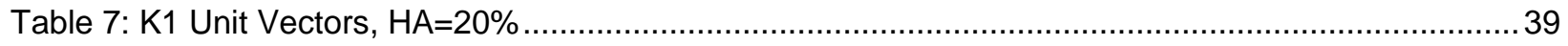

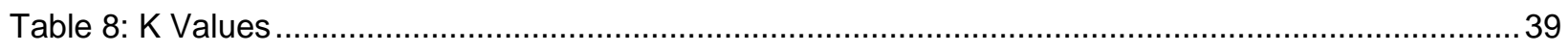




\section{Nomenclature}

\begin{tabular}{|c|c|}
\hline AFC & Alkaline Fuel Cell \\
\hline ASME & American Society of Mechanical Engineers \\
\hline BA & Bleed Air Bypass Valve \\
\hline BFC & Biological Fuel Cell \\
\hline Btu & British Thermal Unit \\
\hline $\mathrm{CA}$ & Cold Air Bypass Valve \\
\hline $\mathrm{CO}_{2}$ & Carbon Dioxide \\
\hline Comb & Combustor \\
\hline DMFC & Direct Methanol Fuel Cell \\
\hline EL & Electric Load on the Gas Turbine \\
\hline $\mathrm{F}$ & Fahrenheit \\
\hline FT & Flow Meter \\
\hline FE & Flow Meter \\
\hline FUF & Fuel Utilization Factor \\
\hline FV & Flow Valve \\
\hline GT & Gas Turbine \\
\hline $\mathrm{HA}$ & Hot Air Bypass Valve \\
\hline HyPer & Hybrid Performance \\
\hline ID & Inside Diameter \\
\hline K & Coefficients \\
\hline K & Kelvin \\
\hline kPag & Kilopascal Gauge \\
\hline $\mathrm{kg}$ & Kilogram \\
\hline $\mathrm{kW}$ & Kilowatt \\
\hline MCFC & Molten Carbonate Fuel Cell \\
\hline $\mathrm{ms}$ & milliseconds \\
\hline NETL & National Energy Technology Laboratory \\
\hline $\mathrm{NO}_{\mathrm{x}}$ & Nitrous Oxide \\
\hline PAFC & Phosphoric Acid Fuel Cell \\
\hline PCFC & Protonic Ceramic Fuel Cell \\
\hline PDT & Pressure Differential Meter \\
\hline PEMFC & Polymer Electrolyte Membrane Fuel Cell \\
\hline PF & Potential Function \\
\hline PFc & Cold Air Valve Potential Function \\
\hline PFh & Hot Air Valve Potential Function \\
\hline
\end{tabular}


$\mathrm{S}$

SOFC

$\mathrm{T}$

TE

U.S.

V

WV

ZAFC

Symbols

$\dot{m}$

$\dot{W}$

$\Delta$

$\eta$ seconds

Solid Oxide Fuel Cell

Turbine

Temperature

United States of America

Volume

West Virginia

Zinc Air Fuel Cell

Mass Flow Rate

Power

Change

Efficiency 


\section{Introduction\& Objectives}

In recent years a need for cleaner more efficient electricity generation has become apparent. The constant depletion of fossil fuels, a finite resource, brings about the necessity of an alternative to conventional power systems. Fuel cells have been identified as a possible solution. Much work has been performed on several configurations of fuel cell types and operating conditions. One promising potential involves the integration of a fuel cell with existing technologies. Gas turbines and commonly used fuels coupled with a fuel cell can experimentally achieve high system efficiencies. However the proper integration and control of these components remains a challenge before such systems become commercially practical.

The research being explored here deals particularly with Solid Oxide Fuel Cells (SOFC) in combination with a gas turbine (GT). This creates a hybrid system. The system is extremely beneficial because the waste heat from the fuel cell is partially recovered by the gas turbine, and the overall efficiency of the system is increased and parasitic losses are eliminated. It has been hypothesized that a configuration of SOFC and gas turbine (SOFC/GT) could achieve efficiencies of up to $70 \%$ based on LHV of natural gas fuel. Siemens-Westinghouse has already developed and tested a tubular hybrid system with a 53\% electrical efficiency using natural gas as fuel and producing $220 \mathrm{~kW}$ of power. The Siemens model's pressure vessel operated at 3 atmospheres and a temperature of about $1000^{\circ} \mathrm{C}(1)$. The Hybrid Performance (HyPer) project, commissioned by the Office of Science and Technology at the National Energy Technology Laboratory (NETL), is an example of a hardware simulation of one such pressurized SOFC/GT hybrid system. The system includes a simulation of a $300 \mathrm{~kW}$ SOFC and a $120 \mathrm{~kW}$ gas turbine auxiliary power unit for electricity generation (2; 3)The HyPer system contains only a simulated fuel cell because fuel cells are very fragile and expensive. Since a fuel cell can be simulated adequately there is no need at the present time to use a "real" fuel cell.

This hybrid fuel cell turbine power system has been identified as a vital component for achieving low emissions and high efficiencies in future power generation technologies $(4 ; 5 ; 6)$. Development of new and effective control strategies is essential to the realization of this type of system. From recent work, cathode airflow management has been identified as critical in the control and performance of the hybrid system. Even minimal changes in the cathode airflow can have a powerful impact on system performance and efficiency as shown by previous work at NETL $(7 ; 8)$. Other former studies at NETL have developed system limitations and operating envelopes for the HyPer system. But thus far the only experimental data collected has consisted of relationships among the pressure, temperature, flow, load and efficiency with system parameters varied one value at a time (2). It is hypothesized that the simultaneous and coordinated operation of the bypass valves and generator electric load could provide a means of increasing the envelope of stable and efficient operation of the hybrid system. Simulation studies by other researchers (e.g. Tsai, Mueller) support this hypothesis, but previously, no demonstration

of such a system has been possible. The present work provides system trajectories and develops the 
control algorithms for desired cathode air flow based on response surfaces that describe the operating state space of the HyPer system. The study was achieved using experimental data from the hardware simulation facility at NETL which is part of the HyPer project and is made available for public research collaboration with universities, industry and other research institutions.

Objectives of this work are:

- Analysis of previously collected data from designed experiments for control development

- Creation of response surfaces for certain state variables critical to the efficient control of the Hyper system

- Identification of system trajectories and development of control algorithms optimizing stability, durability, and efficiency. 


\section{Literature Review}

\subsection{U.S. Energy Usage}

The energy usage in the United States has been increasing over the last few decades at a rapid rate. In fact, the U.S. is the second highest energy using country in the world. The estimated total energy usage for the U.S. in 2010 was 98 Quadrillion Btus (Quads) (9). Figure 1 illustrates the various sources of energy production and their distribution.

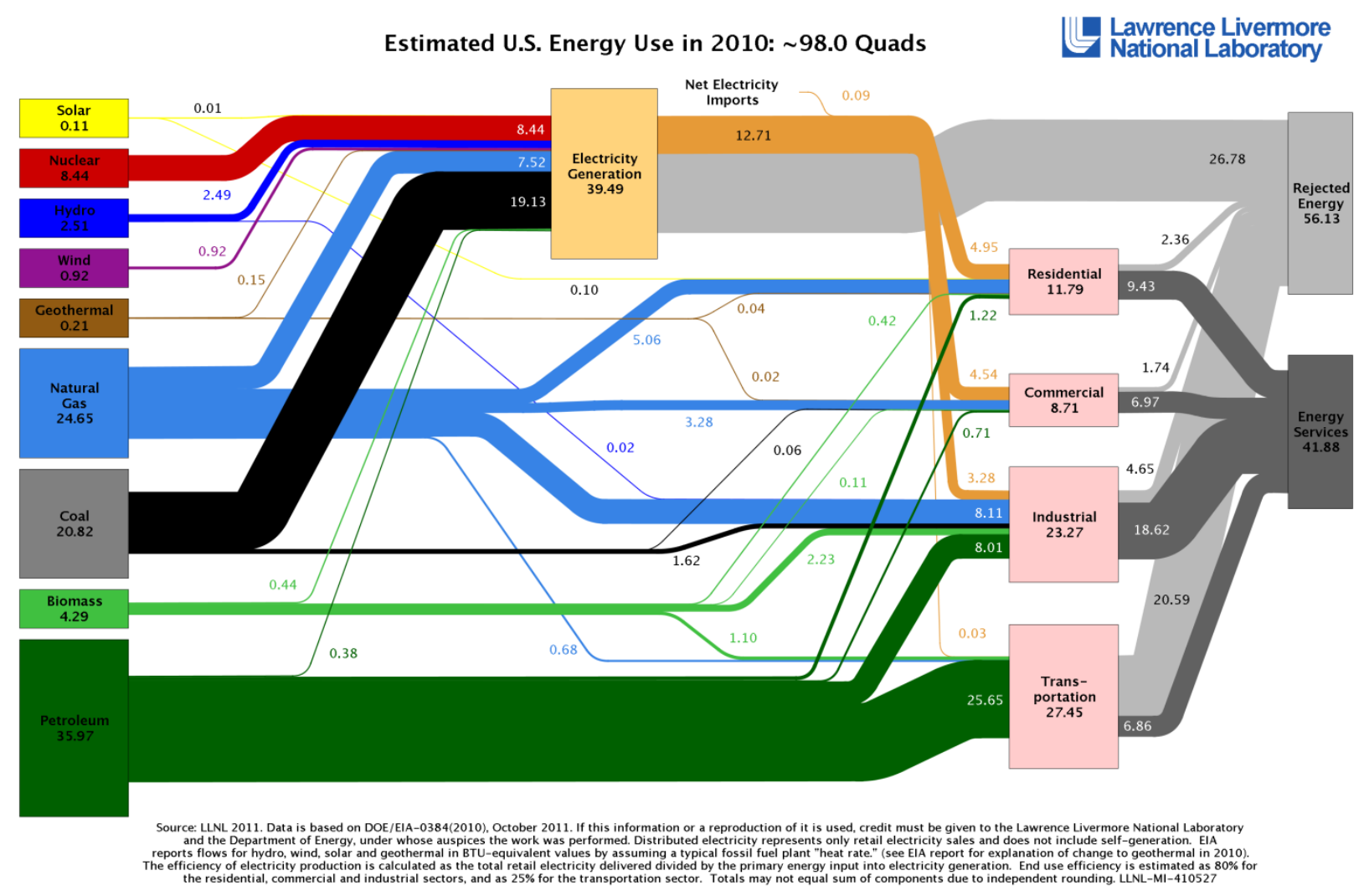

Figure 1: U.S. Energy Usage in 2010

Energy in the U.S. is used in every economic sector, with the primary users being the residential, commercial, industrial, and transportation sectors. Energy is used for generating electricity, heating, industrial processes, and fueling automobiles. Figure 1 also shows that $57 \%$ of energy used in the United States is rejected to the environment as waste heat.

Generating electricity in the United States requires almost 40 percent of our total energy usage. As shown in Figure 2 the main source of this electricity in the U.S. is coal, accounting for almost 50 percent of the electricity generated. While nuclear and natural gas are substantial contributors to electricity generation, the so called renewable energies account for only 10 percent. This leaves the majority of electricity generation dependent upon fossil fuels. 


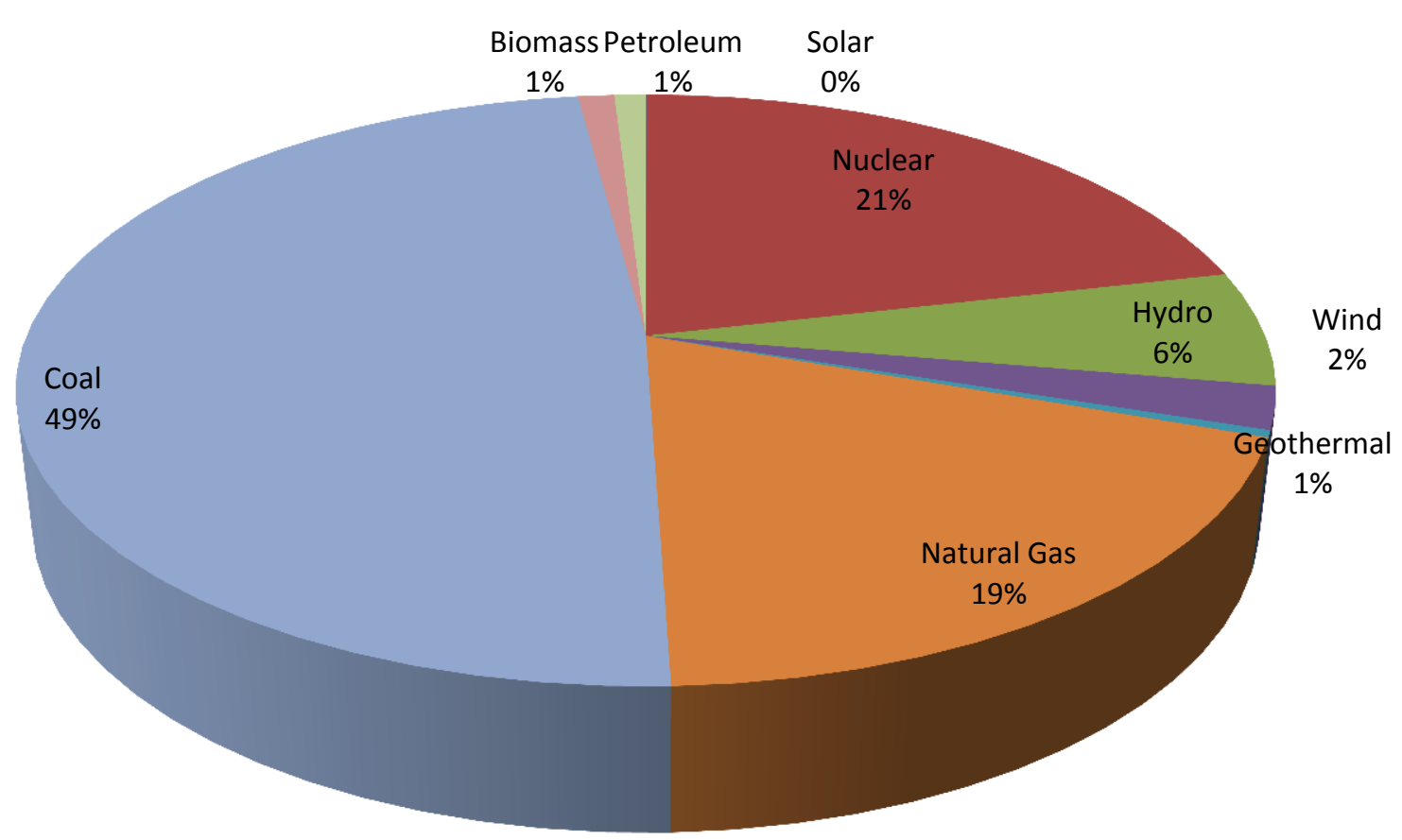

Figure 2: U.S. Electricity Generation Distribution by Fuel Source

It is well known that fossil fuels are a finite resource. There will be a time in the coming centuries when fossil fuels such as coal, petroleum, and natural gas will simply run out. While renewable energy technologies are becoming more advanced and mainstream, they are not yet able to produce enough energy to satisfy the U.S. demand for electricity. One solution to this problem is increasing the efficiency of energy conversion and end-use processes. If coal and natural gas can be utilized more efficiently within a power plant to generate electricity, a substantial decrease in the amount of fossil fuels necessary could be achieved thus postponing the inevitable.

\subsection{Solid Oxide Fuel Cell}

A fuel cell is an energy conversion device transforming chemical energy from component reactions and creating electricity and heat. The active components of a fuel cell include the anode (positive electrode), cathode (negative electrode), and the electrolyte layer. Fuel is fed to the anode and oxygen is fed to the cathode, producing electric current between them (10). In this process the hydrogen and oxygen are ionized and the oxygen ions diffuse through the electrolyte to the anode. Fuel cells combine fuel and an oxidant without burning; this makes fuel cells less polluting than traditional energy generation systems. This is shown in the examination of a traditional power generation system. As previously stated the main producer of electricity in the United States is coal. In a coal power plant coal is burned at high temperatures inside the combustion chamber of a boiler. The combustion of the coal is used to heat water into steam that is run through a steam turbine to turn a generator to produce electricity. The combustion of the coal produces emissions such as carbon dioxide, sulfur dioxide, $\mathrm{NO}_{\mathrm{x}}$, 
carbon monoxide, and particulate matter. Fuel cell emissions vary depending on the fuel used but produce significantly lower carbon dioxide, nitrogen oxide, and sulfur oxide emissions and are much more efficient. A fuel cell has a much more efficient conversion process. The hybrid systems like the one considered in this work produce one and one-half to two times more electricity from one $\mathrm{kg}$ of coal than if the coal was burned in a boiler. This causes an immediate reduction in $\mathrm{CO}_{2}$ from the efficiency increase alone. In addition SOFC designs do not require water for cooling as coal fired plants do and thus reduce water usage. (11)

There are several classifications of fuel cells mostly categorized by the electrolyte or the fuel utilized in the cell. Some of the most common fuel cells include the following:

- Polymer electrolyte membrane fuel cells (PEMFCs)

- Alkaline fuel cells (AFCs)

- Phosphoric acid fuel cells (PAFCs)

- Solid oxide fuel cells (SOFCs)

- Molten carbonate fuel cells (MCFCs)

- Direct methanol fuel cells (DMFCs)

- Zinc air fuel cells (ZAFCs)

- Protonic ceramic fuel cells (PCFCs)

- Biological fuel cells (BFCs)

The PEM fuel cell delivers high power density with a low weight, volume and cost. They are being used for backup power and transportation. AFCs can reach efficiencies of up to $70 \%$ based on hydrogen as fuel with relatively low temperature (up to $250^{\circ} \mathrm{C}$ ). A disadvantage of the alkaline fuel cell is its sensitivity to carbon dioxide; $\mathrm{CO}_{2}$ can react with the electrolyte and degrade performance of the fuel cell. AFCs are therefore limited to closed environments and were used by NASA on several space missions (12). PAFCs are commercially available and widely used, generating efficiencies around $40 \%$ based on natural gas fuel. They have a large size and weight compared to many other fuel cells. MCFCs can use a variety of fuels, operate at high temperatures and show thermal efficiencies of $60 \%$ to $85 \%$ with cogeneration. DMFC fuel cells run directly on methanol, an energy dense and stable alcohol, and are being looked at for portable and transportation purposes. ZAFCs are often called regenerative fuel cells meaning no fuel is added and none of the by-products is wasted. Technically these could even be considered batteries since zinc is consumed. Their thermal efficiency range is about 30 to 50 percent. PCFCs are different than other fuel cells in that they depend on the conduction of hydrogen ions through the electrolyte at higher temperatures (around $700^{\circ} \mathrm{C}$ ). BFCs convert biochemical energy into electricity directly. A big difference with this cell is that the catalyst in its reaction is a microorganism or enzyme instead of metals (10).

The type of fuel cell important to this research is a solid oxide fuel cell or SOFC. Solid oxide fuel cells are anticipated for large industrial applications but the technology is so new that only systems of a few kW have been created.

In a SOFC, fuel and oxygen are fed to the anode and cathode, respectively. The fuel enters the anode and separates into hydrogen ions and electrons. Oxygen from air flowing through the cathode side 
comes into contact with the cathode/electrolyte boundary causing a reaction in which electrons are received from the cathode and the oxygen molecules are split into two oxygen ions. These oxygen ions diffuse through the electrolyte layer reacting with the fuel from the anode producing water, carbon dioxide, heat and the electrons which create the external circuit between the anode and cathode (13). This external circuit constitutes the power output of the fuel cell in the form of electrical energy. This process can be seen in the Figure 1.

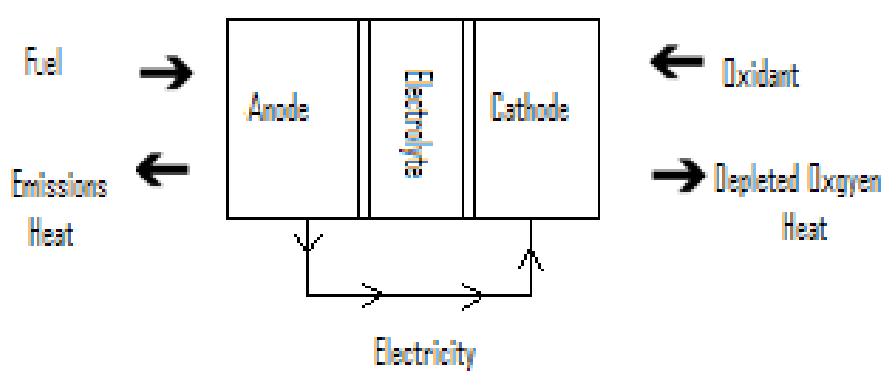

Figure 3: SOFC Flow Diagram

Fuel cells are categorized according to the electrolyte present in their design. A SOFC contains an electrolyte that is a solid oxide or ceramic. The electrolyte must be as thin as possible with high ionic conductivity without having electrical conductivity. The anode layer must be porous to allow fuel to flow toward the electrolyte. The cathode should be a thin porous layer where oxygen reduction occurs (10).

The SOFC has a fully solid state structure, and a very simple design. Several geometries are being constructed, mainly tubular, bipolar, and planar. A tubular design separates the components of the fuel cell with hollow tubes. The electrolyte and anode are layers around the tubular cathode. The air or oxidant flows through the inside of the tube and the fuel flows along the outside. The planar configuration is the most common. It simply consists of flat plates where the electrolyte is between the two electrodes. The air and fuel flows by way of rectangular channels carved or molded into the anode and cathode (14). Planar designs are believed to have higher power densities than tubular designs, and can operate at lower temperatures, benefiting the material stability of the fuel cell.

One advantage of a SOFC is it can utilize a large selection of fuels and achieve efficiencies of $40 \%$ to $60 \%$ assuming LHV natural gas as fuel. This would greatly improve the current thermal power plant with only around $30 \%$ to $40 \%$ efficiencies for coal fired plants, or around $40 \%$ for modern gas turbines. Solid oxide fuel cells run at high temperatures in order to obtain needed power output and current densities. Their temperature can range from about 600 to $1000^{\circ} \mathrm{C}$. They have also been tested at operating conditions up to 15 atmospheres (15). The high efficiencies of SOFCs make them attractive to existing power plants even with high temperature and pressures creating certain material and safety constraints. 


\subsection{Solid Oxide Fuel Cell Gas Turbine Hybrids}

Solid Oxide fuel cell integration into conventional power plant configurations of gas turbines has shown promise when it comes to efficiency. In 2000 Siemens teamed with University of California at Irvine and the first pressurized solid oxide fuel cell/gas turbine system was tested. The system was located at the National Fuel Cell Research Center (NFRC) at the University of California, Irvine and is seen in Figure 4. As stated earlier its operation occurred at 3 atmospheres and $1000^{\circ} \mathrm{C}$. The system output was approximately $220 \mathrm{~kW}$ with a $200 \mathrm{~kW}$ SOFC and $20 \mathrm{~kW}$ from a micro turbine generator. Figure 5 shows a schematic of the system with its components. Using natural gas as fuel, an electrical efficiency of approximately $53 \%$ was achieved in the system's 3400 hours of operation (1). The Siemens system was proof of the concept of a pressurized SOFC/GT system with improved efficiencies.

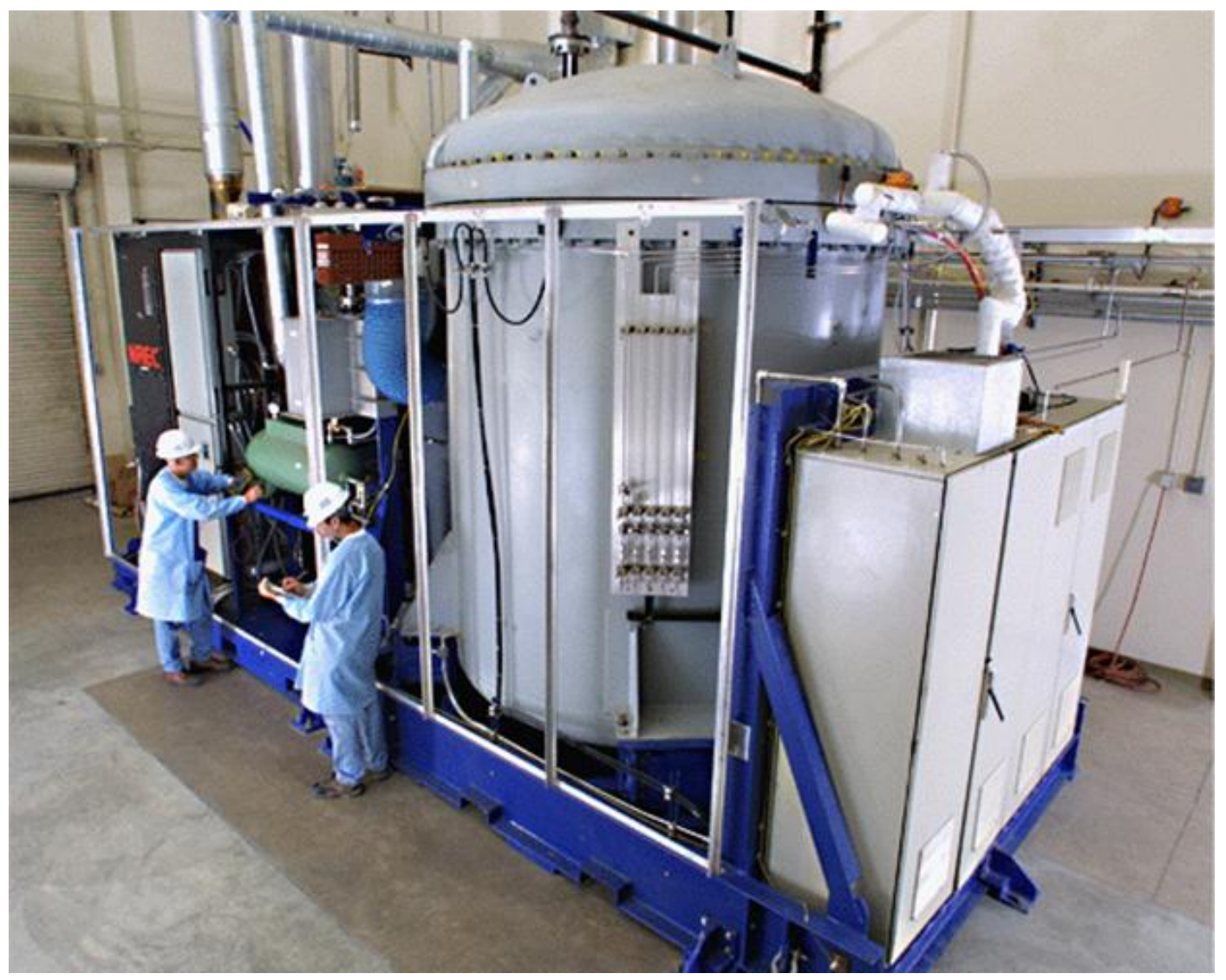

Figure 4: SOFC/GT Hybrid at NFRC 


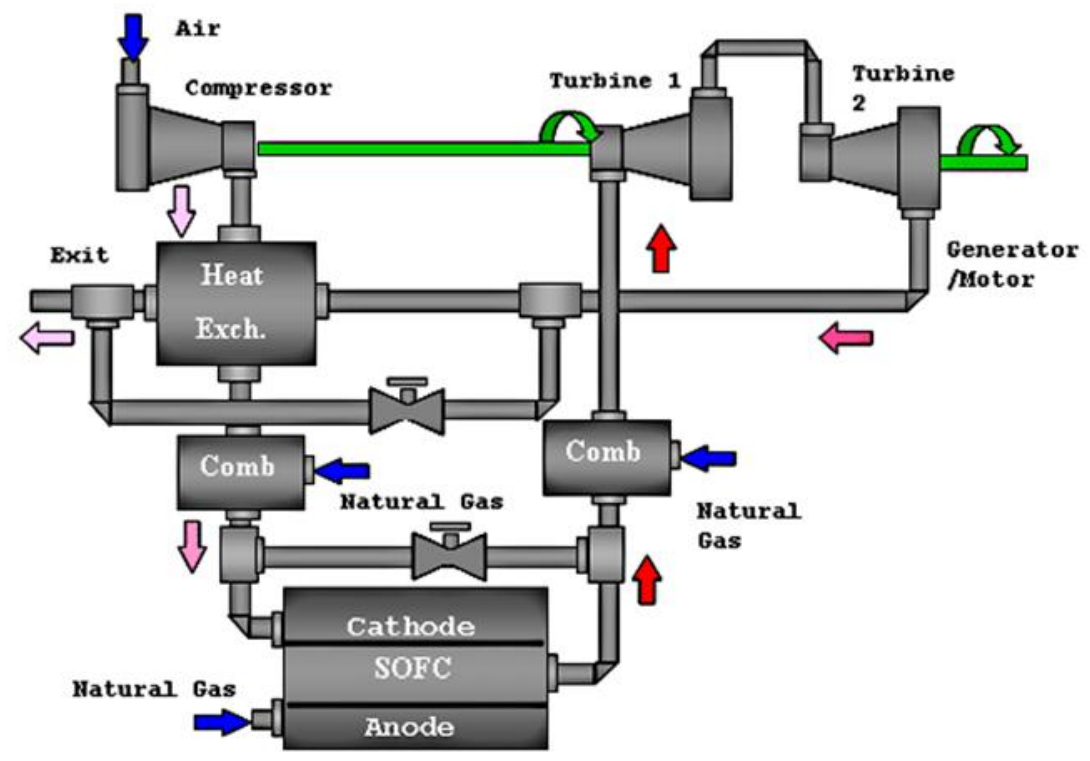

Figure 5: Siemens Hybrid System

The Department of Heat and Power Engineering at Lund University in Sweden conducted theoretical studies of SOFC/GT systems around the same time as the Siemens system was tested. The studies analyzed the operational behavior and performance of a hybrid system. Models were created in Aspen Plus to determine the effects of different parameters on the system. It was found that the pressure ratio has a large effect on the system and electrical efficiencies based on natural gas fuel of around $65 \%$ are feasible for a hybrid system (16).

Several systems have been explored in addition to the Siemens-Westinghouse and Lund University models. Some of the systems currently developed or in stages of development are pressurized while some run at atmospheric pressure, using the Rankine cycle for bottoming. The atmospheric system design would include a high temperature recuperator instead of the combustor of a gas turbine cycle and would position the fuel cell stack at the exhaust outlet of the gas turbine. This then results in fuel cell operation near atmospheric pressure. A pressurized system design on the other hand substitutes the gas turbine combustor with the fuel cell stack making the fuel cell pressurized at the operational pressure of the gas turbine (17). The pressurized system is believed to have a higher specific power due to an approximate $10 \%$ higher efficiency than an atmospheric system (18).

The University of Genoa in Italy has also conducted research on SOFC/GT cycles. In 2000 research was conducted on the design of a SOFC in conjunction with a microturbine generator, including part load operation of the system. The hybrid system was found to have a possible efficiency of $60 \%$ with $50 \%$ at part load. Two different turbine systems were also examined--a fixed speed and a variable speed drive. At fixed speed, the power ratio between the SOFC and turbine was found to be $20 \%$ while at variable speed it decreased to $15 \%(19)$. 
In 2003 researchers at NFCRC published a journal article that defined opportunities for further optimization of SOFC/GT systems. Electrical efficiencies of up to $75 \%$ were claimed feasible based on the LHV of natural gas as the fuel. They also determined as many others had that overall pressure increase in the system produced higher efficiencies. In addition it was concluded that increasing the excess air in the SOFC increases the overall efficiency as well as eliminating some parasitic loss (20).

\subsection{Thermodynamic Analysis of SOFC/GT Systems}

Several models have been created to optimize SOFC/GT systems by means of thermodynamic or thermo-economic analyses. Most thermodynamic models rely on mass and energy balances throughout the system for various components based on the first and second laws of thermodynamics to determine various state properties. Some models have been used to perform an exergy analysis on hybrid power plants. Yildiz Technical University in Istanbul, Turkey modeled a SOFC/GT with combined heat and power generation and created exergetic performance coefficients to find sources of exergy destruction. When working at these maximum exergetic performance conditions (optimizing fuel utilization, current density, recuperator effectiveness compressor pressure ratio and fuel cell temperature) a more favorable

entropy-generation rate was seen. (21). Other models looked at part load operating conditions in a SOFC/GT system and found that simultaneous variation of fuel and air flow rates at a constant air/fuel ratio was the most effective control strategy $(22 ; 23 ; 24)$.

Thermo-economic analyses were also performed by several researchers. One model evaluated 1.5-10 MW SOFC/GT systems that concluded that the goal for small SOFCs is to minimize cost while in large SOFCs the key is to optimize efficiency (25). A study performed by Alexandros Arsalis at Virginia Tech modeled a SOFC capable of $8.5 \mathrm{MW}$ in combination with a gas turbine and steam turbine at temperatures and pressures up to $1100^{\circ} \mathrm{C}$ and 10 bar respectively. This analysis suggested that a larger SOFC would result in higher performance but greatly increases capital costs. The study also identified the difficulty in matching a gas turbine to a small SOFC due to decreasing efficiency as the system size is reduced (26).

\subsection{Control of SOFC/GT Systems}

Control of Hybrid SOFC/GT systems typically proves to be a challenge. The gas turbine and hightemperature SOFC have different characteristics. For instance, a gas turbine only needs a few minutes to reach its rated power output while the fuel cell may require several hours.

Researchers at the Norwegian University of Science and Technology created a dynamic lumped model of a SOFC/GT based system with control in mind. A control strategy for the entire system was developed. The system was complex and the different components had varying effects on one another. For instance Kandepu illustrates that a decrease in load corresponds to a decrease in fuel flow rate as well as lower current in the SOFC. The current decrease causes a weaker electrochemical reaction which decreases the SOFC temperature. The temperature of the fuel cell must be held constant to 
account for material constraints and a decrease in the cathode airflow is needed which is achieved through an increase in the air blow-off rate through the bleed air valve at the compressor outlet. The bleed air valve was more effective than the air bypass across the heat exchanger and the addition of fuel to the combustor in controlling the system. Proportional-Integral controllers were selected for the control structure. A disadvantage to this control is the decrease in efficiency due to the use of blow-off valves to control the SOFC temperature during part-load operation. While this study is beneficial, surges in the compressor and turbine inlet temperature limitations were not accounted for (27).

A paper published in the IEEE International Conference on Control Automation described a control strategy for a solid oxide fuel cell hybrid system. A large $6 \mathrm{MW}$ system was modeled and performance maps were created with responses to variations in three control input parameters: fuel mass flow, SOFC current and the rotational speed of a compressor-turbine subsystem. Limitations were applied such as a maximum temperature of $1000^{\circ} \mathrm{C}$ and a value of $0 \mathrm{~kW}$ for the minimum gas turbine power and system power, and a minimum fuel cell voltage of $0 \mathrm{~V}$. A triple layer control system was created with a control strategy using relationships between controlled and constrained parameters. An adaption layer provided corrections to the first layer and a final layer of regulation dynamically realized the control strategy. Based on the performance maps and control strategy an operational line was created for the system. From this line it was found that, in order to reach the operational system power, the fuel cell current should be increased more than the mass flow rate of the fuel. Also, the shaft speed should be increased until $50 \%$ of the system power is reached at which time the speed can be decreased (28).

The HyPer facility at NETL in Morgantown, WV was built mainly for the purpose of studying control of a SOFC/GT closed loop system. A paper was presented in 2005 at the ASME Power Conference characterizing control of the system via air flow manipulation. In 2009 at the International Colloquium on Environmentally Preferred Advanced Power Generation another paper illustrated the operational envelope of the hybrid system. In these experiments the cold air bypass, hot air bypass, and bleed air bypass were examined to find trends between valve positions and several system parameters such as turbine inlet temperature, cathode air flow, system pressure loss, compressor inlet flow, and compressor surge margin. The trends experienced by these system parameters are summarized in Table 1, Table 2, and Table 3.

Table 1: Characterization of Cold Air Bypass

\begin{tabular}{|l|l|}
\hline \multicolumn{2}{|c|}{ Increased Opening of Cold Air (CA) By-pass Valve (0-100\%) } \\
\hline Cathode Air Flow & $\downarrow$ Decrease \\
\hline Turbine Inlet Temperature & $\downarrow$ Decrease \\
\hline Compressor Inlet flow & $\uparrow$ Increased \\
\hline Compressor Surge Margin & $\uparrow$ Increased \\
\hline Total System Pressure Drop & $\downarrow$ Decreased \\
\hline
\end{tabular}


As seen above cold air valve manipulation proves to be an effective way of increasing the compressor surge margin since it can both increase compressor mass flow and decrease the pressure loss of the system. The cold air bypass is also a good method for absorbing thermal energy when considering high turbine loads. The cold air bypass causes an increase in the operational envelope by expanding the ability of the machinery to sink heat from the fuel cell system (29).

Table 2: Characterization of Hot Air By-pass

\begin{tabular}{|l|l|}
\hline \multicolumn{2}{|c|}{ Increased Opening of Hot Air (HA) By-pass Valve (0-100\%) } \\
\hline Cathode Air Flow & $\downarrow$ Decrease \\
\hline Turbine Inlet Temperature & $\uparrow$ Marginal Effect \\
\hline Compressor Inlet flow & $\uparrow$ Marginal Effect \\
\hline Compressor Surge Margin & $\uparrow$ Marginal Effect \\
\hline Total System Pressure Drop & $\uparrow$ Marginal Effect \\
\hline
\end{tabular}

The hot air by-pass shows less overall effect on the system but does have some benefits. The HA valve provides a means to vary cathode flow without greatly affecting the thermal efficiency of the system and has no impact on energy requirements over its operation range (29).

Table 3: Characterization of Bleed Air By-pass

\begin{tabular}{|l|l|}
\hline \multicolumn{2}{|c|}{ Increased Opening of Bleed Air (BA) By-pass Valve (0-20\%) } \\
\hline Cathode Air Flow & $\downarrow$ Decrease \\
\hline Turbine Inlet Temperature & $\uparrow$ Increased \\
\hline Compressor Inlet flow & $\uparrow$ Increased \\
\hline Compressor Surge Margin & $\uparrow$ Large Increase \\
\hline Total System Pressure Drop & $\uparrow$ Marginal Effect \\
\hline
\end{tabular}

The bleed air by-pass valve can be a limited but effective way of increasing the compressor surge margin to avoid stall but it does so at the cost of wasted energy. Overall the bleed air is an effective way of absorbing the thermal transients to the turbine without changing fuel cell cathode flow (29).

From this previously gathered data, it is hypothesized that the simultaneous and coordinated operation of the CA, HA and BA valves could provide a means of increasing the envelope of stable and efficient operation of the hybrid system. Simulation studies by other researchers (e.g. Tsai, Mueller) support this hypothesis, but thus far, no demonstration of such a system has been possible. Controls play an important role in the system's performance and stability not to mention equipment protection and maximum life. From the plots of previous data it can be seen that there may exist some areas between varying valves separately where the system might be more efficient and better for operation while varying two or even all three valves simultaneously. Experiments using a factorial design method were planned 
and conducted to explore how the system will react when bypass valves are opened simultaneously. The variables included mass flow though the bleed air valve, cold air valve, hot air valve, and the load on the system. 


\section{Technical Approach}

\subsection{Hybrid Performance Facility Description}

The hybrid system at NETL (HyPer) consists of several components: startup blower, a compressor, heat exchangers, fuel cell simulation, post combustor, and a turbine/generator. The system begins with air from the atmosphere passing through the compressor, where its pressure increases to about $250 \mathrm{kPag}$. Next, the air enters into the heat exchangers. The heat exchangers take waste heat from the turbine and heat the compressed air before it enters the fuel cell simulator. The fuel cell simulator consists of an air plenum and a burner or combustor controlled by a real-time model running on a dSpace ${ }^{\mathrm{TM}}$ hardware-in-the-loop simulation platform. The flow goes into the air plenum and combustor, into the post combustor for mixing any additional bypass flows and finally through the turbine. The combustor is used in the system to simulate the fuel cell thermal effluent and to provide a means for injecting auxiliary fuel into the system to control turbine speed. From the turbine outlet, the air will continue through the hot side of the heat exchangers and out the exhaust stack. Though the air does not recycle through the system, some of the energy is recovered in the recuperator. A schematic of the HyPer system can be seen in Figure 6 and photograph of the system can be seen in Figure 7 .

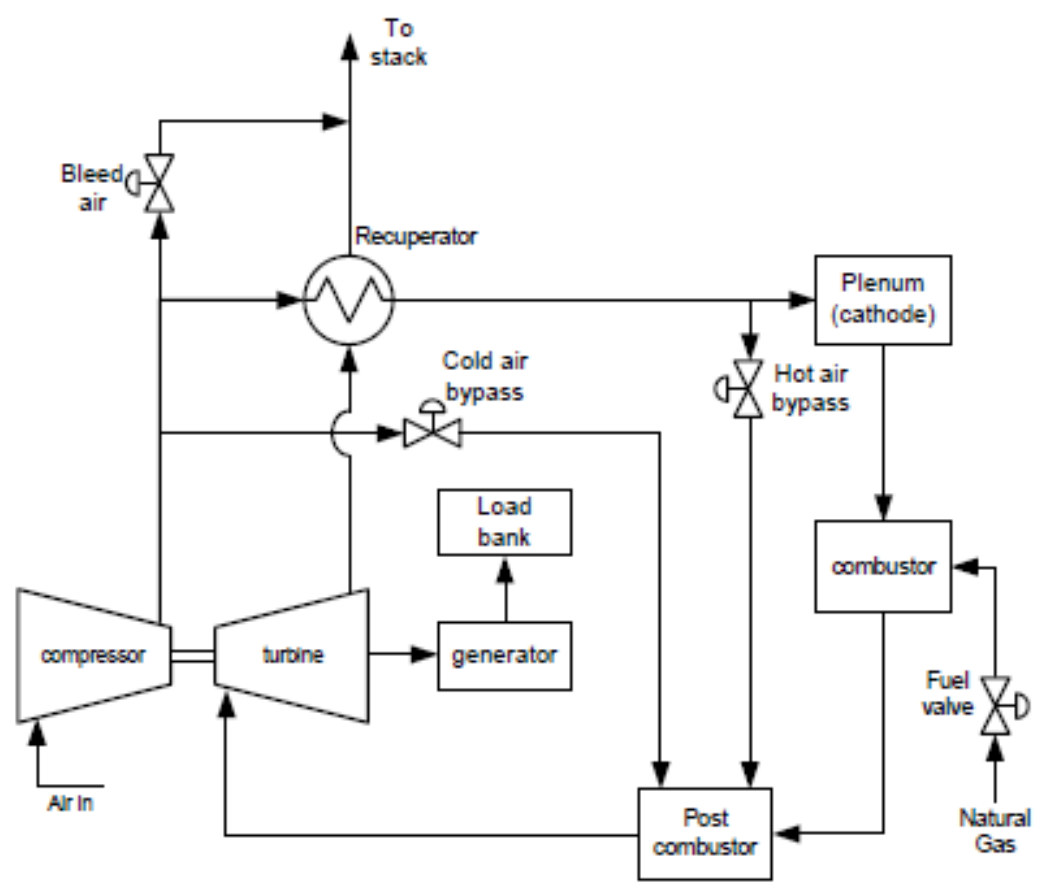

Figure 6: Schematic of HyPer System 


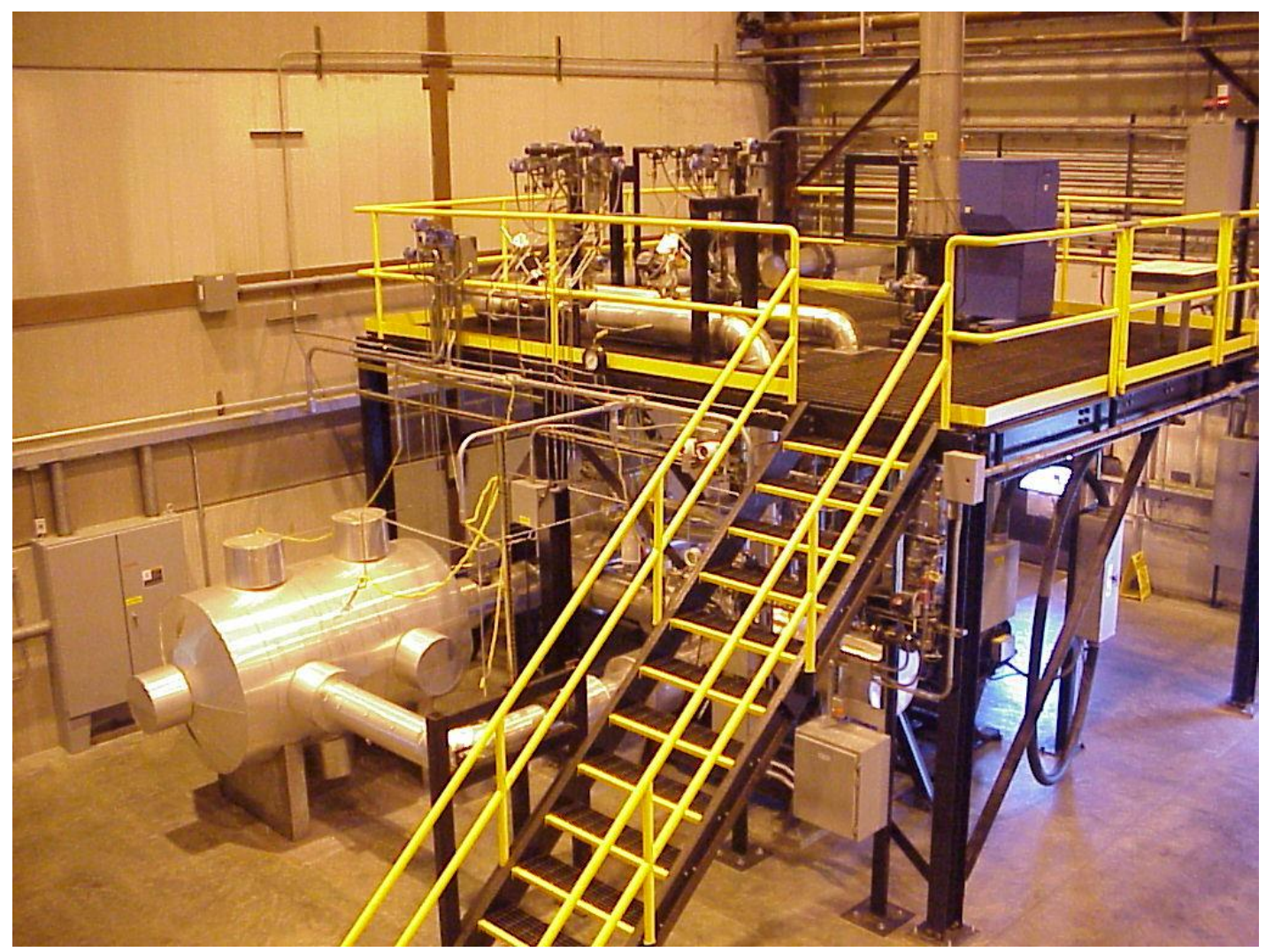

Figure 7: HyPer System at NETL

\subsubsection{Gas Turbine Unit and Compressor}

A 120 kW Garret Series 85 Auxiliary Power Unit formerly used for aircraft serves as the gas turbine (T-101) in this hybrid system (2). The turbine operates at a nominal 40,500 rpm. The turbine and compressor are mounted on a single shaft, which also drives the generator through a gear train. The two stage radial compressor delivers about $2 \mathrm{~kg} / \mathrm{s}$ of air at a pressure ratio of about 2.5. The HyPer operates at about 2.5 atmospheres gauge pressure (2). The turbine and compressor setup at the HyPer facility can be seen in Figure 8. The generator is gear driven synchronously at $400 \mathrm{~Hz}$. 


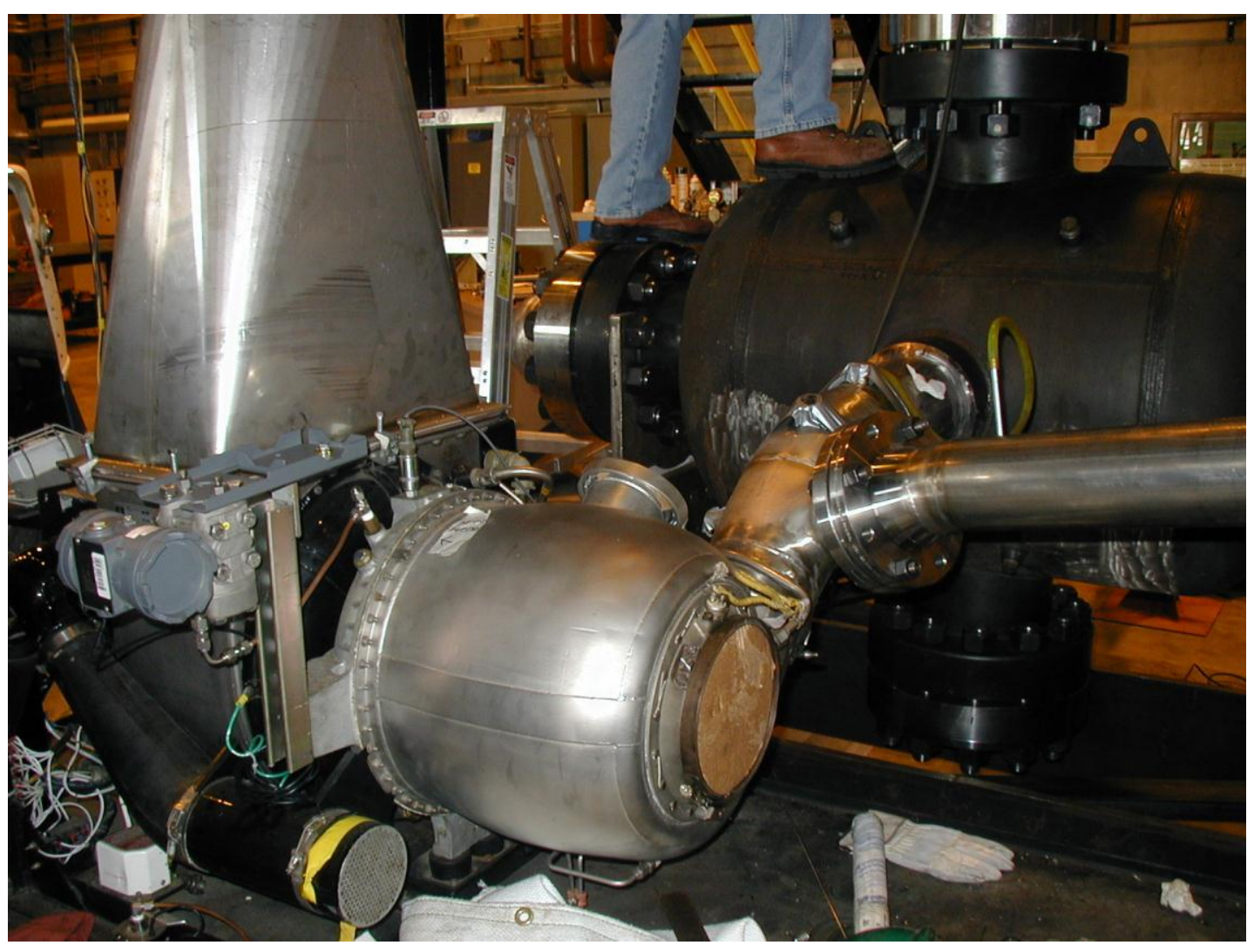

Figure 8: Compressor and Gas Turbine Setup

\subsubsection{Recuperators}

The heat exchangers include two counter flow primary surface recuperators with a nominal effectiveness of approximately $89 \%$ (2). These heat exchangers preheat the air entering the air plenum and are depicted along with the startup blower in Figure 9. 


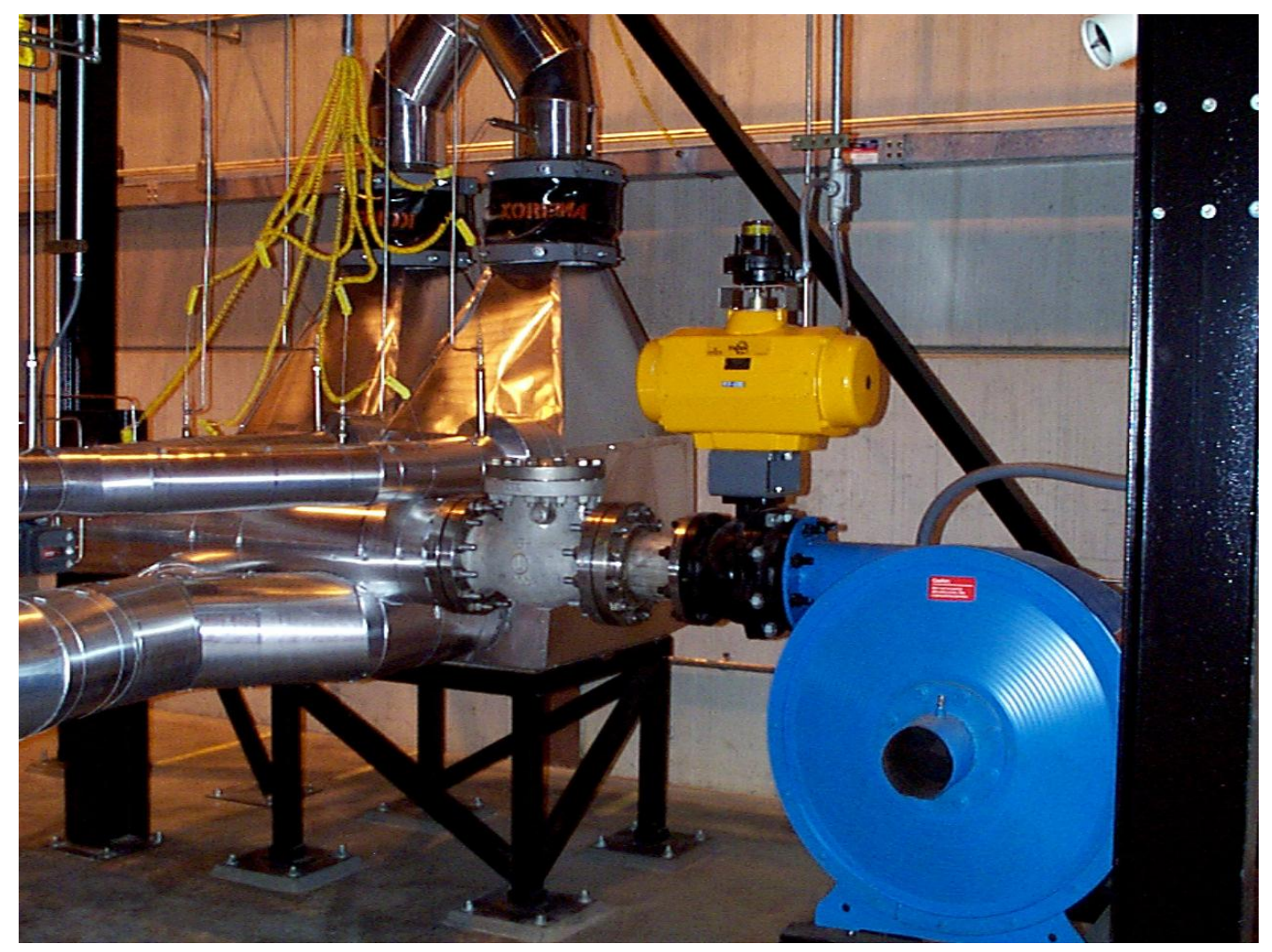

Figure 9: Heat Exchangers and Startup Blower

\subsubsection{Air Plenum and Combustor}

The air plenum (V-301) is piping that represents the volume and thermal capacitance of the fuel cell on the cathode side and the corresponding pressure change and flow impedance. A natural gas burner combustor simulates the amount of heat added to the system when the electrochemical reaction occurs in the fuel cell, often referred to as thermal effluent. The combustor and air plenum can be seen in Figure 10. The currently used model is a one-dimensional finite-volume model developed by Hughes and Haynes at the Georgia Institute of Technology and is capable of quasi-real-time simulation of SOFC operation (30). It assumes the use of coal syngas as the fuel fed into the fuel cell. This model is very useful because it allows the creation of dynamic temperature and current density distribution maps within the fuel cell during transient events. 


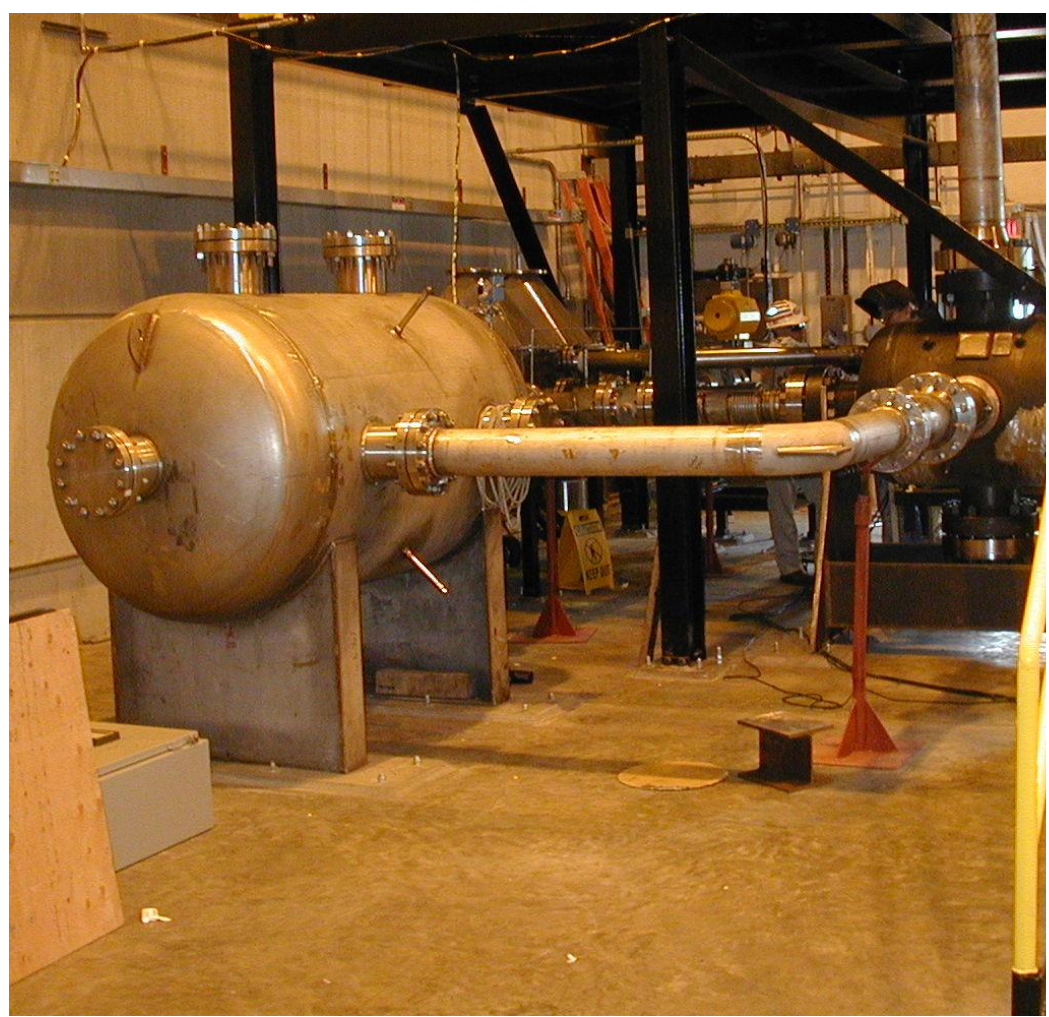

Figure 10: SOFC Simulation Air Plenum and Combustor

\subsubsection{Post Combustor}

The post combustor (V-304) is a pressure vessel that serves as a manifold where all the various flow paths come together and mix. The uniform flow then passes into the turbine inlet.

\subsubsection{Bypass Valves}

The HyPer system contains 3 bypasses or airflow loops. These are the bleed air bypass (BA), cold air bypass (CA), and the hot air bypass (HA). Figure 11 and Figure 12 show the bypass valve locations in the HyPer system. The valves are intended to manage the airflow and air temperature through the fuel cell cathode, and also to prevent compressor surge and stall from occurring.

The bleed air bypass valve (FV-162) essentially bypasses the whole system. Air is taken in from the atmosphere run through the compressor and then sent out into the exhaust stack, back into the atmosphere. The valve is a nominal $15.4 \mathrm{~cm}$ ID Valteck Shear Stream control valve with a full slew range of about 1.5 seconds.

The cold air bypass valve (FV-170) takes air from the compressor outlet directly to the post combustor and then through the turbine. By using the CA bypass, the heat exchangers, air plenum and combustor are all bypassed. The CA bypass valve is nominal 15.4 ID Fischer-Rosemont V-150 Vee-Ball control valve and has a full slew range similar to that of FV-162. 
The hot air bypass valve (FV-380) is a nominal 15.4cm ID Valteck MaxFlow V-300 eccentric plug rotary control valve with pressure operation available at temperatures in excess of $810 \mathrm{~K}\left(1000^{\circ} \mathrm{F}\right)$. It has a slightly longer full slew range of approximately 2 seconds. The HA bypass valve runs from the heat exchanger outlet to the post combustor, thus, bypassing the simulated fuel cell and sending the air directly through the post combustor and into the turbine. The post combustor mixes the air flows present including any of the bypass loops that might be used.

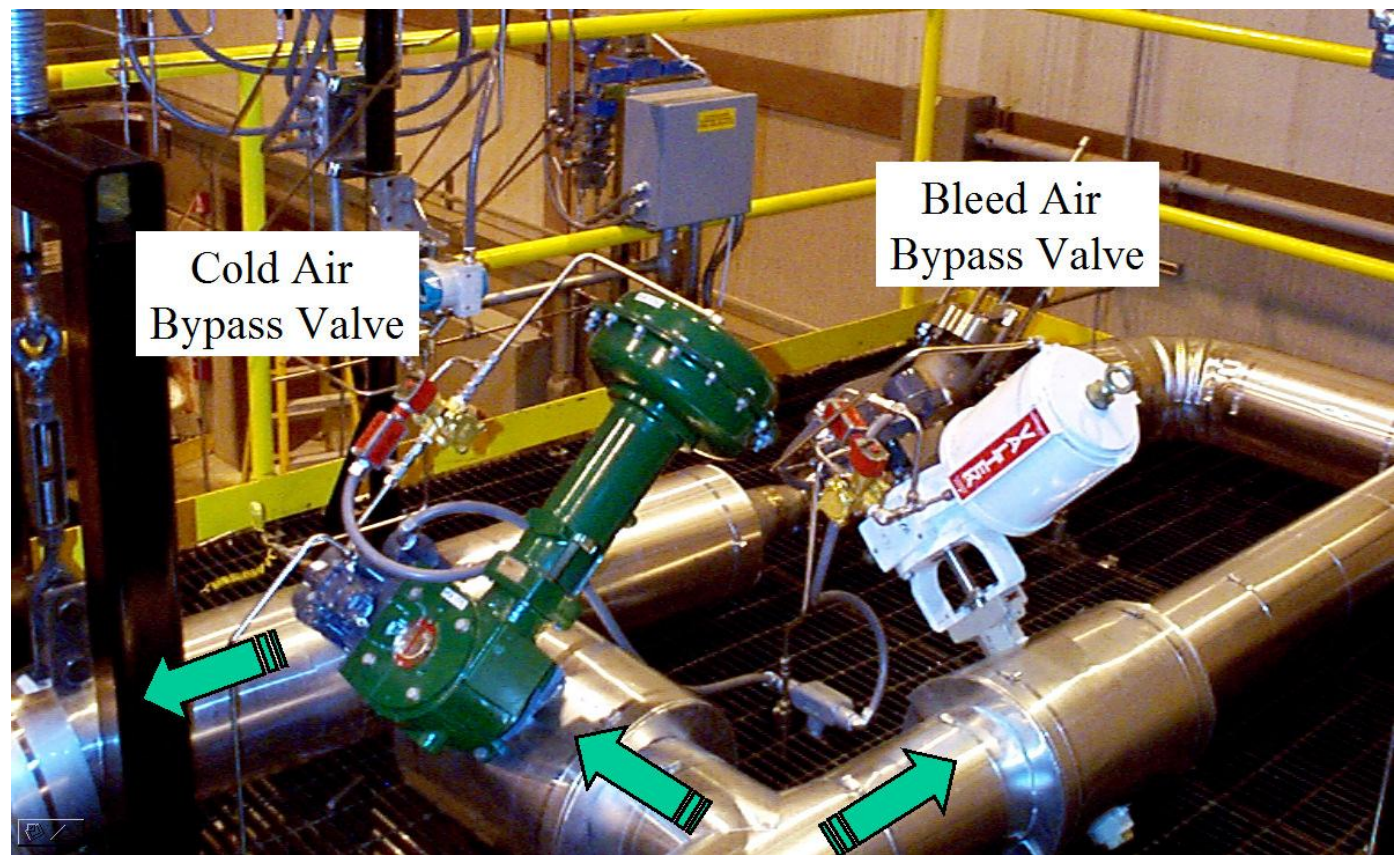

Figure 11: Cold Air and Bleed Air Bypass Valves

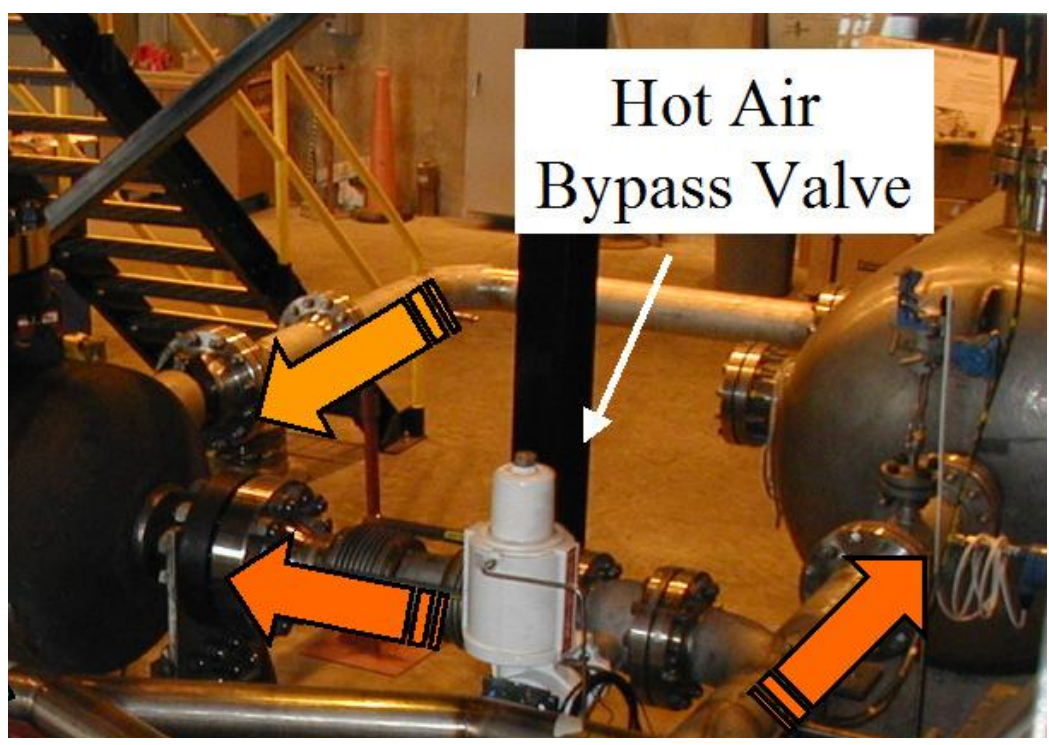

Figure 12: Hot Air Bypass Valve 


\subsubsection{Instrumentation}

A detailed description of the sensors used to collect process data is discussed in previous work (3). Figure 13 is a brief description of key instrumentation.

- FE 162: Annubar type flow meter measuring the combined flow through the Cold Air Bypass Valve and the Bleed Air Valve.

- FE 380: Annubar flow meter measuring the airflow through the cathode side of the fuel cell stack

- TE 326: Thermocouple measuring the temperature of the air entering the cathode

- TE 350: Thermocouple measuring turbine inlet gas temperature

- FT 432: Flow meter measuring natural gas flow to the combustor.

- $\quad$ PT 305: Pressure transducer measuring air pressure in the cathode.

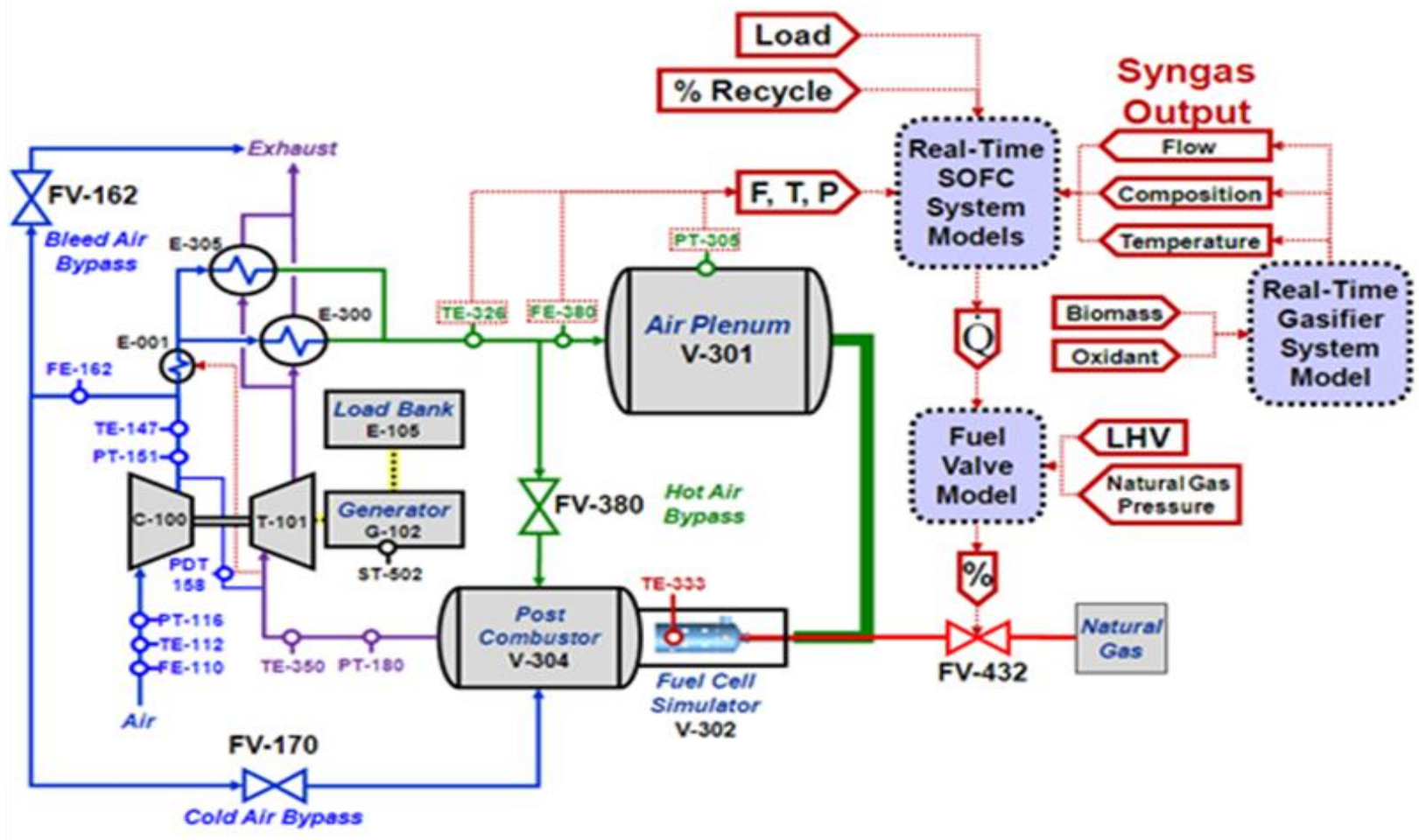

Figure 13: Flow Diagram for the Hybrid Performance Facility at NETL 


\subsection{Experimental Procedure}

The HyPer system previously described has a method of control that depends on transfer functions from mathematical models of the system's behavior as functions of manipulated variables, in this case valve positions and electric load. Previous published proposals from this system's controllers have typically been based on analytical models of system behavior that are linearized about an operating point and simplified out of necessity. The approach of this work was to take advantage of the availability of a hardware test bed to build models based on experimental data over a wide range of operating conditions. Particular interest was taken in understanding the interaction among the four manipulated variables when they were changed simultaneously. For this reason a factorial experiment was designed in which each of the four variables would be tested at three distinct "levels" and the data was examined using a method called Analysis of Variance in order to determine the contribution of each variable to the variation of the system.

The testing itself consisted of 81 test points determined from a $3^{4}$ factorial experiment design Different values for the electric load and positions of the cold air (CA), hot air (HA), and bleed air (BA) bypass valves were assigned to each test. The electric load had three set values: 0,25 , and $50 \mathrm{~kW}$. The bypass valve positions can be seen in Table 4 . These 81 tests were randomized to ensure valid results.

Table 4: Bypass Valve Positions

\begin{tabular}{|c|c|c|c|}
\hline Bypass Valve & \multicolumn{3}{|c|}{ \% Open } \\
\hline CA & 40 & 60 & 80 \\
\hline HA & 20 & 50 & 80 \\
\hline BA & 10 & 12 & 14 \\
\hline
\end{tabular}

Testing began by first bringing the system online and up to operating temperature using standard methods. Once this was achieved the first test point values for electric load and bypass valve positions were set. Each test point had to reach a new steady state condition before setting the values for the next point; this took approximately one hour. A new steady state condition was defined by a less than 3 degree Celsius temperature change on the post combustor skin temperature within a five minute period. The combustor skin temperature was the chosen indicator because it is the slowest variable in the HyPer system. This procedure was followed for each of the 81 test points. Data on 74 system parameters were collected at a $400 \mathrm{~ms}$ sampling rate.

\subsection{Selected Data}

The steady state parameter values were obtained by averaging the last thousand points collected in each test's data log where the system was considered to be most stable for each of the 81 test points. This produced a data base of 81 tests with one value for each of the selected parameters. 


\subsection{Response Surface Characterization}

The objective of this study is to develop control strategies for managing cathode air mass flow rate at various load fluctuations. To do this, relationships between the various control input variables (bypass valve positions) and the output variable (cathode air mass flow) were necessary. A functional relationship between the inputs and outputs was assumed and a least-squares regression was conducted to find the best "fit" of the function parameters to the data. In this case, the function chosen was a second order polynomial with all three valves plus electric load as parameters and the cathode airflow as the output. Cross terms were included in the model, which took the following form:

$$
\begin{aligned}
& \dot{m}=K_{0}+K_{B 1} B A+K_{C 1} C A+K_{H 1} H A+K_{E 1}(E L)+K_{B 2}(B A)^{2}+K_{C 2}(C A)^{2}+K_{B C}(B A)(C A)+\cdots \\
& +K_{C H}(C A)(H A)+\cdots+K_{H E}(H A)(E L)
\end{aligned}
$$

The $\mathrm{K}$ terms are the coefficients to be determined by the least-squares fit to the data. The BA, CA and HA parameters are the valve openings for the bleed air, cold air and hot air bypasses respectively, and EL is the electric load. Higher order cross terms were not included as it was felt that their influence would be negligible. This assumption was proven correct. A quadratic model was deemed appropriate for the constrained range of valve positions as they were operating in nearly linear portions of their characteristic behavior. Other basic functions including arctangent and hyperbolic tangent functions were investigated, but the quadratic form of the model gave a better fit to the data so it is was selected.

MATLAB ${ }^{\mathrm{TM}}$ was used to solve the least-squares regression and obtain an equation for the air mass flow. The coefficients were then examined and the smallest ones (after scaling) were removed to simplify the model. New regressions were run with progressively simpler models, using the $\mathrm{R}^{2}$ statistic to determine which terms could or could not be eliminated. For purposes of visualization, it was desired to reduce the model to select the two most important manipulated variables and plot the output as a function of those two variables. The complete model can still be used in control function calculations, but plots will show the reduced order model correlations.

\subsubsection{Cathode Air Mass Flow}

The steady state parameter of major interest for this research is the cathode air flow (FT-380) and the HA and CA valve positions for each test. The electric load and bleed air valve were found to have negligibly small effect on the cathode air flow. MATLAB ${ }^{\mathrm{TM}}$ was used to solve the least-squares regression and obtain an equation for FT-380. A 3-D visualization of the operating space for the cathode flow was then generated from this equation.

Figure 15 illustrates the surface plot of the response of the cathode mass flow rate against hot air and cold air bypass valve positions for each of the 81 tests. The full equation for FT-380 using all three valve positions and electric load as variables is shown in Equation (2). The statistical $R^{2}$ of Equation 2 
was calculated to be approximately 0.997 . The equation for FT-380 was simplified using only HA and CA as variables to obtain Equation (3). This equation has a lower $R^{2}$ value of 0.991 . Figure 14 is a plot of the flow predicted by the correlation of the full equation, Equation (2), and the simplified equation, Equation (3), compared to the experimentally measured flow at each of the 81 test points.

FT380 $=1.667-0.019 * H A+0.0001 * H A^{2}+0.019 * B A-0.0007 * B A^{2}-0.0126 * C A+0.00004 * C A^{2}+$ $0.001 * E L-0.000008 * E L^{2}-0.0002 * H A * B A+0.000035 * H A * C A-0.00003 * H A * E L-0.00014 *$ $B A * C A-0.00025 * B A * E L-0.00003 * C A * E L+0.0000035 * H A * B A * C A+0.00000066 * H A * C A *$ $E L+0.000005 * H A * B A * E L+0.000004 * B A * C A * E L-0.00000008 * H A * B A * C A * E L$

$F T 380=1.74832-0.02037 * H A+0.0001 * H A^{2}-0.01374 * C A+0.00004 * C A^{2}+0.00007 * H A * C A$
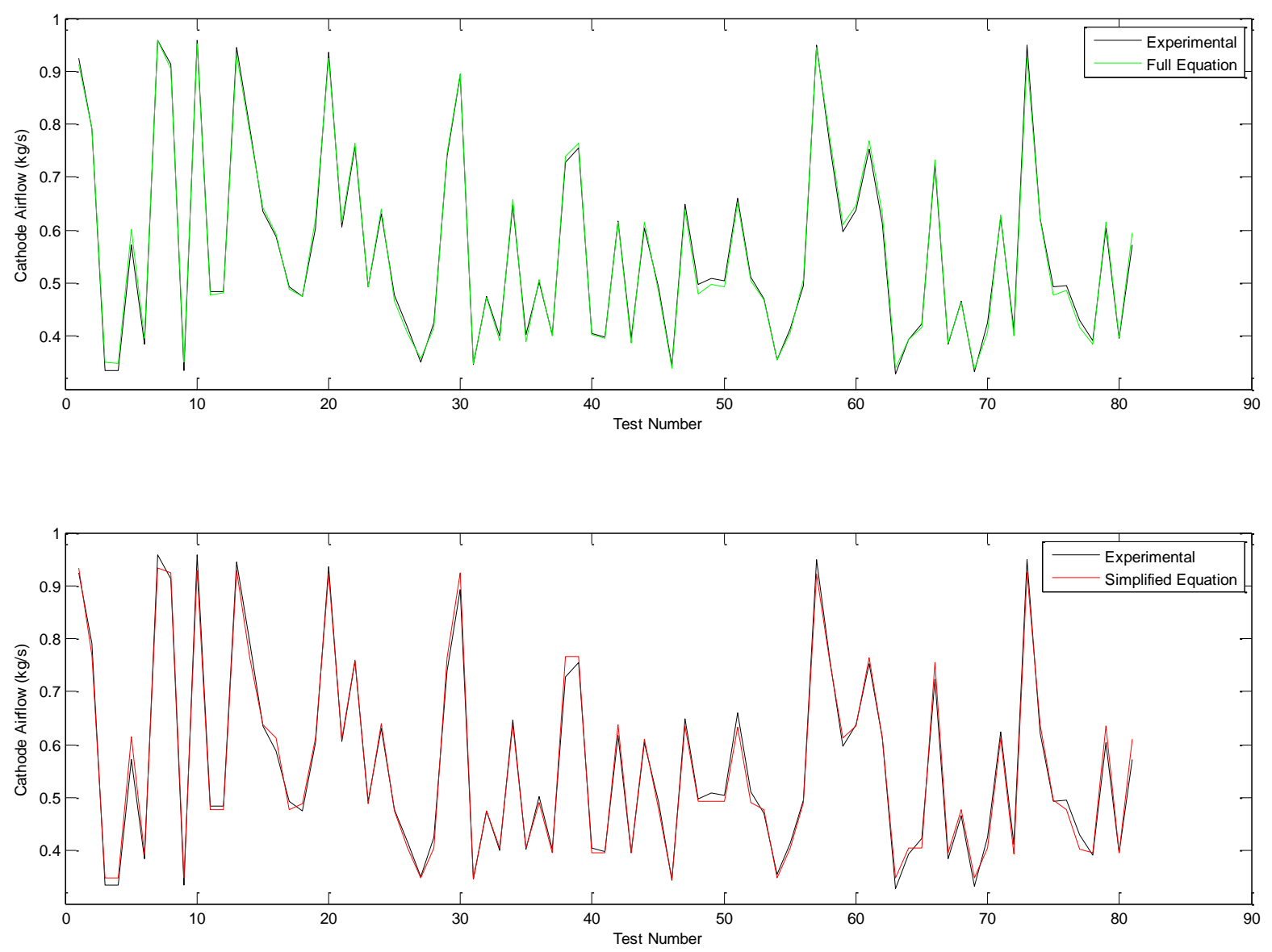

Figure 14: Comparison of Experimentally Measured Cathode Air Mass Flow with Value Predicted by Polynomial Model of Equation (2) and (3) 


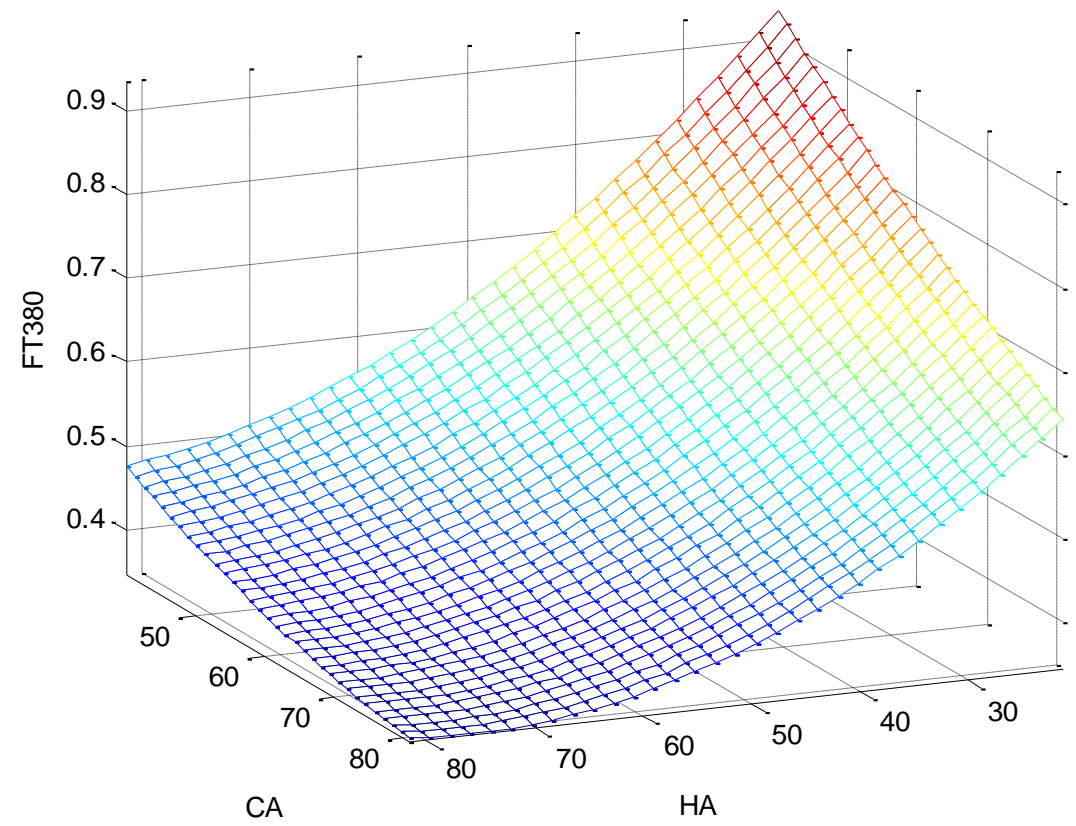

Figure 15: Cathode Mass Flow Rate as a Function of Hot Air and Cold Air Valve Positions

\subsubsection{Total System Pressure Drop}

As previously discussed, the pressure drop (PDT-158) between the compressor and gas turbine has a large impact on the compressor surge margin. Since compressor surge must be prevented this can be a useful tool in optimization. The full equation was computed using all the valve positions and electric load. The equation is displayed in Equation (4) and had a computed $R^{2}$ of 0.992 . The input parameters of major interest for PDT-158 were the cold air bypass valve position and the electric load. The equation is shown in Equation (5) with an $R^{2}$ value of 0.909 . In Figure 16 the accuracy of the Equation (4) and (5) are illustrated. The surface plot of the response of the system pressure drop against cold air bypass valve positions and electric load for each of the 81 tests is depicted in Figure 17.

$P D T 158=10.46+0.05 * H A-0.00029 * H A^{2}-0.058 * B A+0.0015 * B A^{2}-0.174 * C A+0.0008 * C A^{2}-$ $0.048 * E L-0.000024 * E L^{2}-0.00059 * H A * B A-0.00014 * H A * C A+0.00037 * H A * E L+0.00036 *$ $B A * C A+0.0035 * B A * E L+0.00053 * C A * E L+0.000015 * H A * B A * C A-0.0000017 * H A * C A * E L-$ $0.000028 * H A * B A * E L-0.000043 * B A * C A * E L-0.000000005 * H A * B A * C A * E L$

$P D T 158=11.3708-0.011 * E L-0.000007 * E L^{2}-0.17057 * C A-0.0008 * C A^{2}+0.000048 * E L * C A(5)$ 

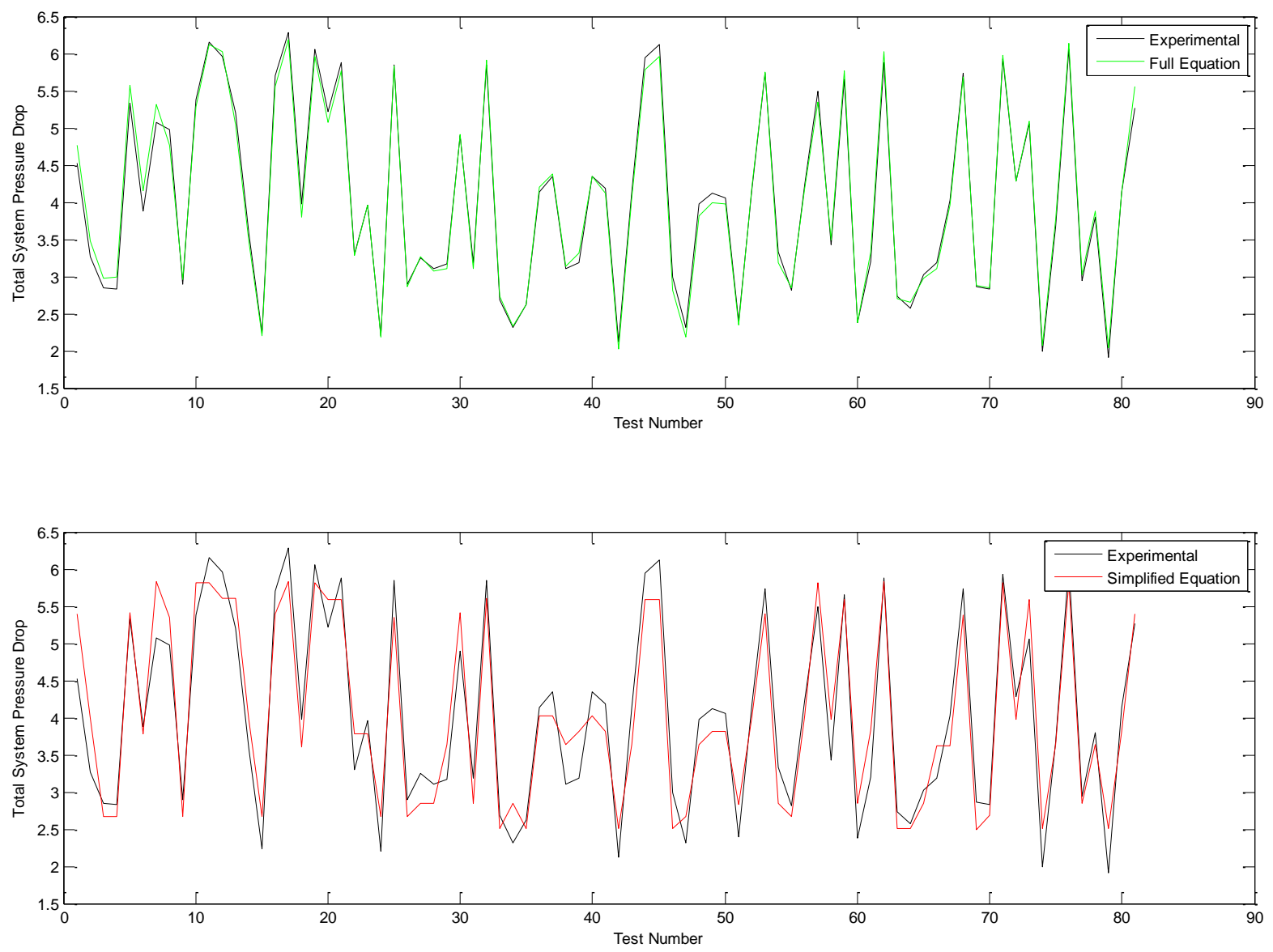

Figure 16: Comparison of Experimentally Measured System Pressure Drop with Value Predicted by Polynomial Model of Equation (4) and (5) 


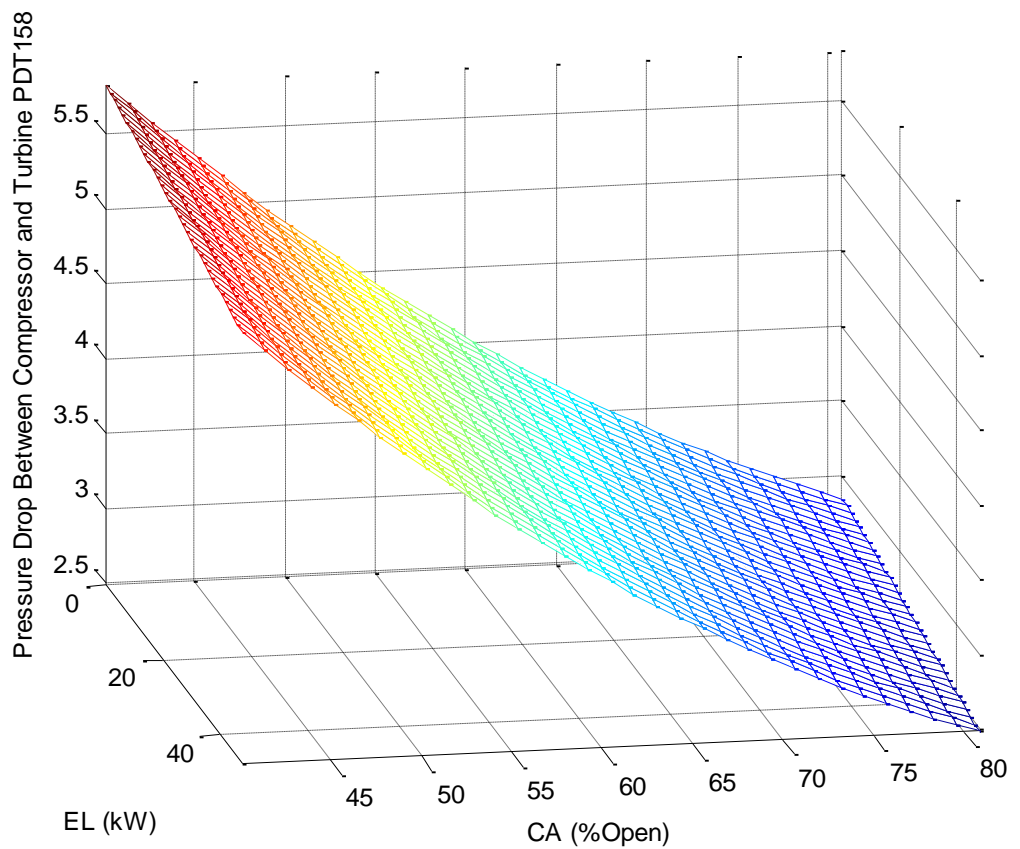

Figure 17: Total System Pressure Drop as a Function of Electric Load and Cold Air Valve Position

\subsubsection{Fuel Flow}

The fuel flow (FT-432) is a mixture of the simulated thermal effluent from the fuel cell and the fuel input needed to regulate the turbine speed. The fuel flow is important for monitoring the efficiency of the system as well as the production of the thermal effluent in the fuel cell. The full equation with all four variables is shown in Equation (6) with a corresponding $R^{2}$ of 0.956 . Equation (7) represents $F T-432$ as a function of the Cold Air Valve (CA) and Electric Load (EL). The equation yields an $R^{2}$ value of 0.905 and the accuracy to the recorded data of both full and simplified equations can be seen in Figure 18. The response surface for FT-432 is shown in Figure 19.

$$
\begin{aligned}
& F T 432=75.211+3.28 * H A+0.0055 * H A^{2}+56.13 * B A-1.56 * B A^{2}+5.726 * C A-0.0076 * C A^{2}+ \\
& 20.99 * E L+0.00815 * E L^{2}-0.379 * H A * B A-0.0658 * H A * C A-0.2725 * H A * E L-0.317 * B A * C A- \\
& 1.7403 * B A * E L-0.236 * C A * E L+0.00619 * H A * B A * C A+0.0037 * H A * C A * E L+0.0248 * H A * B A * \\
& E L+0.0235 * B A * C A * E L-0.000345 * H A * B A * C A * E L
\end{aligned}
$$

$$
F T 432=460+2.731 * E L+0.009 * E L^{2}+2.445 * C A-0.008 * C A^{2}+0.008 * C A * E L
$$



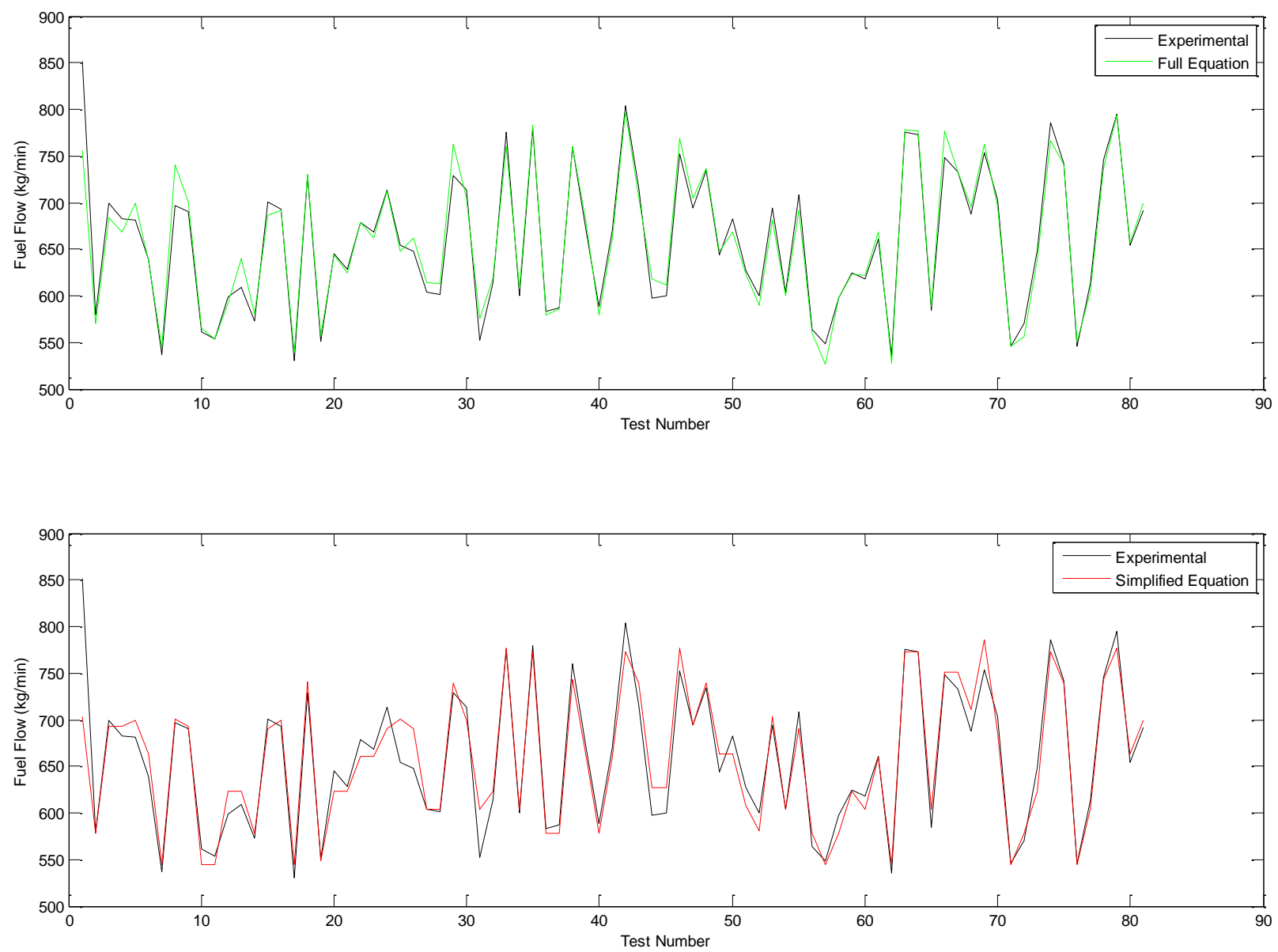

Figure 18: Comparison of Experimentally Measured Fuel Flow with Value Predicted by Polynomial Model of Equation (6) and (7) 


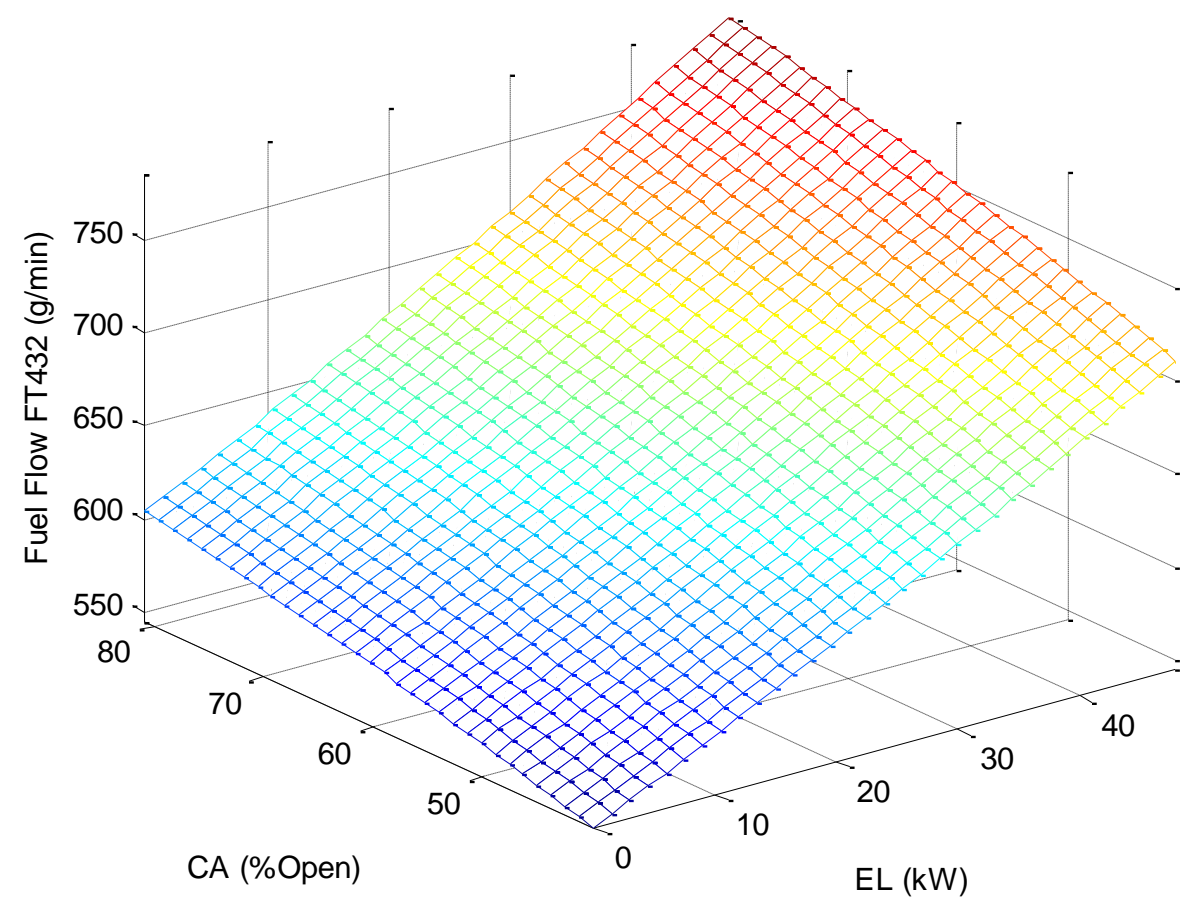

Figure 19: Fuel Flow as a Function of Electric Load and Cold Air Valve Position

The EL load has a nearly linear relationship with the fuel flow. The fuel flow must be manipulated in order to maintain turbine speed under a changing load. Opening of the CA valve causes more air to bypass the plenum and combustor, reducing the system pressure drop, but also lowering the turbine inlet temperature. The lower turbine inlet temperature requires an increase in fuel to maintain turbine speed.

\subsubsection{Cathode Air Inlet Temperature}

The cathode inlet temperature (TE-326) is the temperature of the air entering the pressure vessel that simulates the fuel cell cathode and air manifold volumes. This is a critical parameter to the system due to the sensitivity of the fuel cell to temperature fluctuations. Equation (8) is the full equation of TE326 as a function of all valve positions and electric load and has a $R^{2}$ value of 0.983 . TE-326 was found to be a function of the BA and EL as seen in the Equation (9). The accuracy of the equations with measured data is shown in Figure 20. An $R^{2}$ value of 0.964 was obtained. Figure 21 illustrates the surface plot of the turbine inlet temperature against bleed air bypass valve positions and electric load for each of the 81 tests.

$$
\begin{aligned}
& T E 326=397.475-1.22 * H A+0.0027 * H A^{2}+1.3715 * B A+0.0222 * B A^{2}-1.36 * C A+0.00516 * \\
& C A^{2}+2.768 * E L+0.01318 * E L^{2}+0.0589 * H A * B A+0.0159 * H A * C A-0.01845 * H A * E L+0.04437 * \\
& B A * C A-0.082 * B A * E L-0.020 * C A * E L-0.001 * H A * B A * C A+0.0001 * H A * C A * E L+0.00124 * \\
& H A * B A * E L+0.0015 * B A * C A * E L-0.000006 * H A * B A * C A * E L
\end{aligned}
$$



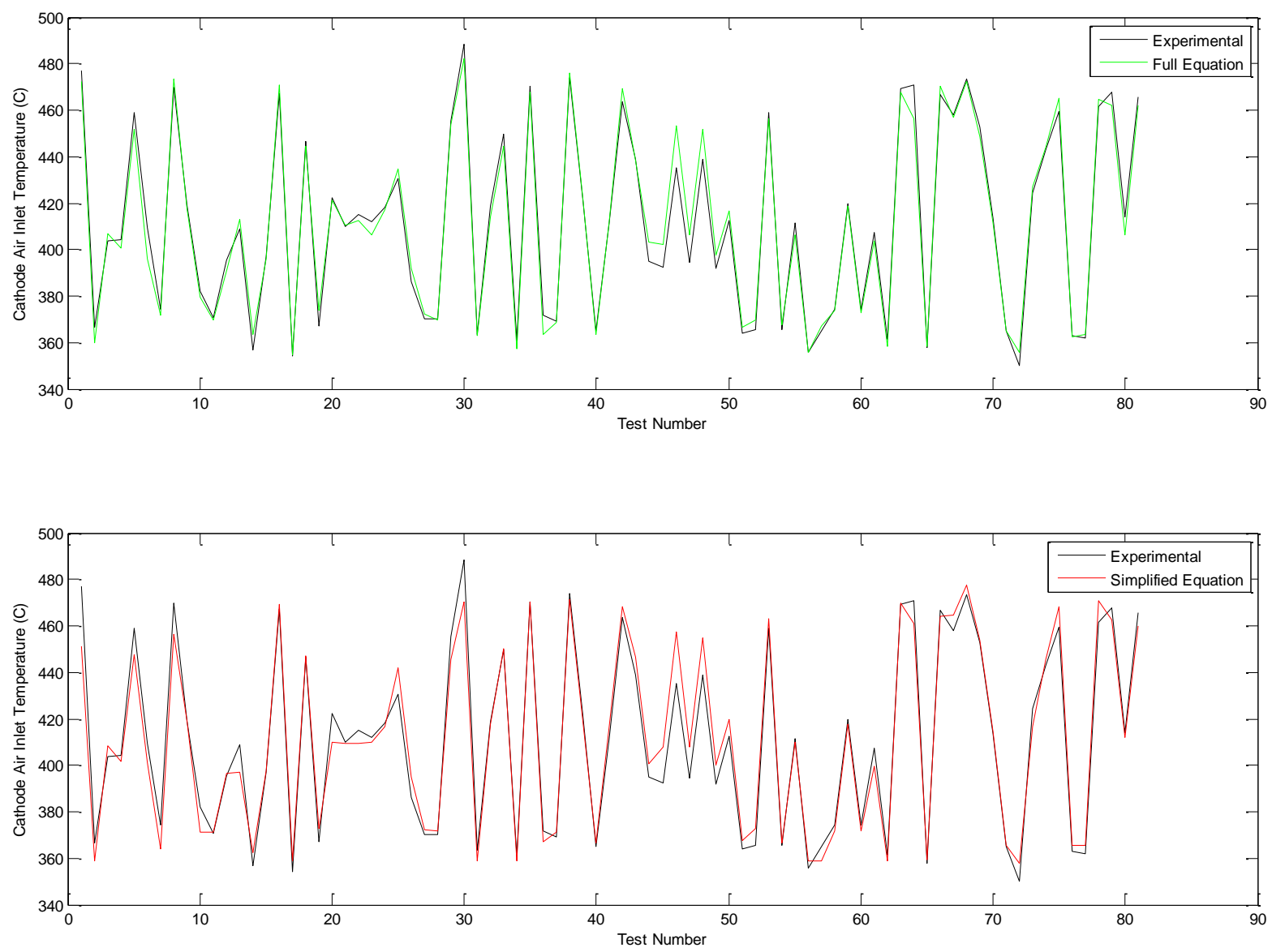

Figure 20: Comparison of Experimentally Measured Cathode Air Inlet Temperature with Value Predicted by Polynomial Model of Equation (8) and (9) 


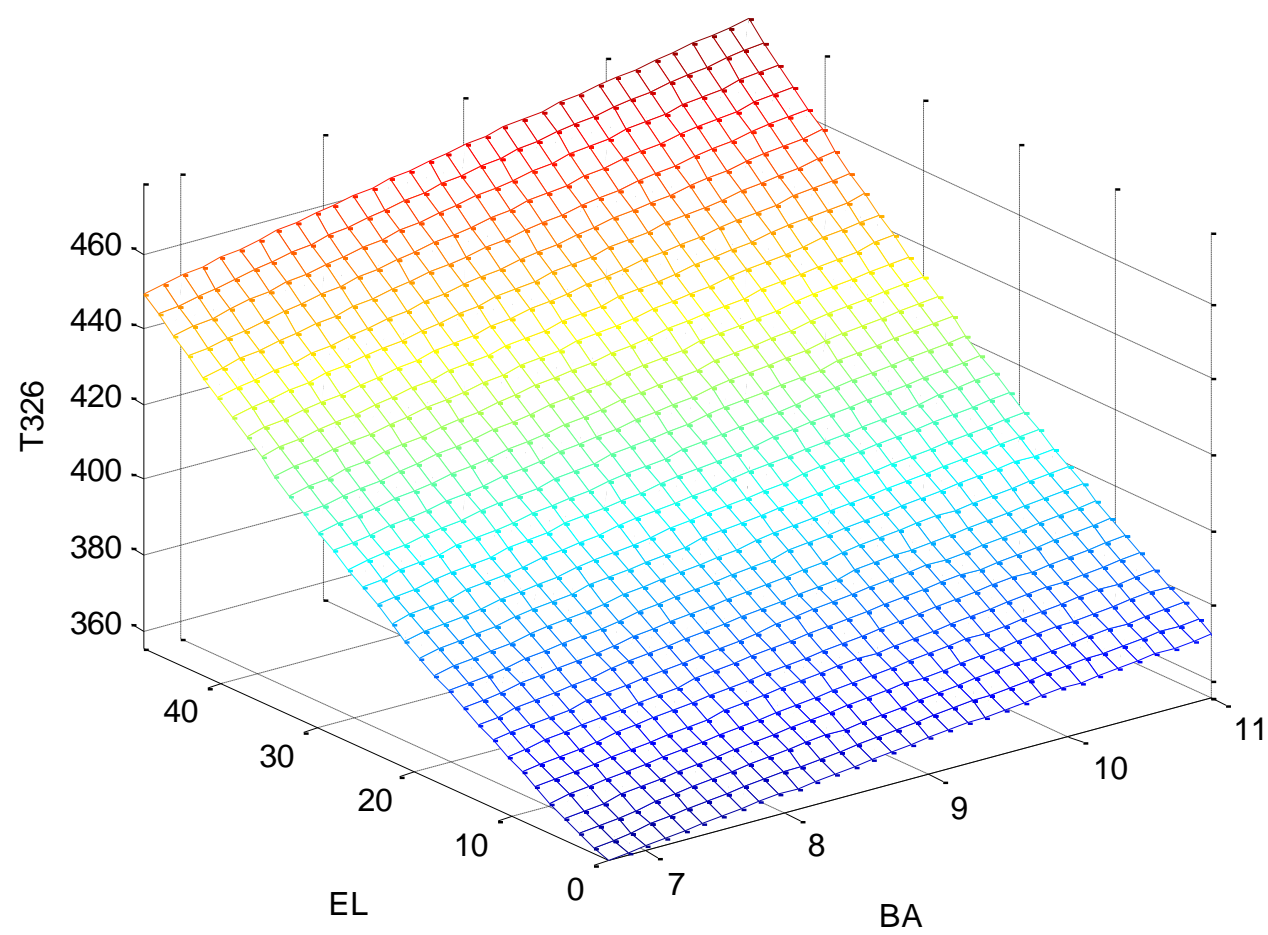

Figure 21: Cathode Inlet Temperature as a Function of Electric Load and Bleed Air Valve Position

Cathode inlet temperature shows a dependence on BA valve because when open the valve causes an increase in compressor load. In order to maintain turbine speed the fuel combustor fires which increases the cathode air flow temperature. The relation with $E L$ is very similar, i.e. with an increase in electric load the combustor fires harder to maintain turbine speed. From this we can conclude the TE-326 has a very close correlation to firing of the combustor.

\subsubsection{Turbine Inlet Temperature}

TE-350 is the temperature of the air entering the turbine. The turbine inlet temperature must be controlled due to material constraints of the turbine. Using all four variables previously specified a full equation was obtained with an $R^{2}$ of 0.985 in Equation (10). The variables were examined and electric load had the most dominant relation with the CA and BA valve having a relatively equal influence. In order to account for this, FT-162, the combined mass flow rate of the CA and BA valves was used as the second variable. TE-350 as a function of EL and FT-162 is shown in the Equation (11) with a $\mathrm{R}^{2}$ value of 0.935. The comparison of the full and simplified equation with the experimental data can be seen in Figure 22. Figure 23 shows the response surface for the turbine inlet temperature against the chosen variables. 

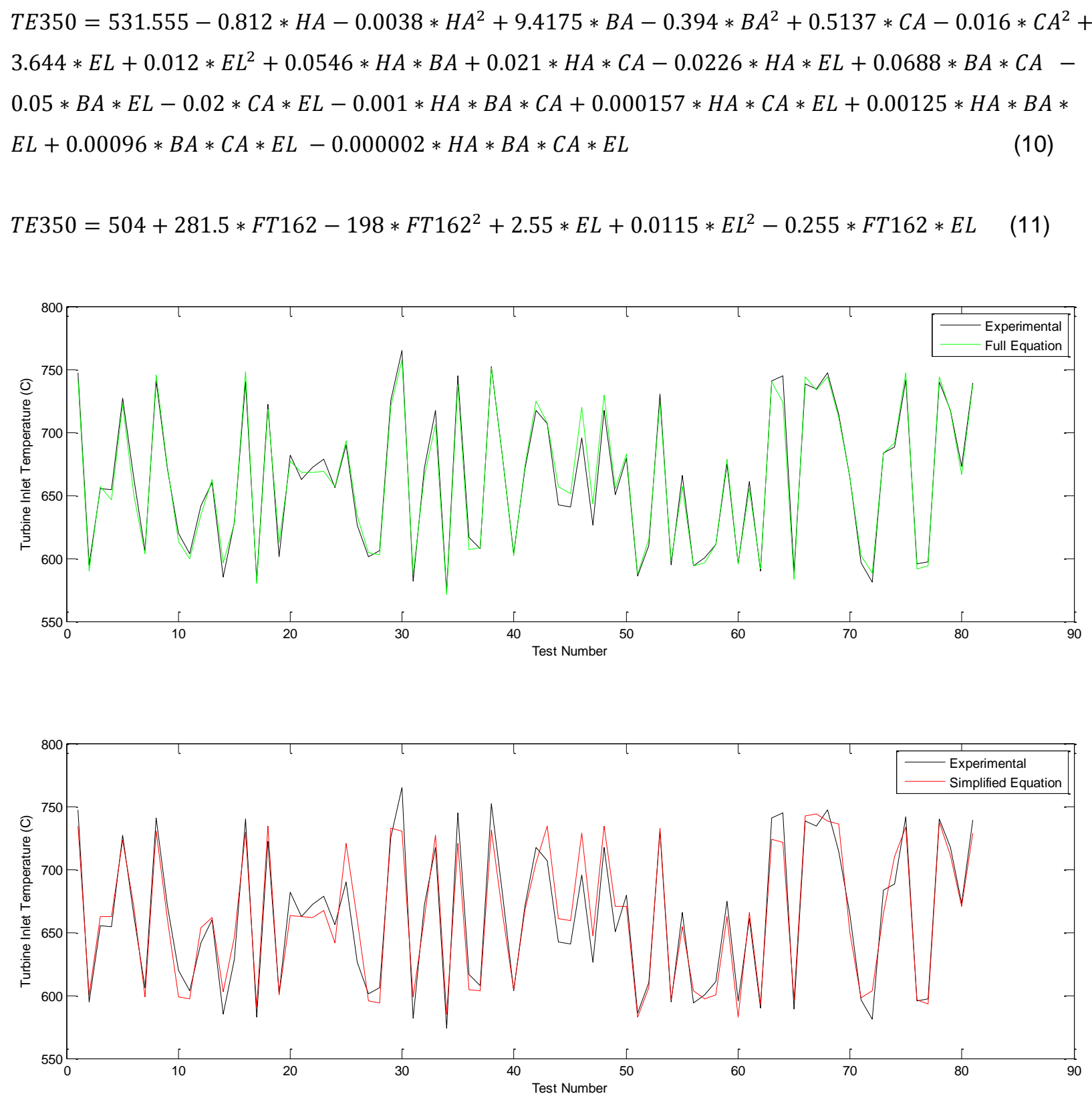

Figure 22: Comparison of Experimentally Measured Turbine Inlet Temperature with Value Predicted by Polynomial Model of Equation (10) and (11) 


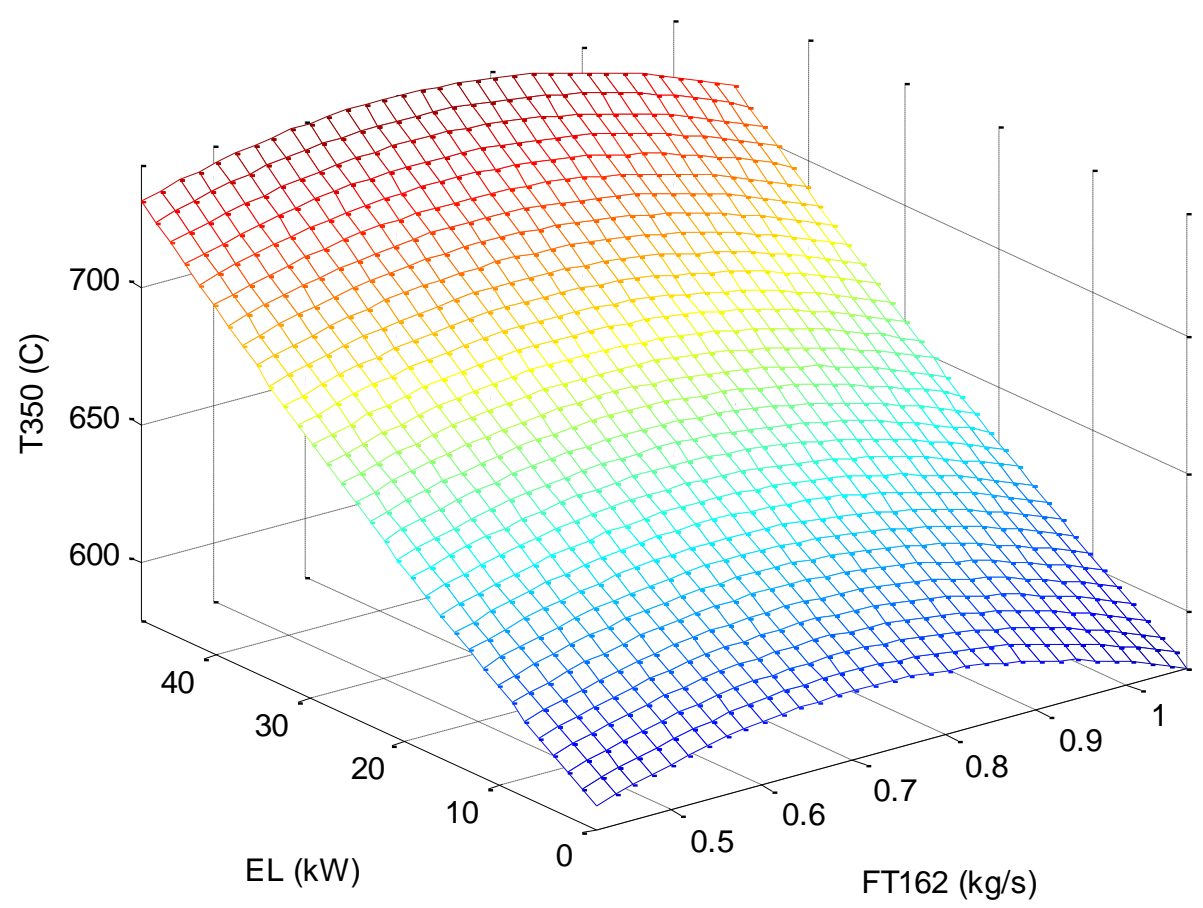

Figure 23: Turbine Inlet Temperature as a Function of Electric Load and Combined CA and BA bypass air flow

\subsubsection{Compressor Inlet Mass Flow}

The compressor inlet mass flow (FT-110) is the measure of the airflow rate at the inlet of the compressor. This is a very important parameter when it comes to compressor surge or stall. The full equation analysis including all three valve position and electric load yielded Equation (12). $A R^{2}$ value of 0.818 was obtained which was not adequate. In order to reach a more accurate equation the ambient conditions were also considered. FT-110 could not be simplified to be a function of only two variables. Instead Equation (13) was formed taking into account the ambient pressure and temperature as well as all the bypass valves and the load. This equation yields an $R^{2}$ of 0.953 which is far more accurate.

$$
\begin{aligned}
& F T 110=1.415+0.0064 * H A-0.00001 * H A^{2}+0.09108 * B A-0.00374 * B A^{2}+0.00722 * C A- \\
& 0.0000305 * C A^{2}-0.000475 * E L-0.000021 * E L^{2}-0.00043 * H A * B A-0.00008 * H A * C A- \\
& 0.0000715 * H A * E L-0.000225 * B A * C A-0.000077 * B A * E L-0.00000374 * C A * E L+0.00000682 * \\
& H A * B A * C A+0.000001416 * H A * C A * E L+0.00000818 * H A * B A * E L+0.00000198 * B A * C A * E L- \\
& 0.000000168 * H A * B A * C A * E L \\
& F T 110=-0.894+9.152 \frac{P_{a m b}}{T_{a m b}}+0.0009 * C A+0.00697 * B A+0.000226 * H A-0.00107 * E L
\end{aligned}
$$



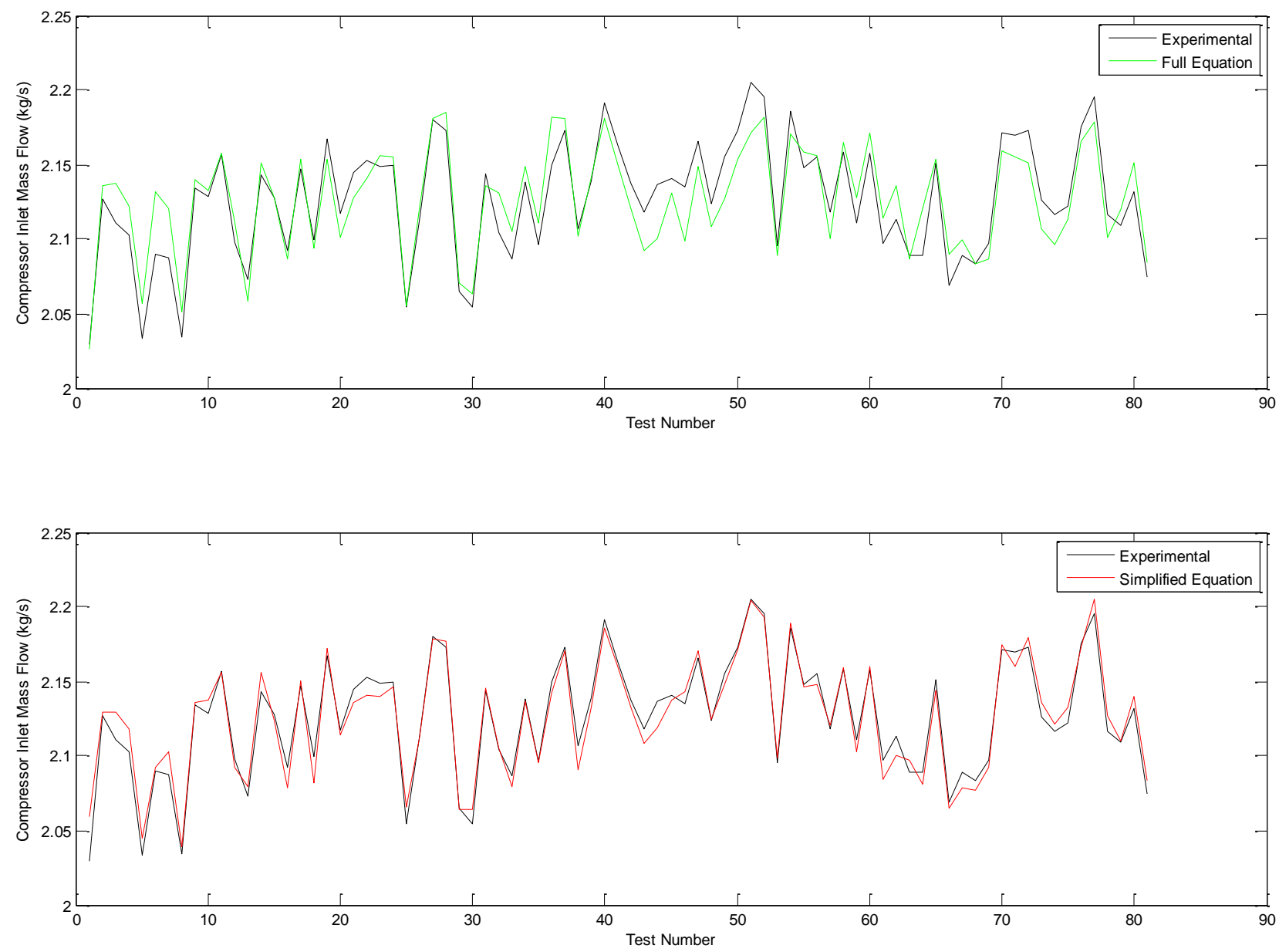

Figure 24: Comparison of Experimentally Measured Compressor Inlet Mass Flow with Value Predicted by Polynomial Model of Equation (12) and (13)

\subsection{Load Division Strategy during Power Demand Step Changes}

A critical concern facing control of the HyPer system is the system response of the cathode mass flow rate, component temperatures and pressures, etc. during transient conditions such as a sudden increase or decrease in load demand. Once the system is implemented into the electrical grid, peaks in consumer usage will cause sudden increases and decreases in power demand. Electric load fluctuations can be nearly instantaneous, and so can the response of the SOFC to track them. The anode of a large SOFC stack has a significant volume, and the fuel flow is regulated by a valve preceding the fuel cell. Despite the instantaneous change in current in the SOFC, the fuel concentration inside the anode can only change as fast as the fuel valve can be opened or closed and the anode can be flushed of its existing contents. During a load drop, the exhaust coming from the anode of the fuel cell will be richer than normal with unreacted fuel. This causes a higher turbine inlet temperature and therefore higher 
power output from the GT. Previous strategies in the HyPer system called for opening the BA valve to expel this excess power to the atmosphere, since the turbine speed must be regulated to the synchronous frequency. As previously stated the fuel cell is fragile and large fluctuations in temperature and pressure can damage components. The goal is to capture excess fuel by generating electricity instead of bypassing air. Controlling the power production between the SOFC and the gas turbine was investigated as an alternative.

Previous work was performed for load management by Mark Magee at West Virginia University (31). His work defined an optimal division of load between the fuel cell and gas turbine during load drops. Magee's strategy called for overshooting the load drop in the SOFC and increasing the generation by the turbine for a short time while the anode is cleared of excess fuel. Then the system would return to the optimal SOFC/GT load division. This strategy is illustrated for a $150 \mathrm{~kW}$ step load decrease in Figure 25 below.

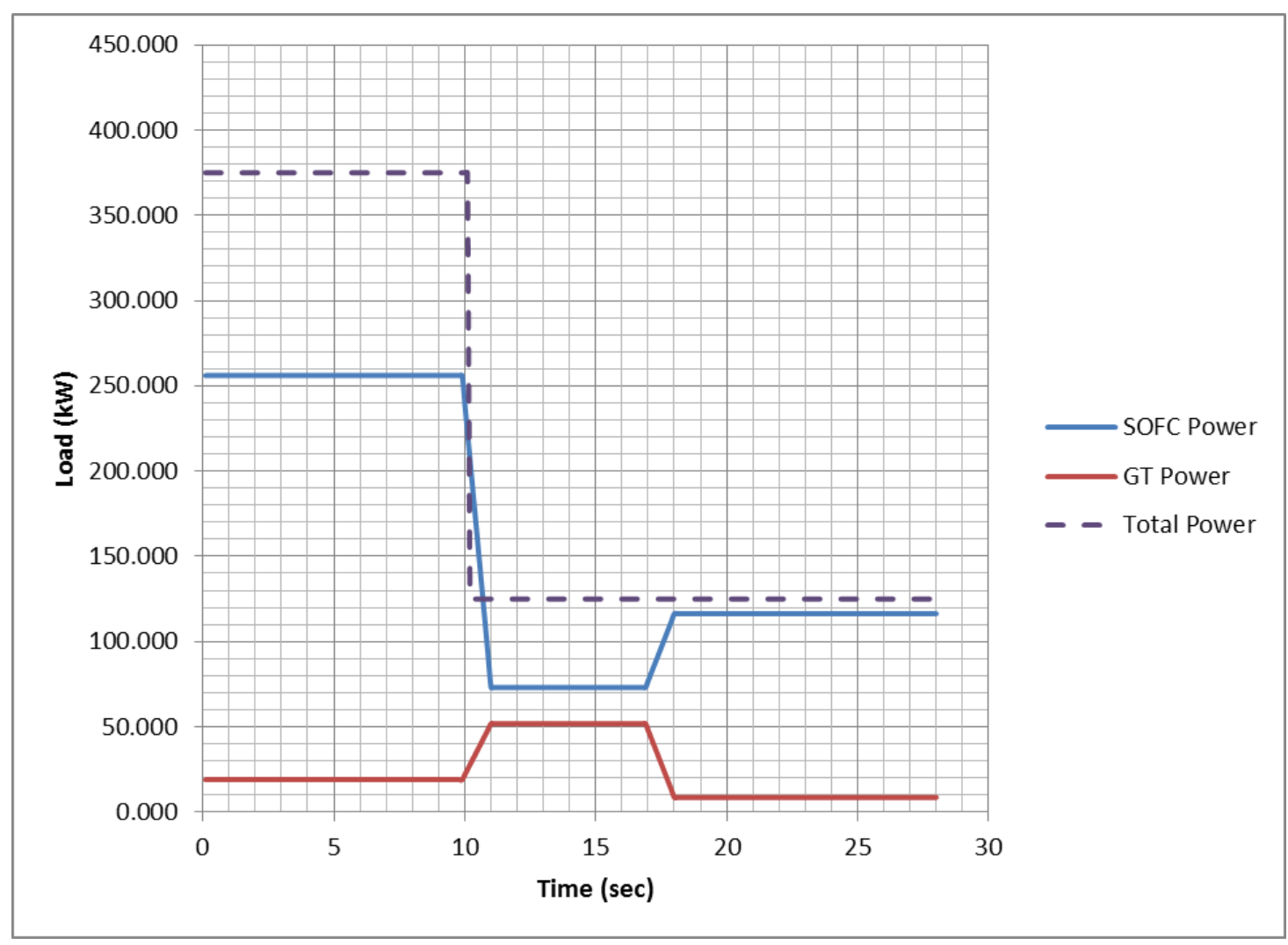

Figure 25: Load Profile for a 275kW to 125kW Decrease

The process is reversed during a step load increase. An instantaneous increase in the SOFC current results in a momentary increase in the fuel utilization factor which starves the gas turbine of fuel. These strategies were used to calculate the desired mass flow rate through the cathode to achieve such load divisions and thus create an optimal path for the cathode mass flow rate in which efficiency and safety can also be taken into account. Examples of these situations will be given in Chapter 4 . 


\subsubsection{Steady State Load Distribution and SOFC Mass Flow Rate}

During constant load operation of the HyPer system there is an ideal division of power between the fuel cell and the gas turbine. This is driven largely by fuel cell efficiency and fuel utilization factor. A percentage of the fuel entering the SOFC is converted into electricity while the remaining fuel is combusted and expanded in the gas turbine. The gas turbine produces additional power after losses due to the efficiency of the combustor and turbine. In order to determine these power divisions this analysis used thermodynamic relationships between the solid oxide fuel cell, post combustor, and gas turbine. Certain system parameter values were established as seen in Table 5 . The stack parameters were based on previous work done at NETL and the turbine efficiency and skin heat loss are assumed values that must be validated through future testing (32).

Table 5: System Parameters

\begin{tabular}{|l|r|}
\hline \multicolumn{2}{|c|}{ Nominal Values of Stack Parameters } \\
\hline Fuel Cell Stack Power (kW) & 529 \\
\hline Fuel Cell Stack Fuel Utilization (\%) & 80 \\
\hline Fuel Cell Stack Efficiency (\%) & 40.4 \\
\hline \multicolumn{2}{|c|}{ Approximated Parameters } \\
\hline Turbine Efficiency (\%) & 10 \\
\hline Skin Heat Loss (\%) & 5.0 \\
\hline
\end{tabular}

Equations (14-18) were used to determine the individual power outputs:

$$
\begin{aligned}
& \dot{W}_{F u e l}=\frac{\dot{W}_{S O F C}}{0.95 \eta_{S O F C F F}} \\
& \dot{W}_{\text {Comb }_{\text {In }}}=\dot{W}_{\text {Fuel }}-\frac{\dot{W}_{\text {SOFC }}}{\eta_{S O F C}} \\
& \dot{W}_{\text {Comb }_{\text {Out }}}=0.95 \dot{W}_{\text {Comb }_{I n}} \\
& \dot{W}_{G T}=\dot{W}_{\text {COmb }_{\text {Out }}} \eta_{G T} \\
& \dot{W}_{\text {Total }}=\dot{W}_{\text {SOFC }}+\dot{W}_{G T}
\end{aligned}
$$

where $\dot{W}_{F u e l}$ represents the power capacity of the fuel, $\dot{W}_{S O F C}$ is the electrical power generated by the fuel cell, $\eta_{S O F C}$ is the efficiency of the fuel cell, FUF is the fuel utilization, $\dot{W}_{\text {Comb }_{I n}}$ is the power entering the combustor, $\dot{W}_{\text {Comb }_{\text {Out }}}$ is the power exiting the combustor, $\dot{W}_{G T}$ is the power generated by the gas turbine, $\eta_{G T}$ is the gas turbine efficiency, and $\dot{W}_{\text {Total }}$ is the total power output for the system.

Iterations were performed to determine the fuel power requirement into the system to achieve the desired load at steady state. The load divisions of the SOFC and gas turbine were found for several values of desired system load at steady state operation. The load divisions were based on having the turbine use only the waste heat from the SOFC, with little or no auxiliary fuel. These load divisions were calculated to be $93.1 \%$ generated by the SOFC and $6.9 \%$ from the gas turbine. The percentage of power produced by the gas turbine and SOFC were found to be independent of the load demand because the efficiencies and losses are assumed to be fixed values in Magee's study. 
The power division can be indirectly controlled through the manipulation of the mass flow rate through the solid oxide fuel cell. The power output of the SOFC is controlled by manipulation of the current drawn by the inverter by way of controlling the output voltage in order for the fuel cell output to move along the IV curve. The fuel flow to the anode is altered to match the fuel cell power output and maintain a constant fuel utilization factor. Instead of referring to the fuel side of the fuel cell the air mass flow rate required at a certain load division to maintain a constant SOFC temperature was determined. This was achieved by calculating the air needed to carry away the waste heat from the electric generation process using Equation (19).

$$
\dot{m}_{\text {Cathode SOFC }}=\frac{\dot{W}_{S O F C} *\left(\frac{1}{\eta_{S O F C}}-1\right) * 0.95}{C_{p} * T_{S O F C}}
$$

Several values were needed for this calculation. The temperature change was assumed to be a constant $200^{\circ} \mathrm{C}$ with an inlet and outlet temperature of $900^{\circ} \mathrm{C}$ and $1100^{\circ} \mathrm{C}$ respectively. And the constant pressure specific heat value $C_{p}$ for air of $1.185 \mathrm{~kJ} / \mathrm{kg}^{*} \mathrm{~K}$ at $1000^{\circ} \mathrm{C}$ or $1273 \mathrm{~K}$ was also used (33). The power divisions between the gas turbine and solid oxide fuel cell as well as the mass flow rate through the SOFC for several total power requirements are displayed in Table 6.

Table 6: Steady State Power Requirements

\begin{tabular}{|c|c|c|c|}
\hline$\dot{W}_{\text {Total }}(\mathrm{kW})$ & $\dot{W}_{\text {SOFC }}(\mathrm{kW})$ & $\dot{W}_{G T}(\mathrm{~kW})$ & $\dot{m}_{\text {SOFC }}(\mathrm{kg} / \mathrm{s})$ \\
\hline 75 & 69.816 & 5.184 & 0.413 \\
\hline 100 & 93.088 & 6.912 & 0.550 \\
\hline 125 & 116.359 & 8.641 & 0.688 \\
\hline 150 & 139.631 & 10.369 & 0.826 \\
\hline 175 & 162.903 & 12.097 & 0.963 \\
\hline 200 & 186.175 & 13.825 & 1.101 \\
\hline 225 & 209.447 & 15.553 & 1.239 \\
\hline 250 & 232.719 & 17.281 & 1.376 \\
\hline 275 & 255.991 & 19.009 & 1.514 \\
\hline 300 & 279.263 & 20.737 & 1.651 \\
\hline
\end{tabular}

\subsubsection{Power Division and SOFC Mass Flow Rate in Response to a Load Change}

As previously discussed a sudden increase or decrease in load is an important event in the HyPer system. Magee's work investigated this situation for various changes in load at different initial conditions to determine the fuel utilization factor and optimal power division between the gas turbine and SOFC. The excess power exiting the anode side of the fuel cell at an altered power demand is the thermal and electrical power from the fuel cell subtracted from the initial fuel power into the fuel cell as seen in Equation (20). To calculate the power division for a given load reduction, the fraction of the power 
produced by the turbine is necessary. This will reflect the absorption of the transient jump in the amount of unreacted anode fuel in the fluid stream. The set point for the SOFC output power during the transient will then be the difference between this number and the total electric load demanded by the grid as shown in Equation (21). In order to complete this analysis Equations (20) and (21) were used in conjunction with those previously defined.

$$
\begin{aligned}
& \dot{W}_{\text {Excess }_{\text {Fuel from Anode }}}=\dot{W}_{\text {Fuel }_{\text {Previous }}}-\frac{\dot{W}_{\text {SOFC }} \text { Current }}{\eta_{S O F C}} \\
& \dot{W}_{\text {SOFC }}=\dot{W}_{\text {Total }} \text { Current } \\
& -\dot{W}_{G T}
\end{aligned}
$$

It was determined that as the change in load increases the percentage of power produced by the turbine increases while the SOFC percentage decreases. This is due to a drop in load causing a large amount of unreacted fuel to enter the turbine increasing the amount of power produced by the turbine.

The optimal behavior of the HyPer system during a sudden load decrease is to absorb the excess thermal energy present by increasing the turbine power while decreasing the SOFC power to meet the required demand. In addition to the needed load conditions of the system the mass flow rates were also calculated using Equation (19). To understand the full load division behavior during a load increase or decrease the initial and final load divisions and SOFC mass flow rate were calculated using steady state Equations (14-19) as well as the intermediate load and SOFC flow rate using Equations (19-21). The results of this analysis can be seen for various test cases in Appendix B: Load Change Examples. This analysis on system behavior during load fluctuations offers the challenge of how to control the cathode mass flow rate through the solid oxide fuel cell to meet the required load divisions during a specific load change.

\subsection{Control Valve Trajectory for Cathode Airflow using Modified Steepest Ascent Method}

In prior work (34), Banta examined strategies for control of temperature gradients in the fuel cell stack during startup. It was found that the cathode inlet air temperature can rise rapidly following turbine light-off and that management of temporal and spatial temperature gradients in the fuel cell stack can be accomplished by manipulation of the cathode air mass flow rates. Ramping of the cell temperature gradually will require quasi-continuous manipulation of the cathode airflow, generating a "trajectory" on the HA-CA surface.

The response surface shown in Figure 15 for the cathode mass flow rate was used to create a control strategy for varying cathode airflow. Ramping during startup is slow, due to the large thermal capacitance of the physical system. For mechanical stability it is desirable to approximate a quasi-static process for state changes, making small changes in valve positions to move between operating points. As an initial operating strategy, the path of steepest ascent/descent was chosen to determine the 
trajectory to be followed by the system for set point changes. This path is both easy to compute and provides the maximum change in airflow rate while minimizing changes in valve positions.

In order to create a trajectory of steepest ascent, the gradient of the FT380 surface must be calculated. From equation (22) and (23) the gradient of the response surface is straightforward to calculate:

$$
\nabla \dot{m}=\llbracket \frac{\partial \dot{m}}{\partial C A} ; \frac{\partial \dot{m}}{\partial H A} \rrbracket
$$

$$
\nabla \dot{m}=\llbracket 0.0137-\left(8 \times 10^{-5}\right) * C A+\left(7 \times 10^{-5}\right) * H A ; 0.0204-(0.0002) * H A+\left(7 \times 10^{-5}\right) * C A \rrbracket
$$

At each sampling instant the current valve positions are used to calculate the gradient and its associated unit vector. The current mass flow rate through the cathode is obtained from the flow sensor FE 380 (Figure 13) and is compared with the desired mass flow rate from the algorithm proposed. The new valve set point positions are then computed by multiplying the gradient unit vector by the flow rate error and a gain term, and adding these set point changes to the current valve position.

Gradient algorithms sometimes get trapped in local minima and require a momentum term or other device to overcome this problem. In this case, there is no local minimum, but the gradient algorithm can choose a path that leads outside the boundaries of the response surface correlation. Figure 26 illustrates such a case that HA goes below the $20 \%$ open value bounding the validity of the correlation equation. Referencing Figure 15 shows that this is because the gradient of the response surface is steeper in the $\mathrm{HA}$ direction than in the CA direction.

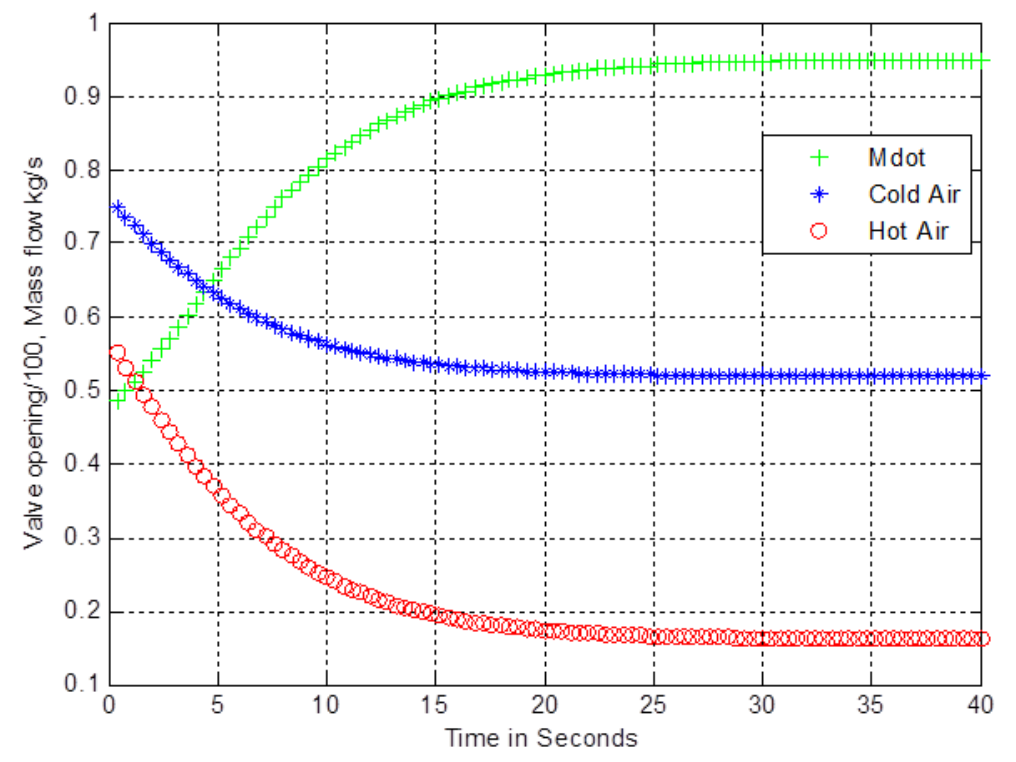

Figure 26: Steepest Accent Method Drives HA below 20\% Open for Certain Initial Conditions which Violates the Correlation Equation Boundaries 
To constrain the steepest ascent (SA) algorithm, a potential function was created along the bounding borders of the $\mathrm{CA}$ and $\mathrm{HA}$ valve range. The boundary conditions for HA and CA were set to be about $1 \%$ of valve opening outside the extremes shown in Table 4 , i.e. $39 \%$ and $81 \%$ for CA and $20 \%$ and $80 \%$ for HA. Figure 27 shows how this potential function keeps the valve positions within the boundary conditions. The potential function, the black rectangle with blue arrows, acts like a fence to force the gradient, black arrows, back into our operating boundary shown as the green area.

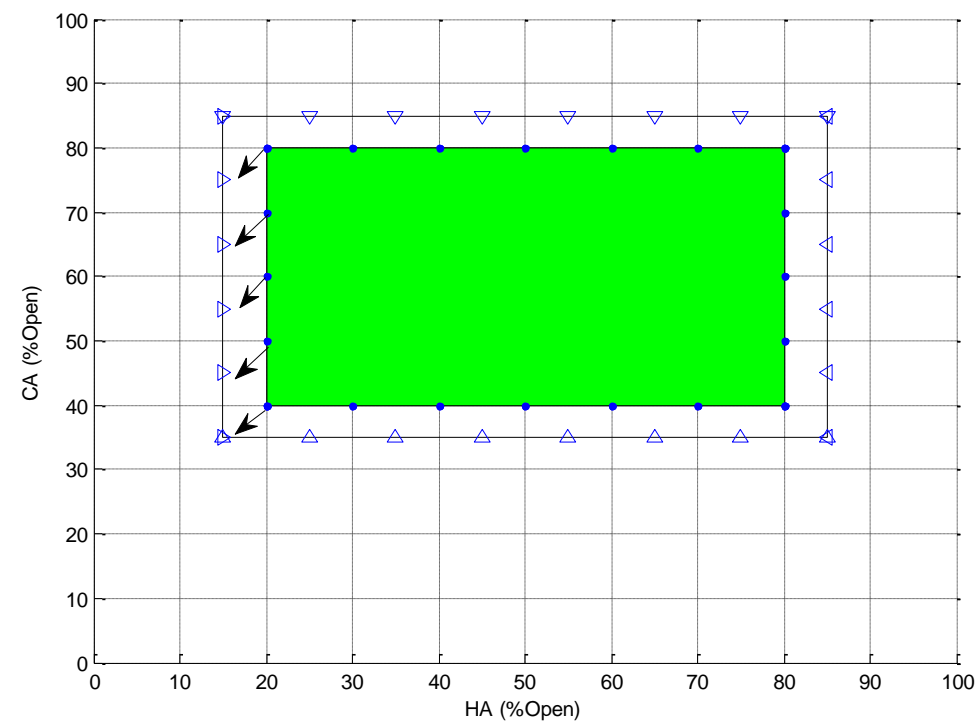

Figure 27: Potential Function Reaction with Gradients along Operational Boundary

The potential function was computed as follows:

$$
P F h=\frac{K 1}{H A-19}+\frac{K 2}{H A-81} P F C=\frac{K 3}{C A-39}+\frac{K 4}{C A-81}
$$

PFh is the potential function applied to the boundaries of the work envelope in the HA direction, and PFc was applied in the CA direction. The constants $\mathrm{K} 1-\mathrm{K} 4$ were computed based on the magnitude of the SA unit vector component normal to the boundary along each side of the bounding box. For example, the steepest ascent (SA) unit vector was computed at $5 \%$ increments for $\mathrm{HA}=20 \%$ while $\mathrm{CA}$ ranged from $40 \%$ to $80 \%$. The result shown in Table 7 is the unit vector for that boundary range. Based on this, $\mathrm{K} 1$ was chosen to be 0.51 , because this was the highest magnitude in the HA direction along the $\mathrm{HA}=20 \%$ boundary. Thus, when HA was within $1 \%$ of the boundary, the PF algorithm would overpower the SA component in the "out of bounds" direction. Analogous processes were used to compute the other constants, K2-K4. The values used for each of the constants are given in Table 8. 
Table 7: K1 Unit Vectors, HA=20\%

\begin{tabular}{|c|c|c|}
\hline $\begin{array}{c}\text { CA Position } \\
(\% \text { Open })\end{array}$ & CA-Direction & HA-Direction \\
\hline 40 & -0.8602 & -0.5100 \\
\hline 45 & -0.8703 & -0.4926 \\
\hline 50 & -0.8802 & -0.4746 \\
\hline 55 & -0.8900 & -0.4560 \\
\hline 60 & -0.8996 & -0.4367 \\
\hline 65 & -0.9090 & -0.4169 \\
\hline 70 & -0.9181 & -0.3964 \\
\hline 75 & -0.9269 & -0.3753 \\
\hline 80 & -0.9354 & -0.3536 \\
\hline
\end{tabular}

Table 8: K Values

\begin{tabular}{|l|l|}
\hline $\mathrm{K} 1$ & 0.51 \\
\hline $\mathrm{K} 2$ & 0.82 \\
\hline $\mathrm{K} 3$ & 0.86 \\
\hline $\mathrm{K} 4$ & 0.57 \\
\hline
\end{tabular}

The resulting PFh was added to the HA component of the steepest ascent unit vector and PFc was added to the CA component of the steepest ascent unit vector. This new, modified direction vector was used to compute the valve trajectories. Figure 28 shows the result of using the constrained SA algorithm with the same initial conditions and endpoint goal as those used in in Figure 26.

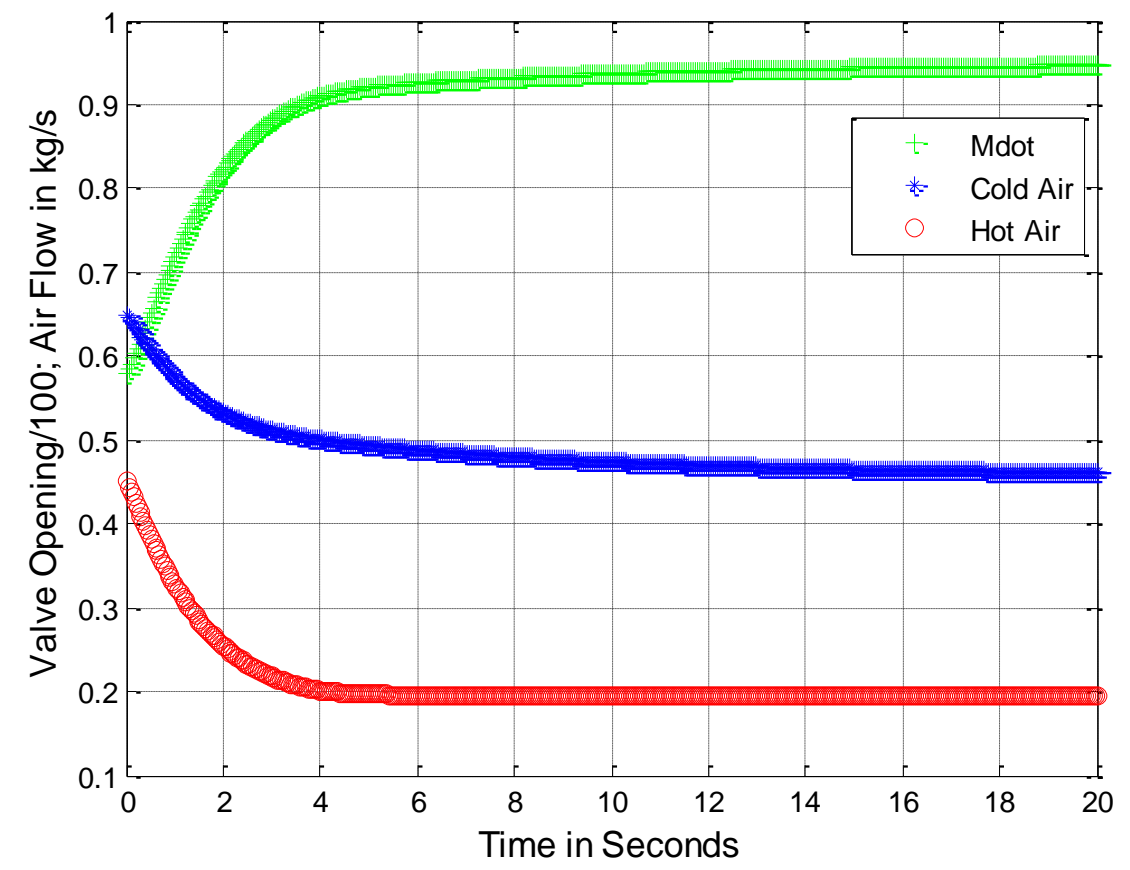

Figure 28: Constrained Steepest Accent with HA in Bounds 
The steepest ascent lays the ground work for optimized path for the cathode mass flow rate. The problem, however, is that there are various paths one can take to achieve the same mass flow rate. Figure 29 shows a comparison of two steepest ascent trajectories where starting mass flow rates are unique but the final mass flow rate is identical.
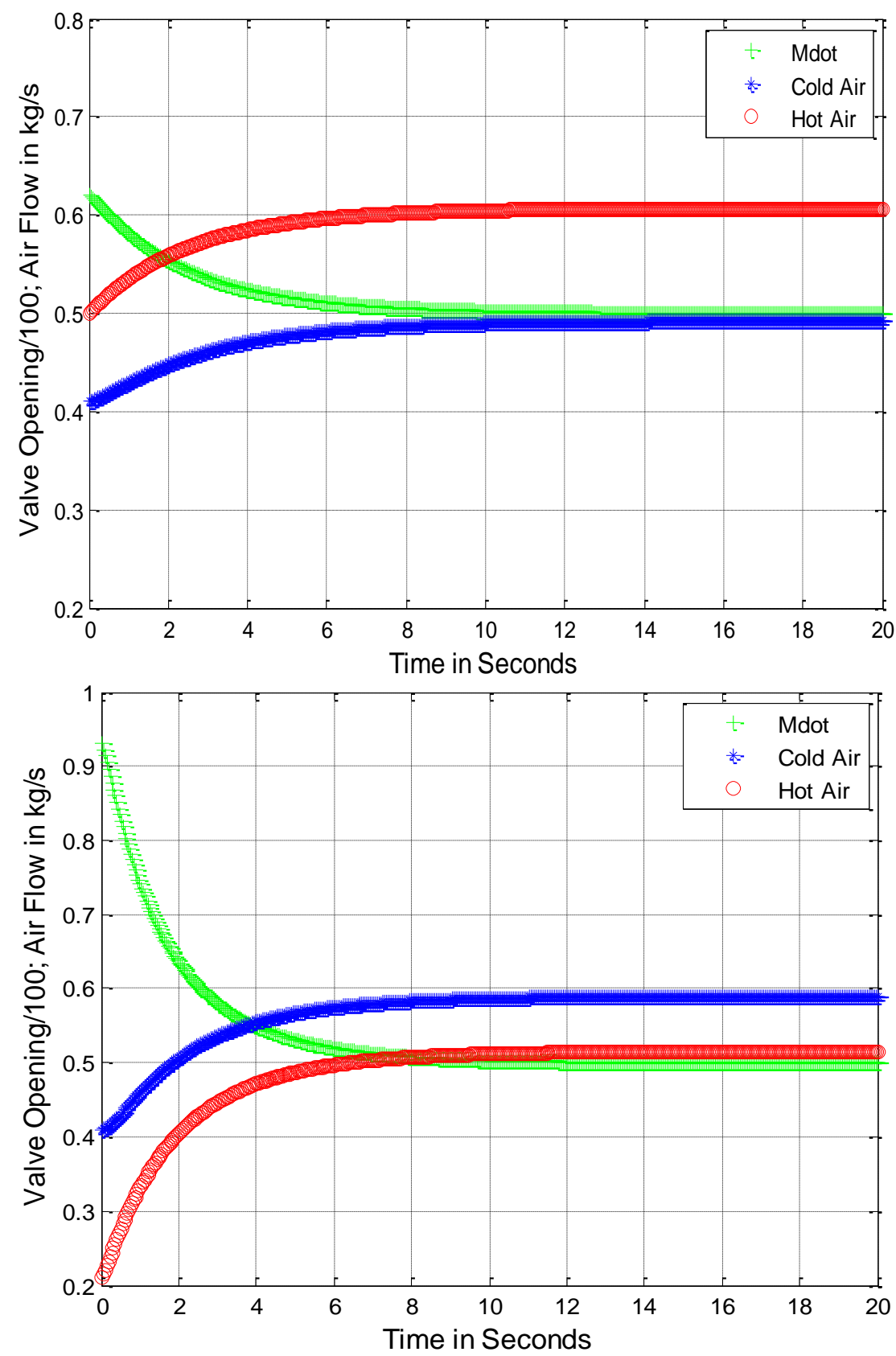

Figure 29: Comparison of Two Different Initial Cathode Airflow but Identical Final Cathode Airflow

These trajectories were applied to the response surface of cathode airflow (Figure 15) to create Figure 30. This figure along with the cathode airflow contour plot shown in Figure 31 clearly illustrate that there are many combinations of $\mathrm{CA}$ and $\mathrm{HA}$ that will result in the same mass flow rate. 


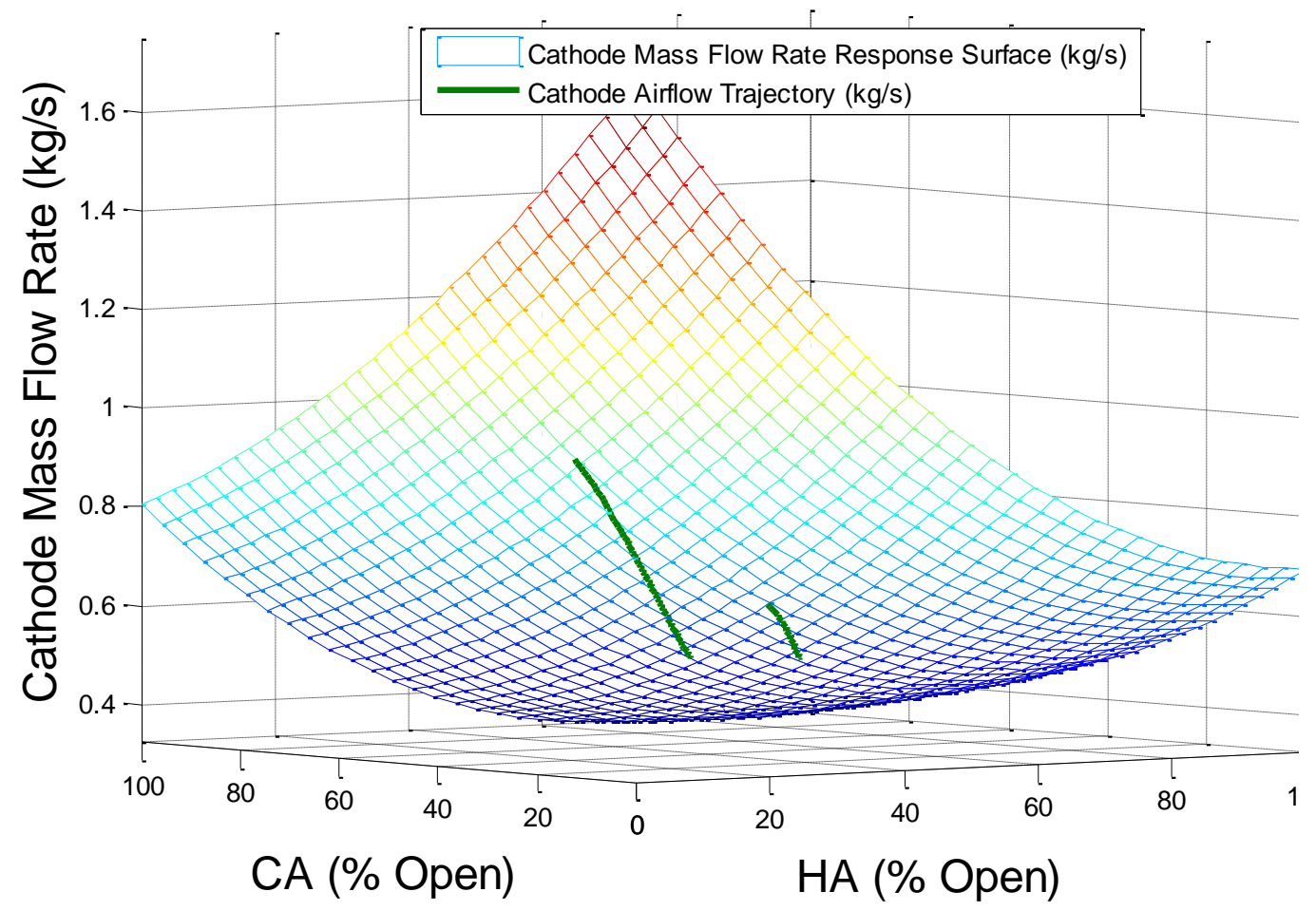

Figure 30: Comparison of Identical Final Cathode Airflow Trajectories on the Response Surface of Cathode Airflow

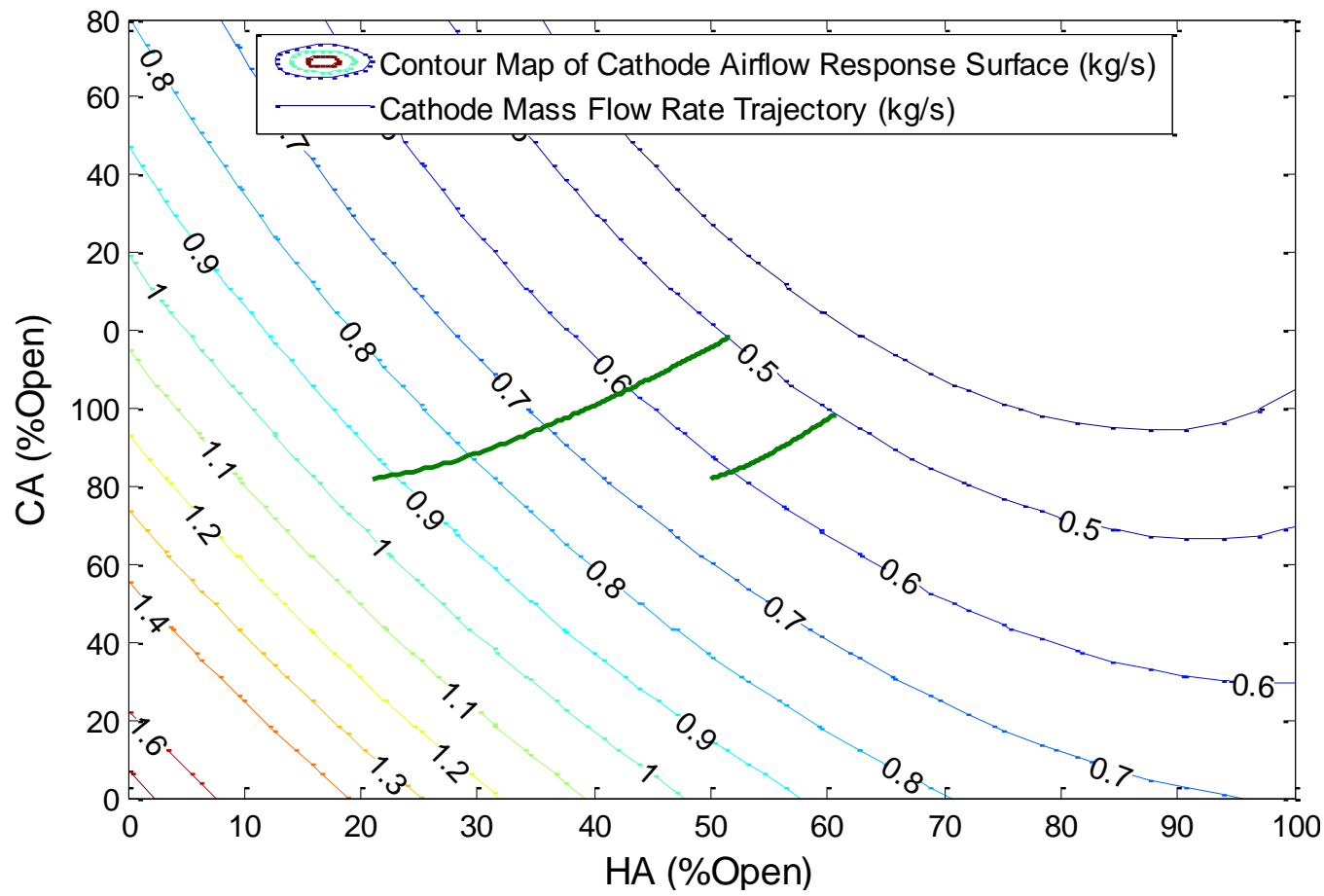

Figure 31: Comparison of Identical Final Cathode Airflow Trajectories along the Contour of Simplified Cathode Airflow Response Surface 
The modified SA algorithm doesn't take an efficient path it just goes the closest desired mass flow rate position. It is known that some combinations of CA and HA are better than others from an efficiency point of view and this trajectory is not optimal in that respect.

\subsection{Optimal Control of Cathode Airflow}

Several combinations of valve positions achieve the same flow rate through the cathode. The goal was to change the airflow through the cathode using the most "optimal" trajectories. The optimal control of the cathode had several parameters that must be considered, mainly stability, durability, and efficiency. The stall margin for the compressor must be considered for safety as well as for stable operation. The temperature of the fuel cell or turbine inlet temperature as well as airflow through the fuel cell had limits. If these were not taken into consideration major damage could be done to the system. While safety was the first priority, maximizing efficiency was the next major concern.

As identified earlier the cathode airflow is dependent upon the HA and CA valve positions with the surface response seen in Figure 15. The data was extrapolated in order to obtain a response for all valve positions of the hot air and cold air bypass. A 2D contour map was created to clearly display the lines of constant cathode flow rate against the $\mathrm{HA}$ and $\mathrm{CA}$ valve positions in Figure 32 . This shows that in moving from one flow rate or line to the next there are an infinite number of possible trajectories and the goal of this work was to identify an optimal trajectory.

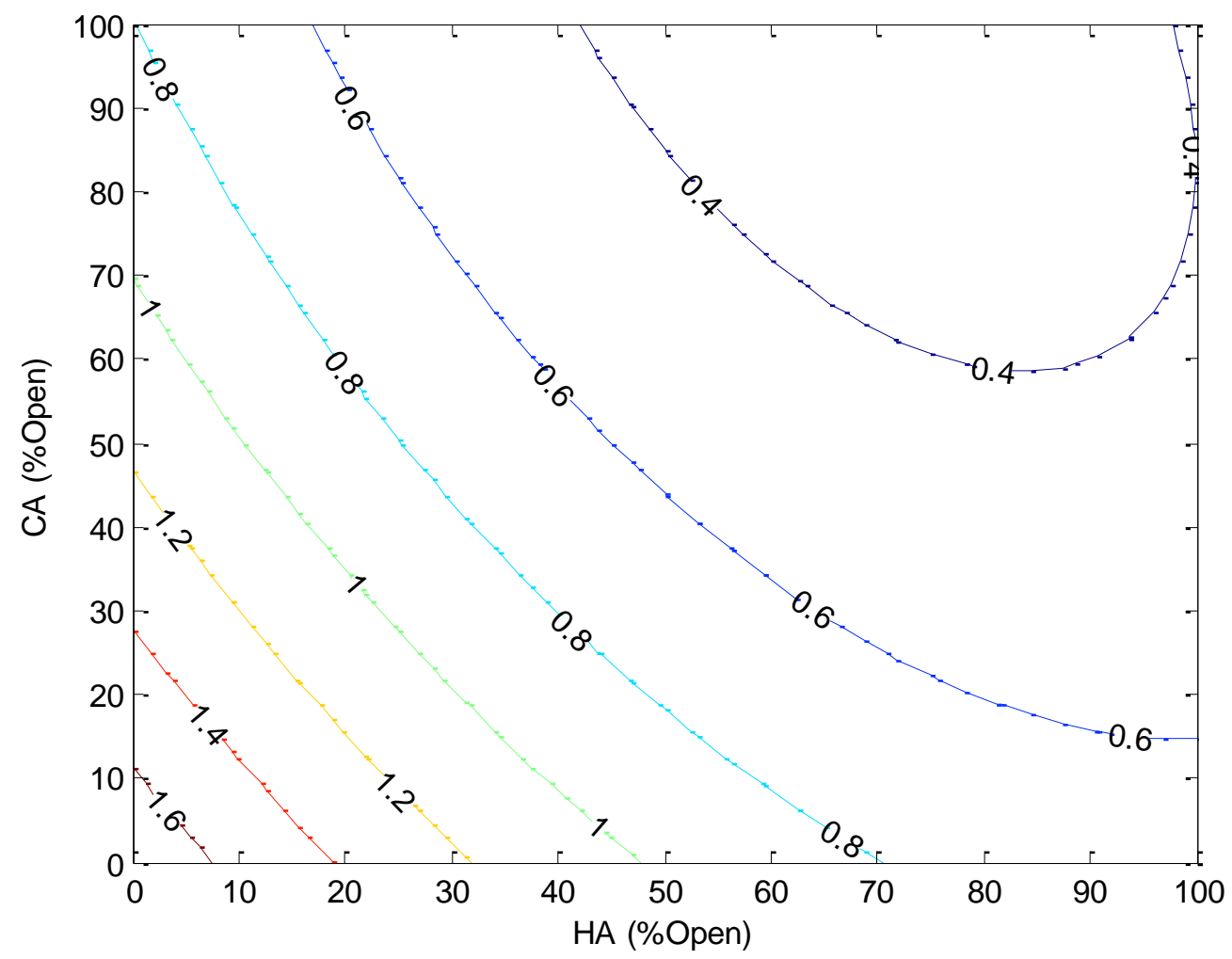

Figure 32: Contour Map of Cathode Flow Rate with respect to HA and CA Valve Positions Contour lines are for constant air mass flow through the cathode, and are given in $\mathrm{kg} / \mathrm{s}$ 
However as you can see in Figure 32 at the boundary of the flow a strange relationship is seen. Around $0.4 \mathrm{~kg} / \mathrm{s}$ the contour curves in on itself. The simplest explanation for this is that data was not collected for this portion with the HA and CA values above $80 \%$. This relationship is obviously not accurate and Figure 33 shows a more reasonable depiction of what the boundary would look like.

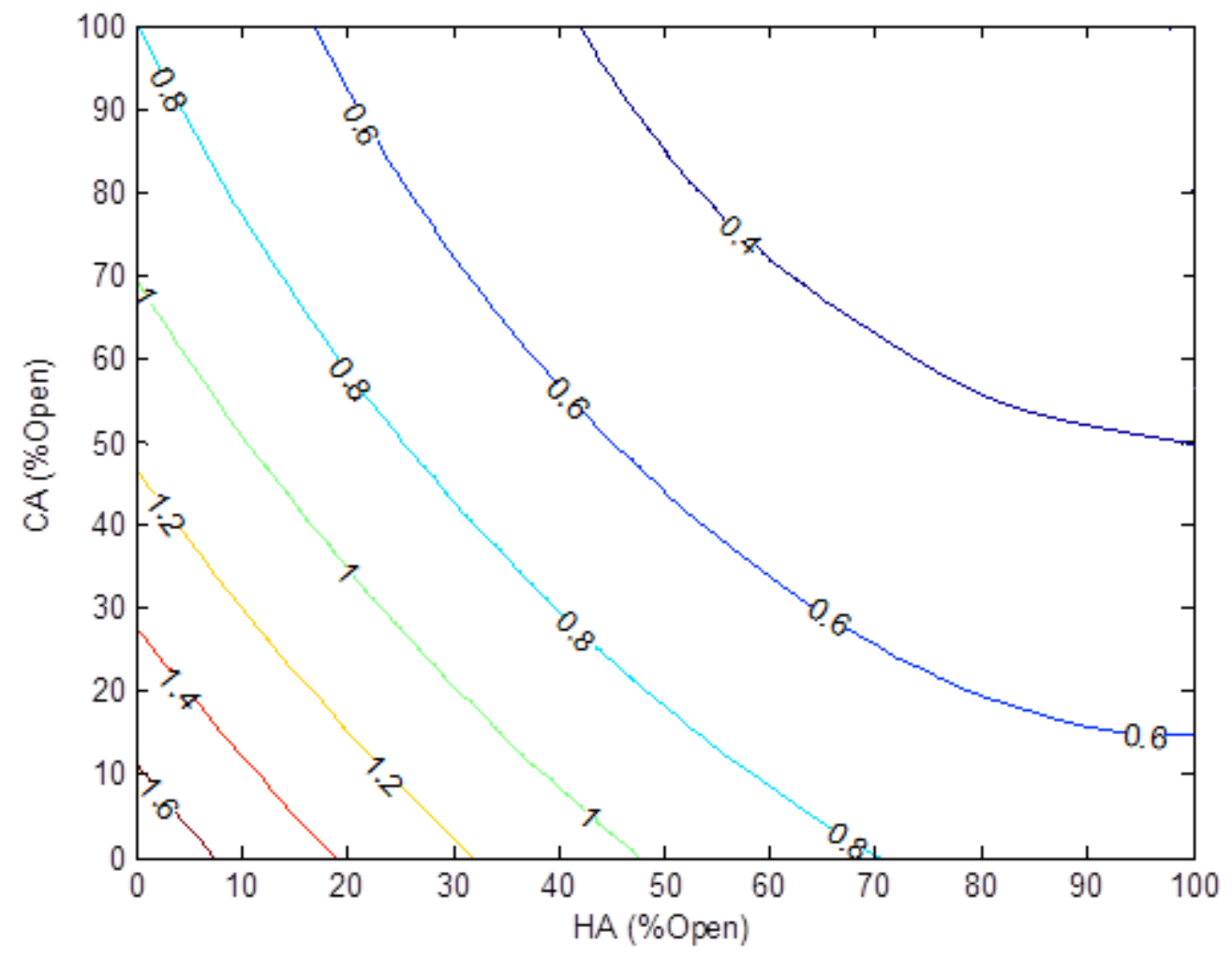

\section{Figure 33: Contour Map of Cathode Flow Rate with respect to HA and CA Valve Positions Contour lines are for constant air mass flow through the cathode, and are given in $\mathrm{kg} / \mathrm{s}$}

Optimal control of the cathode airflow was established using several criteria. As previously mentioned the definition of optimal will be mainly a balance of safety and efficiency. The stall margin is the main concern in safely operating the system. A specific margin of safety was assigned to ensure that compressor surge or stall will not occur during operation of the system by way of monitoring the compressor inlet mass flow. The efficiency similarly was considered by preferred use of certain valves to alter cathode mass flow to limit wasted energy. Other considerations in the optimal criteria were the speed of the response and minimizing the valve movement as in the steepest ascent algorithm. These were included in order to avoid slow response and unnecessary wear on the system.

The available methods of control for the HyPer system are the electric load on the turbine and the 3 bypass valves. Since the electric load will be set for this analysis according to the needed load distribution, the bypass valves were examined. The HA valve is attractive as the primary control 
mechanism because it allows recovery of waste heat from the turbine exhaust and does not reduce system efficiency. However the HA valve sometimes does not allow the bypass of as much air as is necessary to reach the desired flow through the cathode. The CA also has several attractive properties it improves the stall margin and lowers the turbine inlet temperature. Unfortunately the CA valve does not recuperate waste hear from the turbine exhaust as the HA does but it does lower the system pressure drop. The BA is another option. It offers an increase in stall margin which can be very useful. However it causes the largest drop in efficiency of the bypass valves. The control diagram in Figure 34 shows that these valves can be modified iteratively to achieve the desired cathode mass flow rate. The unknown is how these 3 valves operate most optimally. The goal in this optimization is to determine a tradeoff between the bypass valves to achieve high efficiency operation and safe operation with no compressor stall.

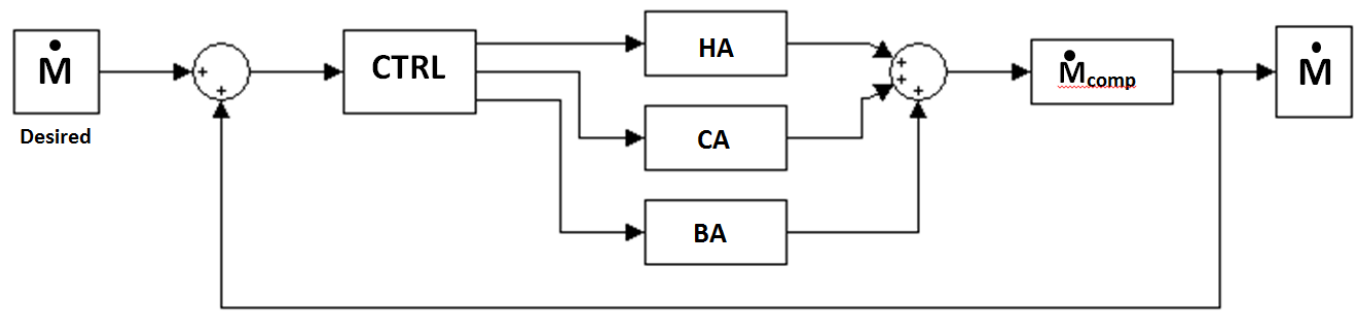

Figure 34: Cathode Airflow Control Diagram

\subsubsection{Optimizing System Efficiency}

Efficiency was a major concern when determining how to control the airflow through the cathode portion of the SOFC. When considering efficiency the best approach of altering the cathode airflow is to use the HA valve, if that does not offer the appropriate airflow then the CA valve must come into play. The BA should only be used as a last resort. The unknown element investigated in this work is at what range or value is CA the most efficient.

Previous work done by Tucker was summarized in Section 2.5 and Table 1, Table 2, and Table 3 (2). Tucker described the effect of the CA valve on the HyPer System in detail. The CA valve's effect on the fuel flow gives a direct correlation to efficiency. As seen in Figure 35 the minimum fuel flow occurs at a value of the CA bypass flow (FE-162) is approximately $0.1 \mathrm{~kg} / \mathrm{s}$ or approximately $9 \%$ open. There is a slight increase in FIT-432 up to roughly $0.45 \mathrm{~kg} / \mathrm{s}$ or $40 \%$ open on the bypass. But after this range a much steeper parabolic relationship is seen in which increasing the CA valve greatly increasing the fuel flow and therefore lowers the efficiency. (3) 


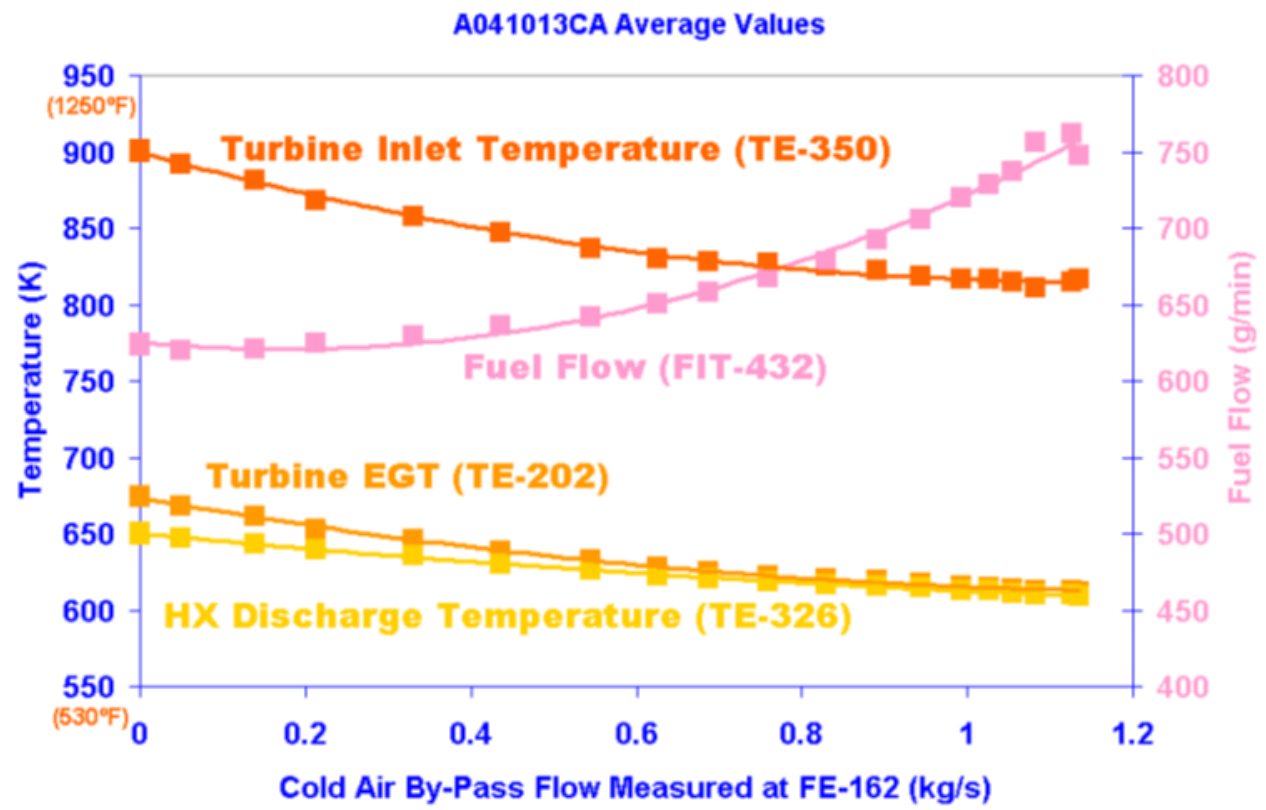

Figure 35: Cold Air System Effects (3)

The most desirable CA valve position is approximately $8 \%$ but since the change in fuel flow is rather negligible up to $20 \%$ any position in this range would offer favorable efficiencies. The 81 tests run for this work only had a CA range of $40 \%-80 \%$ and there was no desire to extrapolate the control algorithms. However previously collected data in Figure 36 illustrates that as the CA bypass flow is increased from $10 \%$ to $100 \%$ with HA, BA, and EL held constant at zero the flow through the cathode is linear. Figure 37 uses current data to illustrate the same basic trend when the BA is open $10 \%$ and the HA is open $20 \%$.

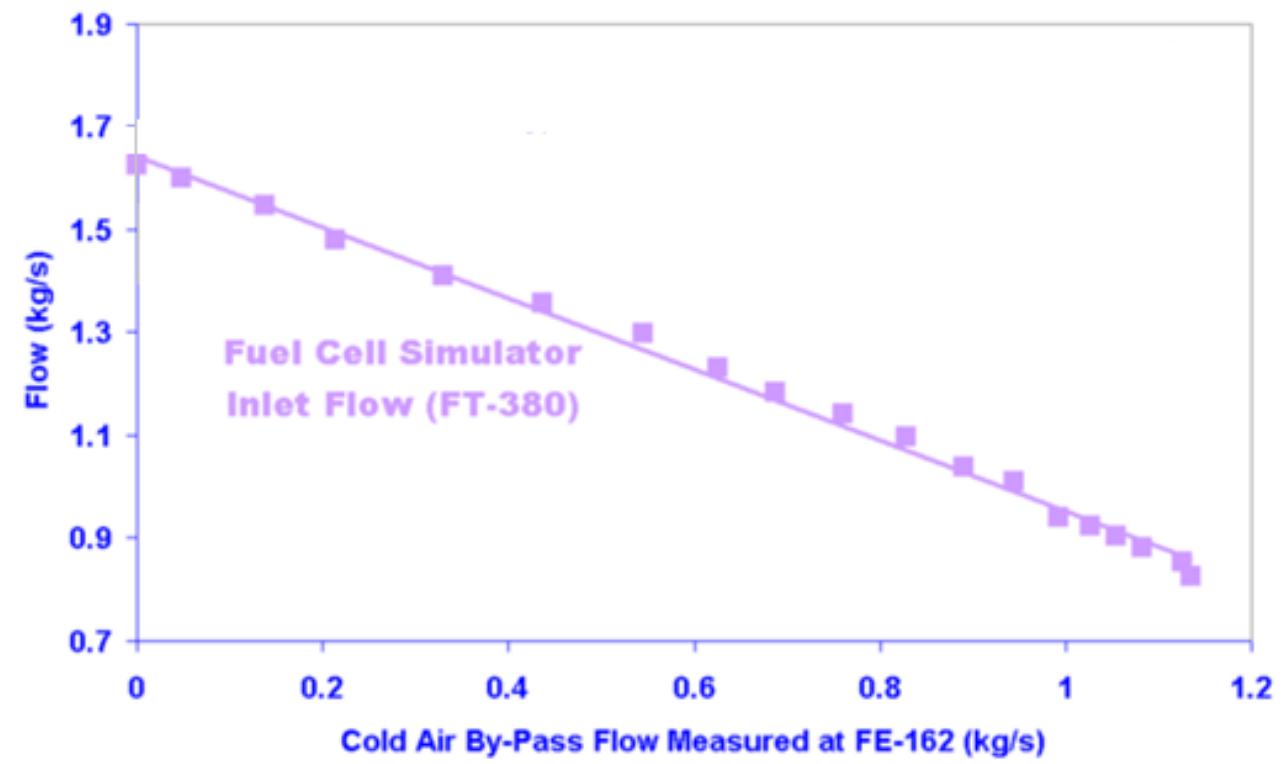

Figure 36: Cold Air Bypass Effect on Cathode Mass Flow Rate (F380) with Old Compressor (3) 


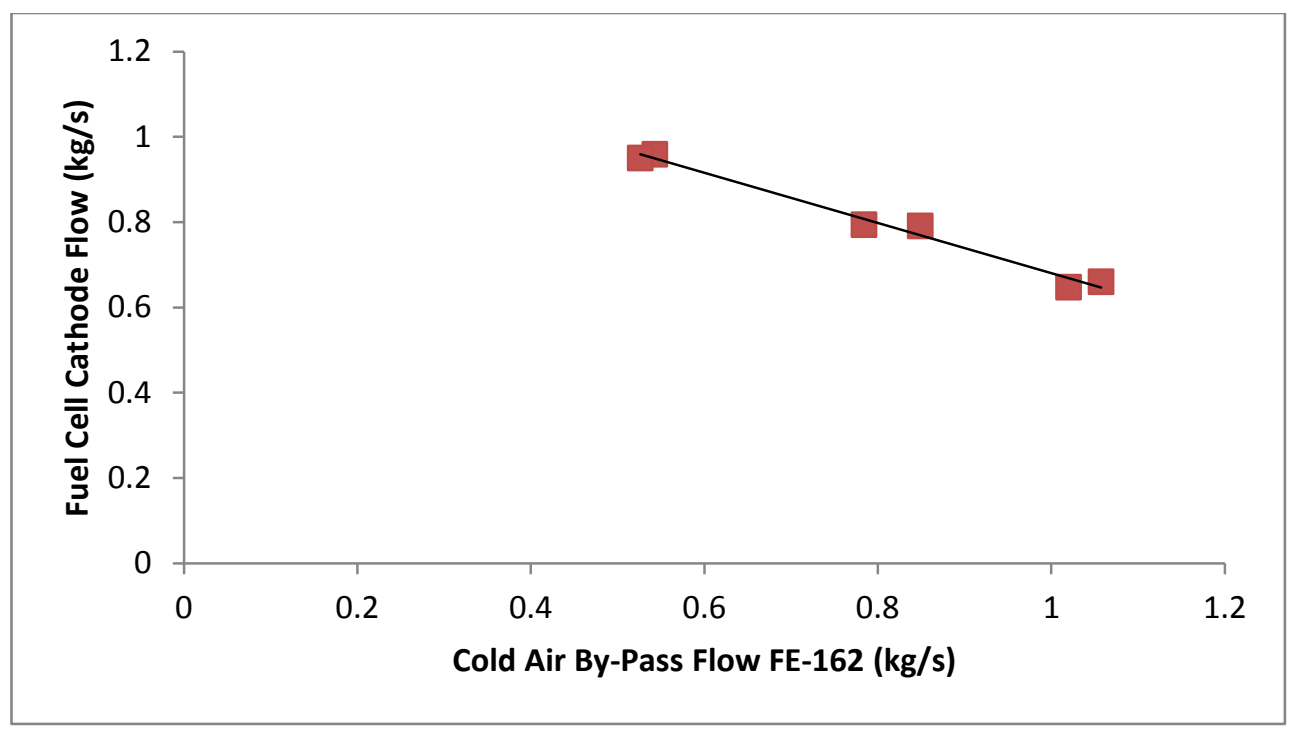

Figure 37: Cold Air Bypass Effect on Cathode Mass Flow Rate (F380) from Current Data

The linear relationships exhibited make it possible to extrapolate in this region. The target value was then lowered to an acceptable $20 \%$. This CA position offers a high efficiency and can accurately be represented with the given data. However this $20 \%$ target cannot be achieved in every given situation or might need to be supplemented with some BA due to stall concerns at certain system conditions.

\subsubsection{Stall Margin}

The stall margin is very important for safe operation of a hybrid system. A compressor surge or stall can cause a lot of damage to both the compressor and other components in the system. In order to mitigate stall a specific limit on the compressor mass flow rate was developed from examination of current data from the 81 tests as well as data collected previously from the HyPer system.

Dr. David Tucker did previous work on the calculation of the stall margin for the HyPer system. In his work his compressor would begin to show signs of stall at approximately $1.75 \mathrm{~kg} / \mathrm{s}(2)$. The current experiment was performed with a new compressor and therefore the stall limit will not be the same. The new stall line for the compressor used in the 81 tests performed can be seen in Figure 38 as well as the location of the tests performed in relation to this stall line. 


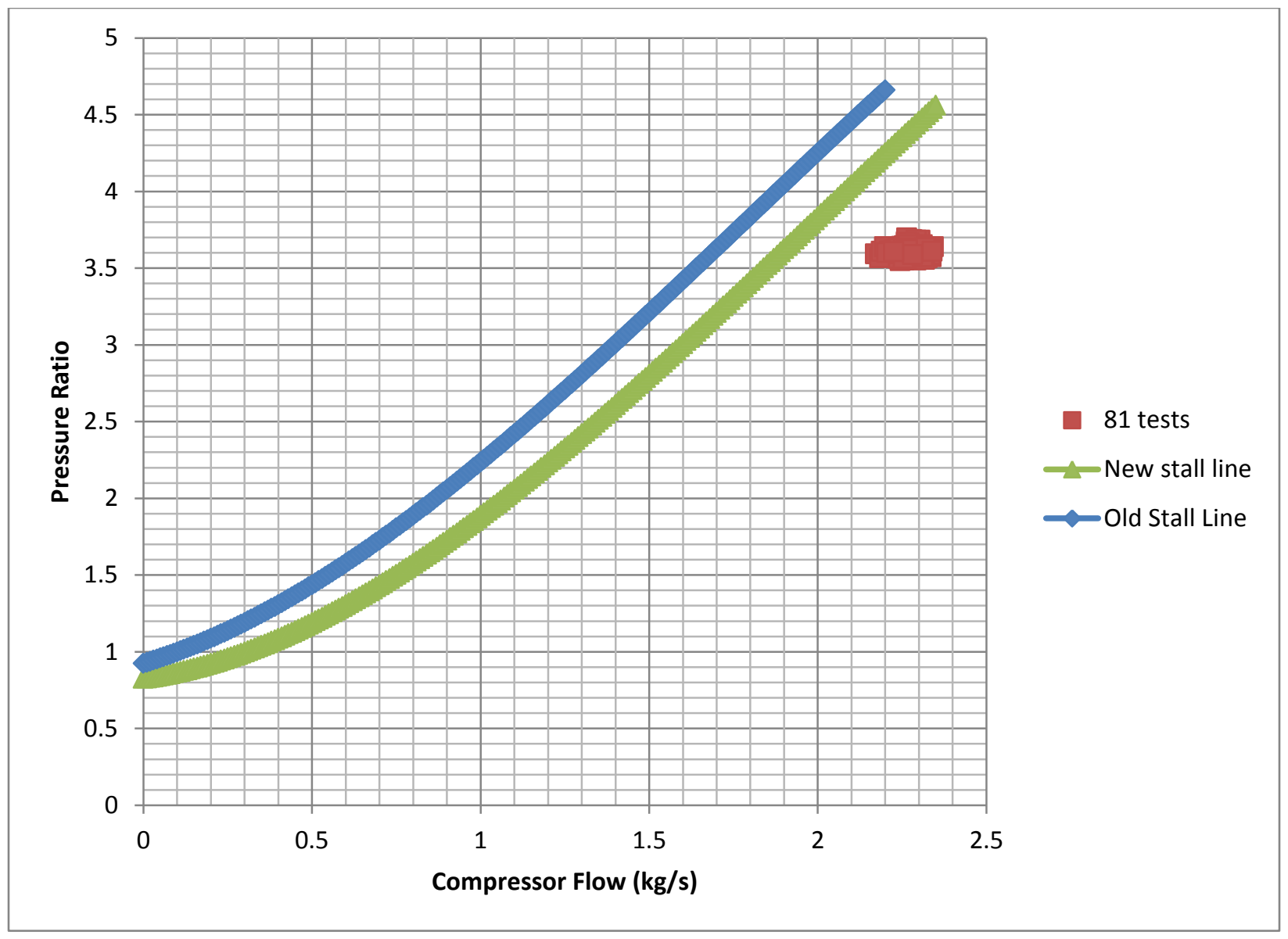

Figure 38: Stall Line Analysis

The 81 tests displayed in this plot all occur around a pressure ratio of between 3.5 and 4 . This is the normal operating condition of the HyPer system. By taking a mean pressure ratio of 3.6 for the 81 test points and relating it to the corresponding compressor flow along the stall line a referred flow of around $1.9 \mathrm{~kg} / \mathrm{s}$ was in danger of stall. A factor of safety was applied to arrive at a minimum acceptable normalized flow of $2.15 \mathrm{~kg} / \mathrm{s}$ to prevent compressor stall. It is important to note that $2.15 \mathrm{~kg} / \mathrm{s}$ is the referred or corrected flow at the inlet of the compressor. Equation (24) shows the referred flow calculation

$$
m_{\text {referred }}=\frac{m_{\text {actual }} *\left(\frac{T_{a m b}}{T_{a t m}}\right)^{2}}{\left(\frac{P_{a m b}}{P_{a t m}}\right)}
$$

where $T_{a m b}$ and $P_{a m b}$ represent the ambient temperature pressure during the test and $T_{a t m}$ and $P_{a t m}$ are the standard sea-level atmosphere temperature and pressure respectively. During the rest of the analysis the actual measured compressor flow is examined. Therefore the non-referred or actual minimum flow through the compressor in order to avoid stall was calculated to be $2.02 \mathrm{~kg} / \mathrm{s}$. As stated this calculation assumes an average temperature and pressure for the 81 tests. For future work it may be useful to consider other ambient conditions because this can vary the referred flow. In order to further 
validate the need for a selected minimum allowable compressor flow previously collected data was examined. Figure 39 from Tucker's work displays the effect CA bypass flow has on the compressor inlet flow with HA, BA, and EL held constant at zero. It can be seen that for low CA bypass flow there was a danger for stall with flows going below $1.7 \mathrm{~kg} / \mathrm{s}$ which was an approximate stall threshold for the old compressor.

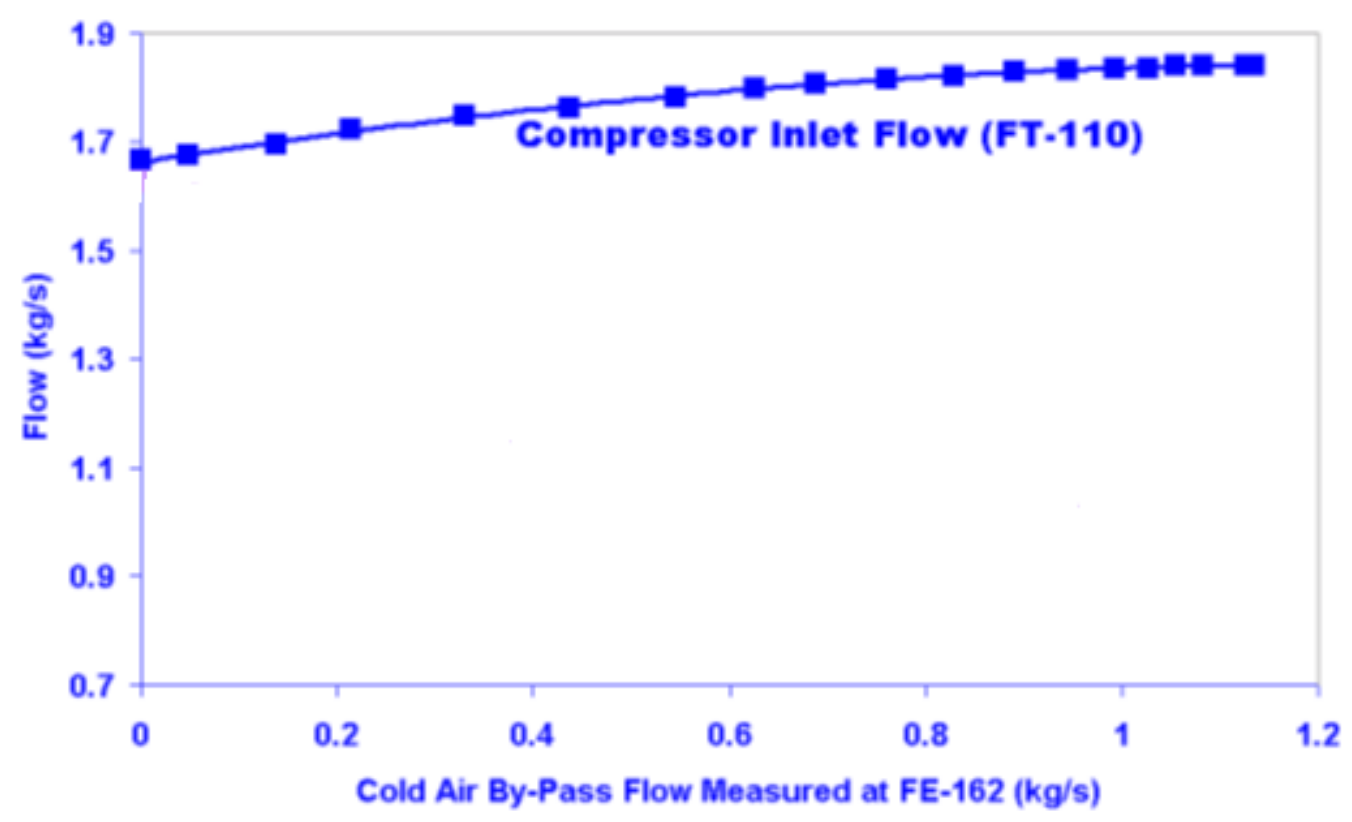

Figure 39: Cold Air Bypass Effect on Previous Compressor's Flow (3)

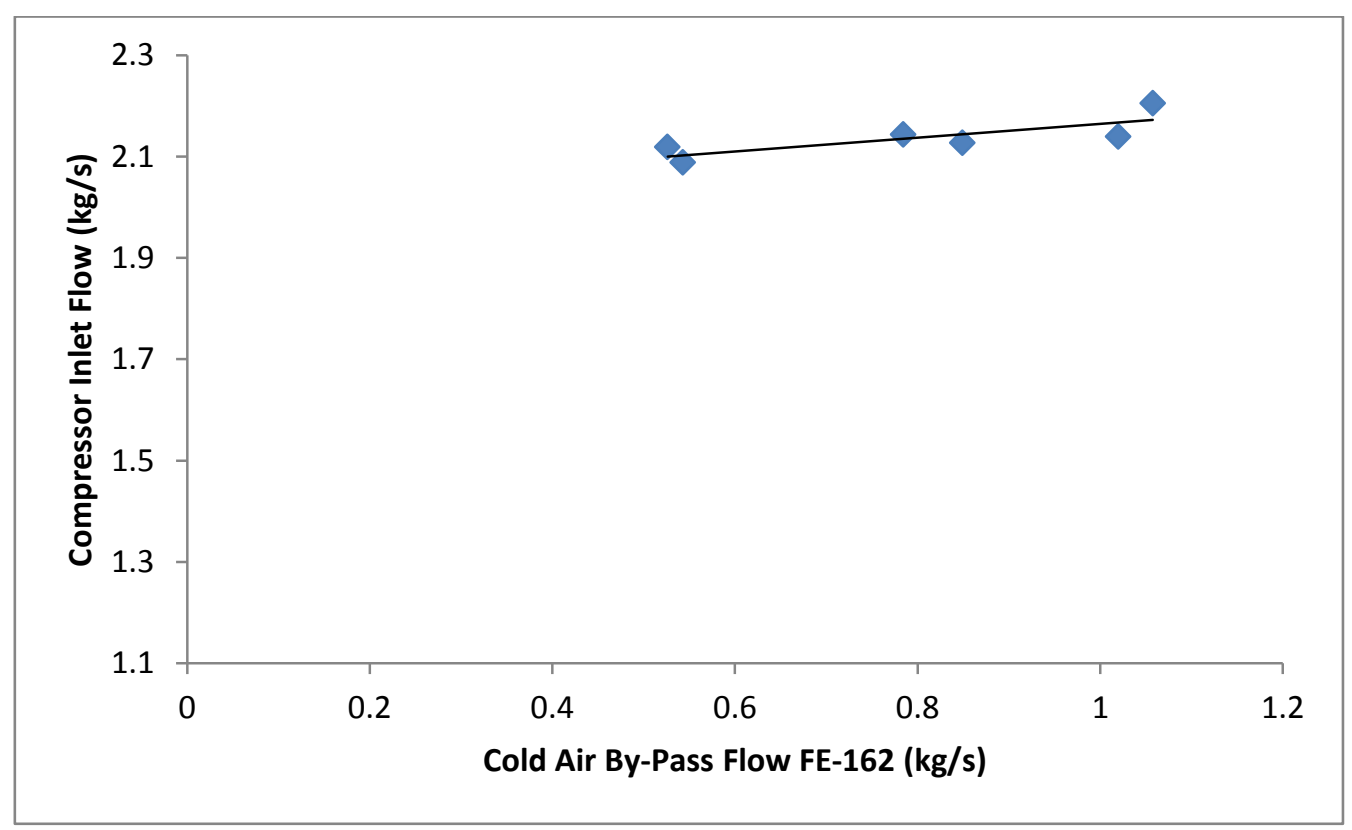

Figure 40: Cold Air Bypass Effect on Current Compressor's Flow 
Figure 40 shows a similar trend even though the CA bypass is not lowered below $40 \%$ open. It is important to note that this is not an exact replication of Figure 39 in this data the BA is open $10 \%$ and the HA is open $20 \%$ however the same basic trend can be seen. This further illustrates the need to include a stability check within the optimal trajectory.

\subsubsection{Optimal Control Trajectory Strategy}

The control criteria were set and a strategy for an optimal trajectory was determined. The desired change in cathode air mass flow was determined using calculations from Section 3.5 Load Division Strategy during Power Demand Step Changes. The desired cathode air mass flow will then be achieved by way of changes to the bypass air valve positions. The CA will be held constant at $20 \%$ for greater efficiency and the HA will be varied to achieve the desired flow through the cathode. If however the flow is not achieved the CA valve will be increased incrementally and potentially up to $100 \%$ open to achieve the desired flow. At low CA bypass flows and high electric load on the gas turbine there may be a concern for stall. A stability check is included to ensure that the stall margin of $2.02 \mathrm{~kg} / \mathrm{s}$ through the compressor is not violated during the step change. If a violation does occur the BA will be opened to alleviate the strain on the compressor and stabilize the system. It must be noted that the $\mathrm{HA}$ valve is allowed to operate its full range. Previous collected data determined that the HA bypass valve had only a marginal effect on other system parameters (Table 2: Characterization of Hot Air By-pass). This was further validated in these experiments by Figure 17 and Figure 23 were it is seen that the HA valve has little to no effect on the total system pressure drop or turbine inlet temperature. 


\section{Results and Discussion}

Taking into consideration all the factors described in the Technical Approach a model was created in MATLAB ${ }^{\text {TM }}$ to determine optimal trajectories of the flow through the cathode of the SOFC during a load swing. This code first calculates the necessary cathode mass flow rates to reach the initial and final load requirements that are specified by the user. This is accomplished using the Equations 14-19 provided in Section 3.5.1 Steady State Load Distribution and SOFC Mass Flow Rate. Next the intermediate flow rate through the cathode during the load change is determined as described in Power Division and SOFC Mass Flow Rate in Response to a Load Change using Equations 19-21. Once the flow rates are obtained valve positions for these flow rates were determined.

This was achieved using the equation for the cathode airflow, FT380, as a function of HA, CA, $B A$, and EL positions obtained in Section 3.4.1 and setting the original BA position to $0 \%$ open. But there are infinite choices for $\mathrm{HA}$ and $\mathrm{CA}$ valve positions so certain criteria were determined. Mainly the efficiency and stall margin were considered. The best efficiency within safe operation was selected at a CA position of approximately $20 \%$, because Tucker's work had previously determined that maximum system efficiency occurs with CA at $20 \%$. Therefore the first valve positions were held constant at $20 \%$ $\mathrm{CA}$ and the corresponding HA valve was found analytically using the quadratic equation to solve the Cathode Airflow equation, Equation (2). If this attempt did not achieve the desired flow rate, then HA was held constant at $100 \%$ and the CA was found analytically using the similar methods but this time solving for CA. If the flow rate was still not met the flow rate was out of the possible boundary for the system and the specified initial and final loads are not possible. The BA valve was set to be opened if the system does not meet the minimum required flow through the compressor determined by a stall margin check in the code. If the BA is needed it will be opened to an analytically calculated value using the Compressor Flow rate equation, Equation (13), to reach an acceptable flow rate, however if this is not achieved within $10 \%$ BA the load change is determined unfeasible.

\subsection{Test Cases to Showcase a Control Scheme over a Wide Range of Load Change Scenarios}

Several different test cases are represented to show the range and accuracy of the model. These test cases represent the model previously explained. The model can determine the optimal trajectory along the cathode mass flow rate for any load change within the operational boundary however only a number of test case are presented here. The selected load changes were chosen to represent small medium and large load changes in a range of cathode mass flow rates. Load increases and decreases are displayed to fully represent the results of the control scheme. 


\subsubsection{Optimal Cathode Mass Flow Rate during a Total System Load Increase}

An increase in total system load is an important event that must be controlled in the HyPer system. This is a common occurrence in system startup. The figures in this section show the load distributions between the gas turbine and SOFC as well as the valve positions and cathode mass flow rate variations for a given addition of load. The cathode airflow trajectories found are also graphically shown along the cathode airflow response surface and the contour map. This clearly depicts a strategy that travels between optimal points, as much in the CA $20 \%$ region as possible, and using the path of steepest ascent/descent to travel between points while staying along the calculated response surface.

\subsubsection{Cathode Airflow Trajectory for Total System Load Increase from 100kw to 125kW}

The following case represents a small load change, starting from a very lightly loaded system. Figure 41 illustrates the load distribution for a load increase from $100 \mathrm{~kW}$ to $125 \mathrm{~kW}$. In this distribution it can be seen that in order to achieve a higher overall load the fuel cell load overshoots and then settles into a higher load, while the gas turbine loses load and then increases to a higher load than initially.

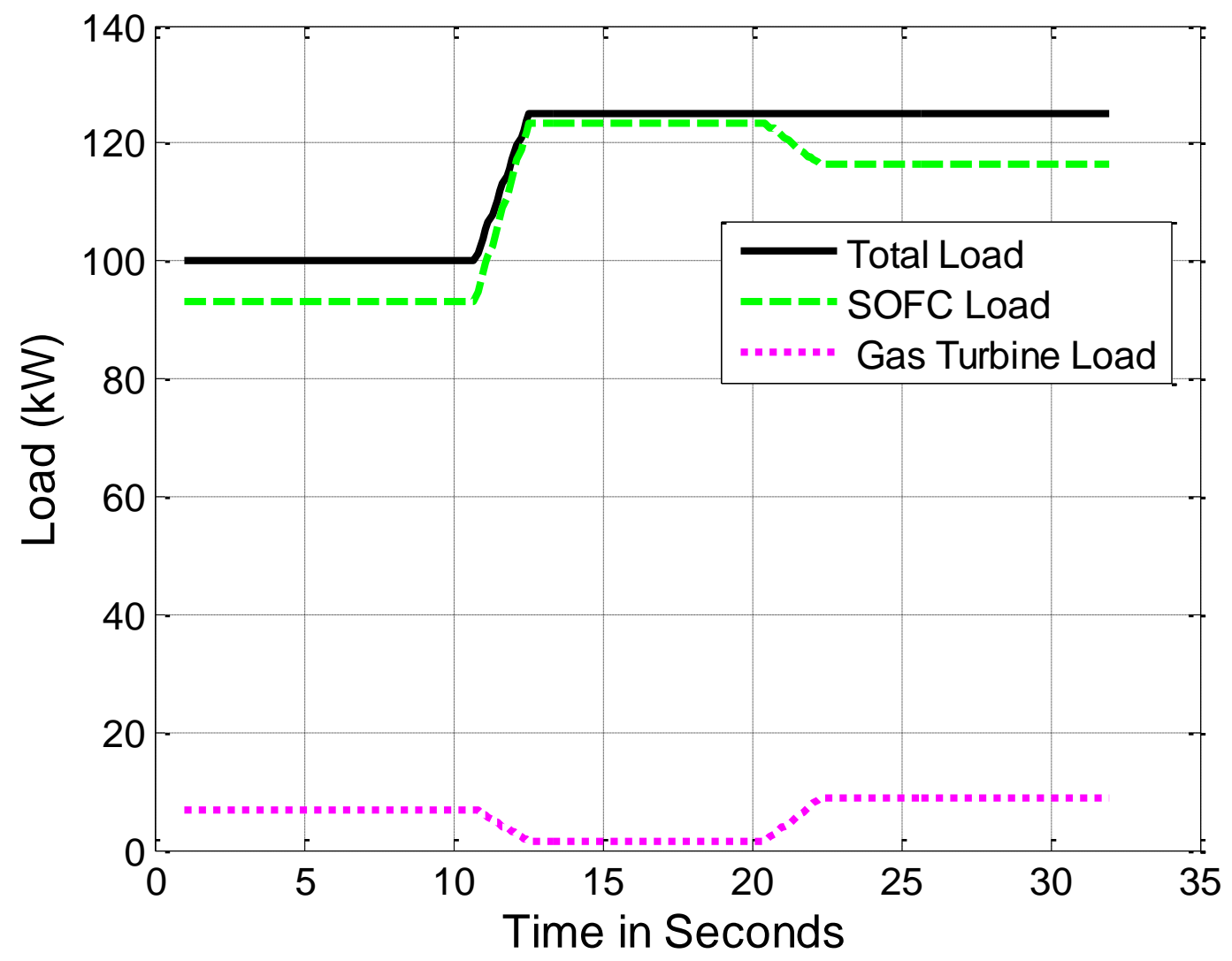

Figure 41: Load Distribution for Load Increase from 100kw to 125kW

For this small load change the bypass air starts out basically on the edge of the operational envelope of the HyPer as illustrated in Figure 42 below. It is important to note that in this case the system 
is operating in a region out in the extrapolated area of the cathode airflow response surface. Once the HA valve reaches beyond $80 \%$ open the surface and therefore control scheme may not be completely reliable. This area needs further experimentation; however based on previous experiments with the old compressor this control scheme achieves reasonable results. Though this scheme might not be "optimal" in this region it does produce a first step for achieving optimal control.

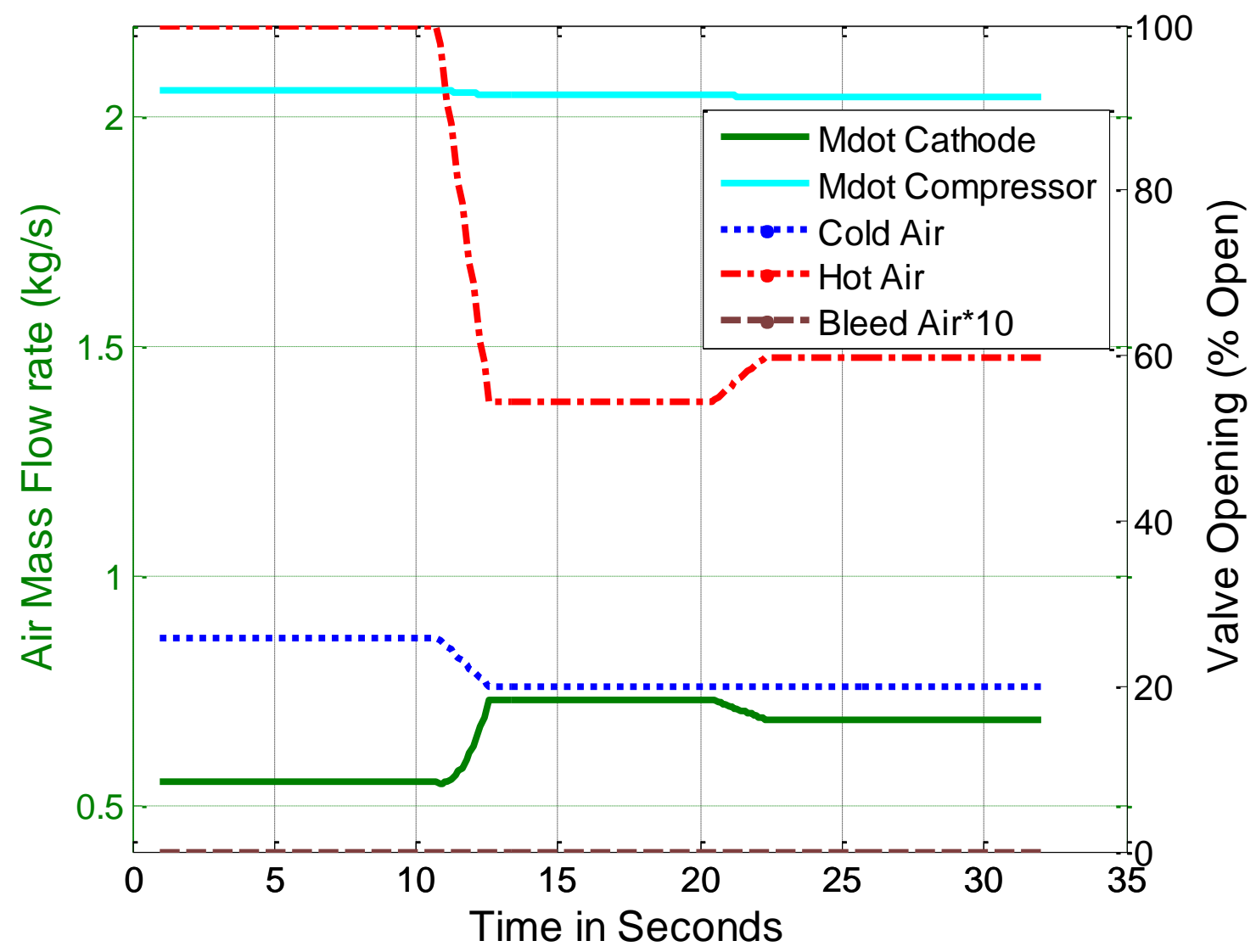

Figure 42: Cathode Mass Flow Rate and Valve Position Variation for a Total Load Increase from $100 \mathrm{~kW}$ to $125 \mathrm{~kW}$

The general relationships in valve positions are seen in Figure 42. It shows that during a small load change HA must undershoot to a lower value and CA will start slightly higher and then converge to its target $20 \%$. The flow through the compressor lowers but does not reach its minimum selected value so no bleed air is necessary. The cathode mass flow rate follows the same basic trend as the SOFC power output but during the transitions does not show a linear relationship. In transition the cathode mass flow rate follows the steepest ascent/descent along the control surface as seen in Figure 43 below. By not deviating much from the surface the flow rate most accurately matches the HyPer's operation. 


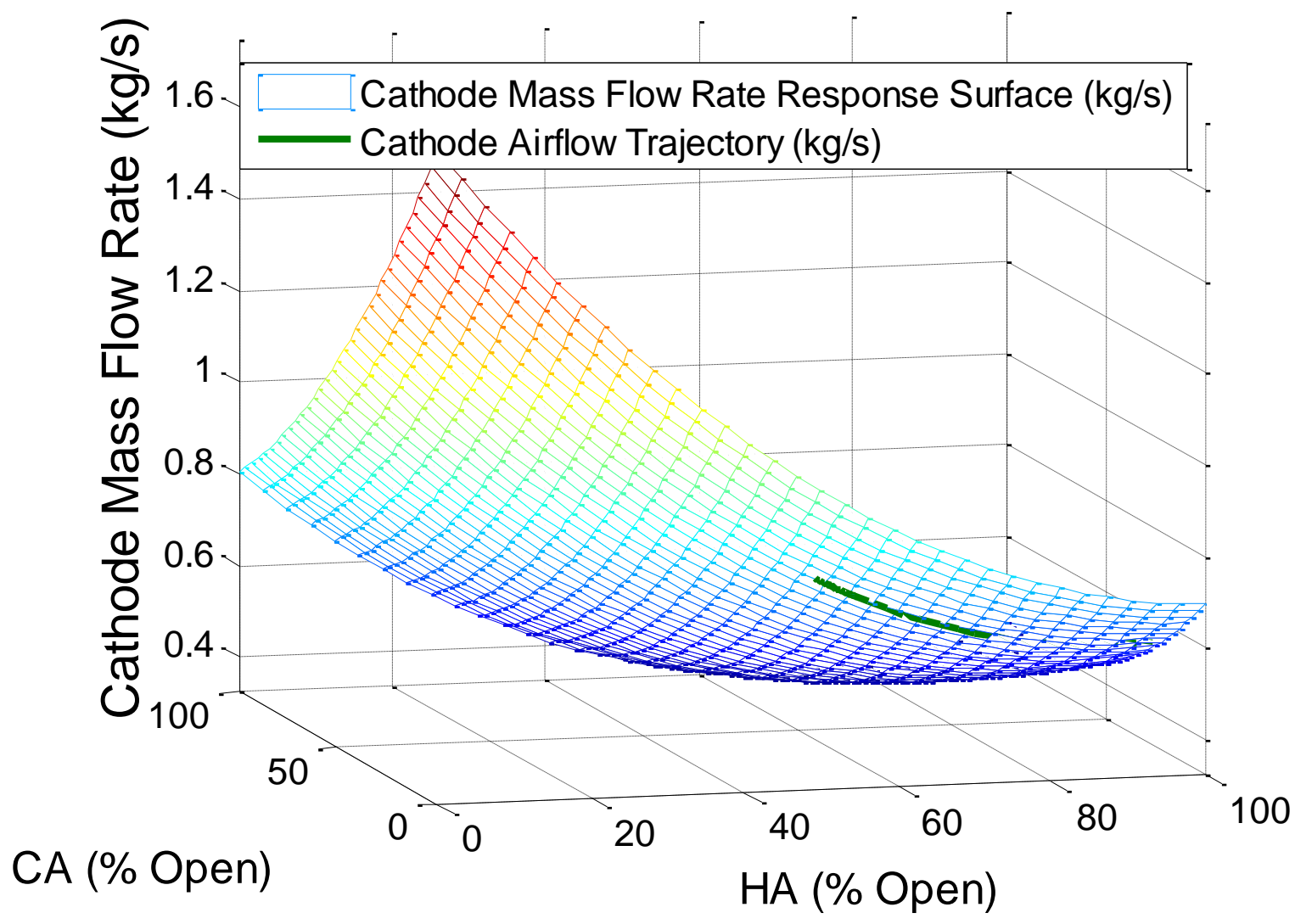

Figure 43: Cathode Airflow Trajectory on the Response Surface of Cathode Airflow for a Total Load Increase from $100 \mathrm{~kW}$ to $125 \mathrm{~kW}$

In Figure 44 below the trajectory is more clearly seen along a contour of HA and CA valve positions. As stated earlier this contour is extrapolated and the values beyond $80 \%$ for both the HA and $C A$ valves are not entirely accurate because there is no experimental data for that region. For the contour plots in this section the $0.4 \mathrm{~kg} / \mathrm{s}$ cathode mass flow rate has been omitted due to the fact that it is known to be inaccurate. The contour below shows a trajectory that travels from a fully open $\mathrm{HA}$ to about $60 \%$ with CA also decreasing to its desired $20 \%$. The cathode airflow then overshoots and settles to the desired optimal split in load which results in the V-turn seen below. 


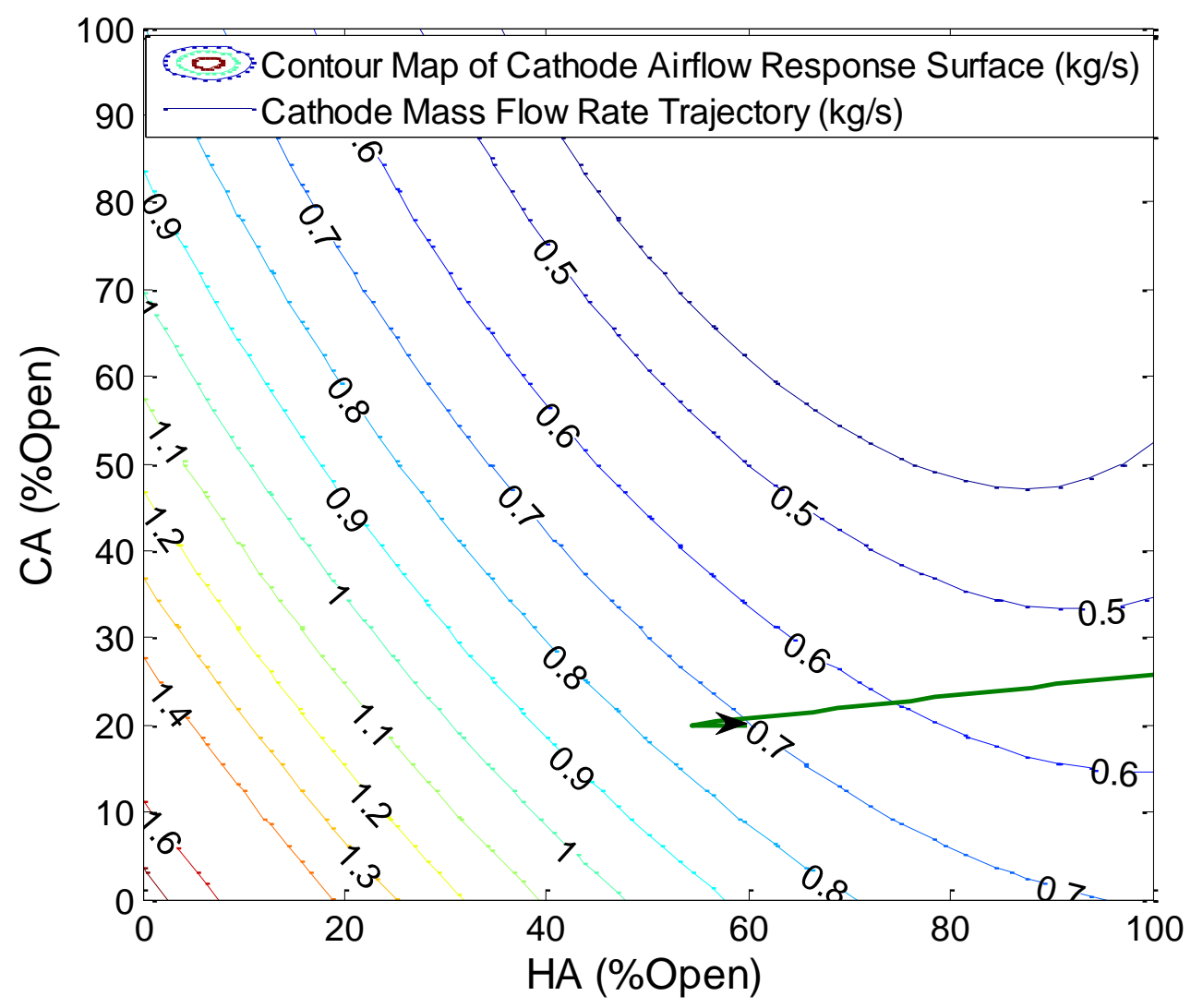

Figure 44: Cathode Airflow Trajectory along the Contour of Simplified Cathode Airflow Response Surface for a Total Load Increase from $100 \mathrm{~kW}$ to $125 \mathrm{~kW}$ 


\subsubsection{Cathode Airflow Trajectory for Total System Load Increase from $125 \mathrm{~kW}$ to $200 \mathrm{~kW}$}

An intermediate load increase case is now displayed to show a case fully in the interpolated region where all data is known. In Figure 45 the load splits act just as before in the small load increase case except that in this case the gas turbine load is reduced to zero in the intermediate step. When the gas turbine is fully unloaded the SOFC produces the total load.

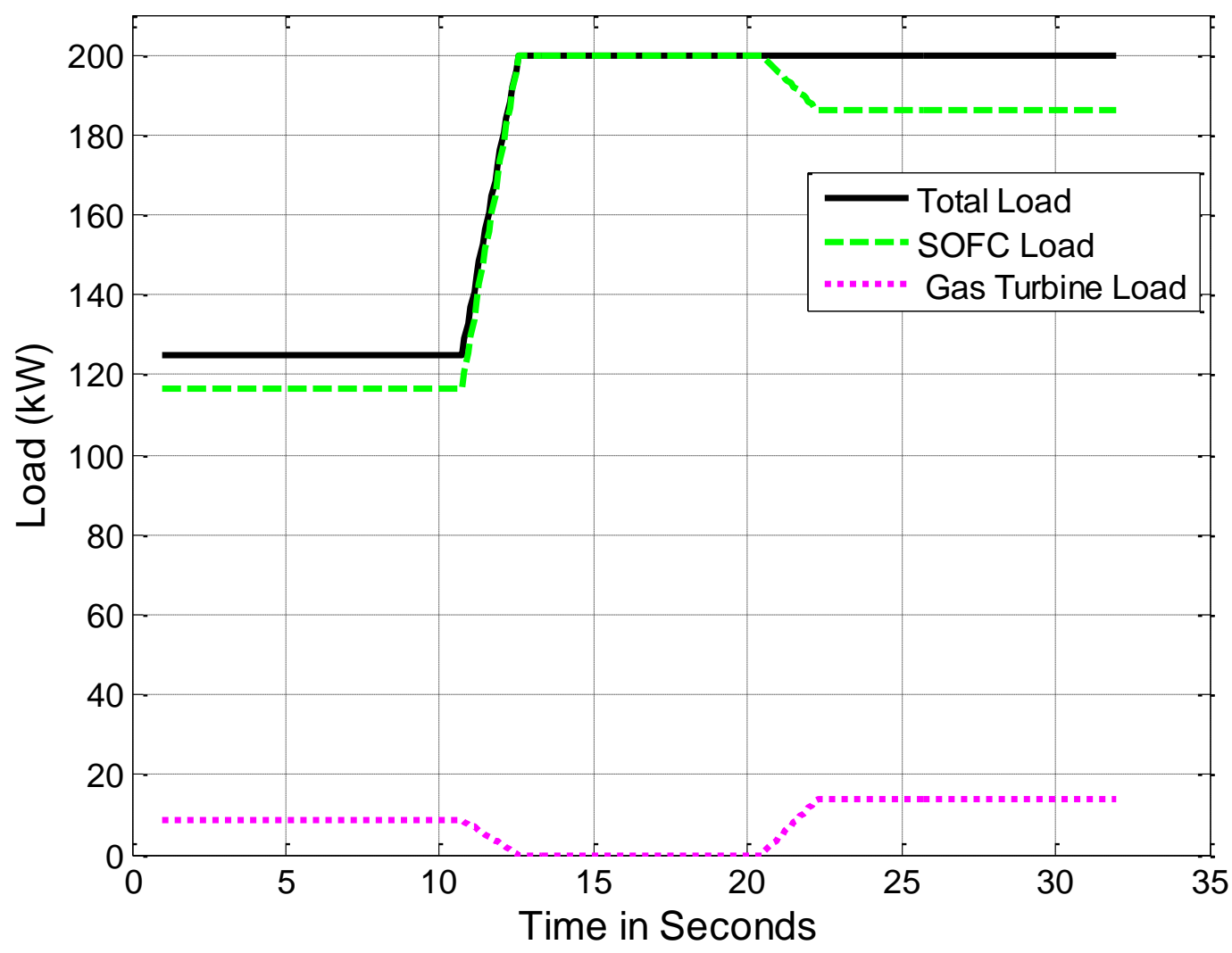

Figure 45: Load Distribution for Load Increase from 125kw to 200kW 
The valve positions and flow rates seen below in Figure 46 act as expected following the previously seen trends. The HA valve position acts much like before but in this region needs only to lower from $60 \%$ to $40 \%$ and the CA maintains its target at $20 \%$. The compressor flow once again decreases but not enough to warrant a need for BA.

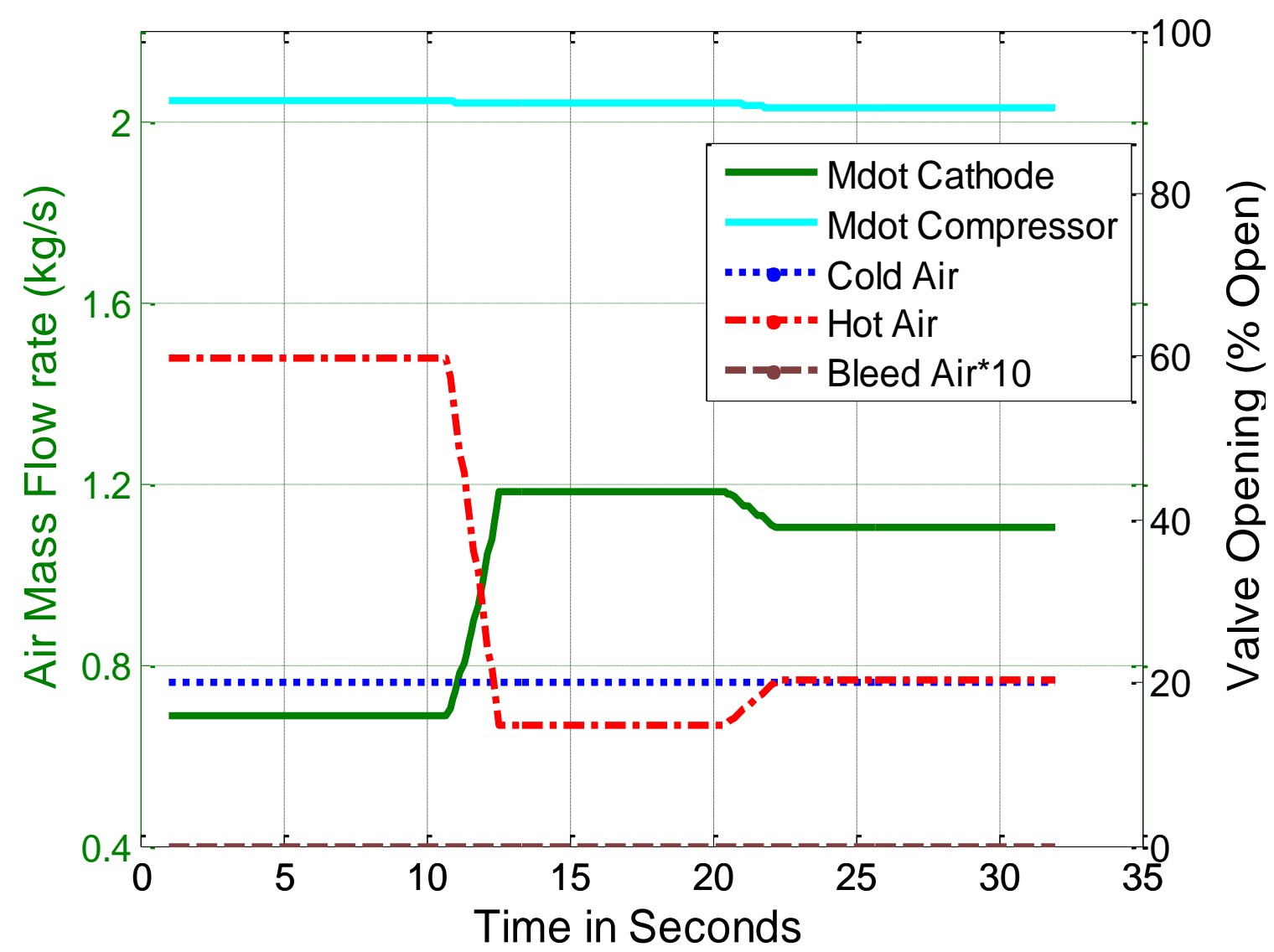

Figure 46: Cathode Mass Flow Rate and Valve Position Variation for a Total Load Increase from $125 \mathrm{kw}$ to $200 \mathrm{~kW}$ 


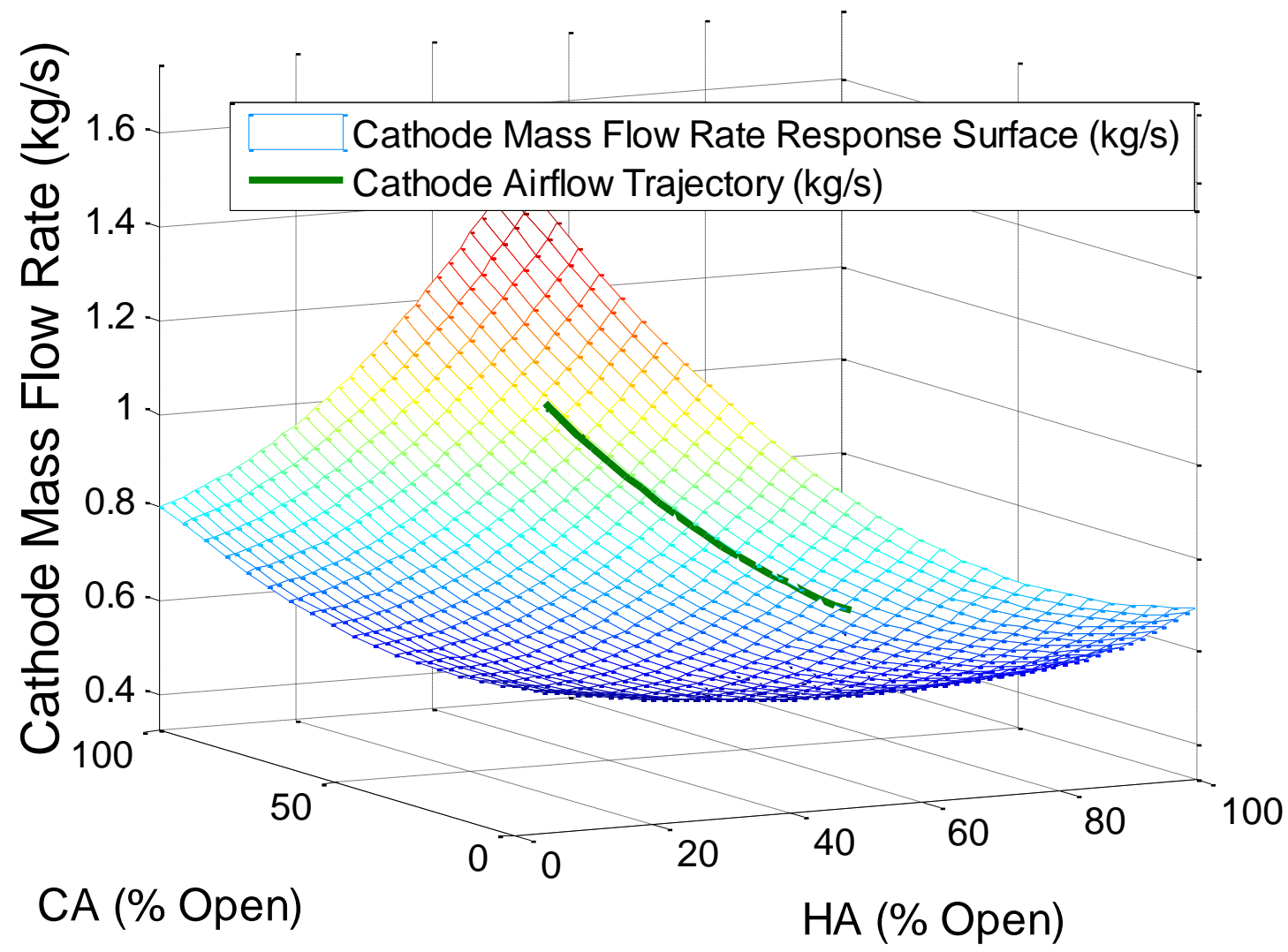

Figure 47: Cathode Airflow Trajectory on the Response Surface of Cathode Airflow for a Total Load Increase from $125 \mathrm{kw}$ to $200 \mathrm{~kW}$

Figure 47 and Figure 48 clearly show that the cathode mass flow rate increases smoothly along the surface maintaining a CA position of $20 \%$ and traveling from HA $60 \%$ to approximately $20 \%$. The cathode airflow increases from $0.7 \mathrm{~kg} / \mathrm{s}$ to an overshoot of around $1.2 \mathrm{~kg} / \mathrm{s}$ and then back down to the optimal power division resulting in a cathode mass flow rate of about $1.1 \mathrm{k} \mathrm{kg} / \mathrm{s}$. This overshoot is not as clearly seen in Figure 48 due to the fact that it overlaps onto itself as it returns to the desired value. 


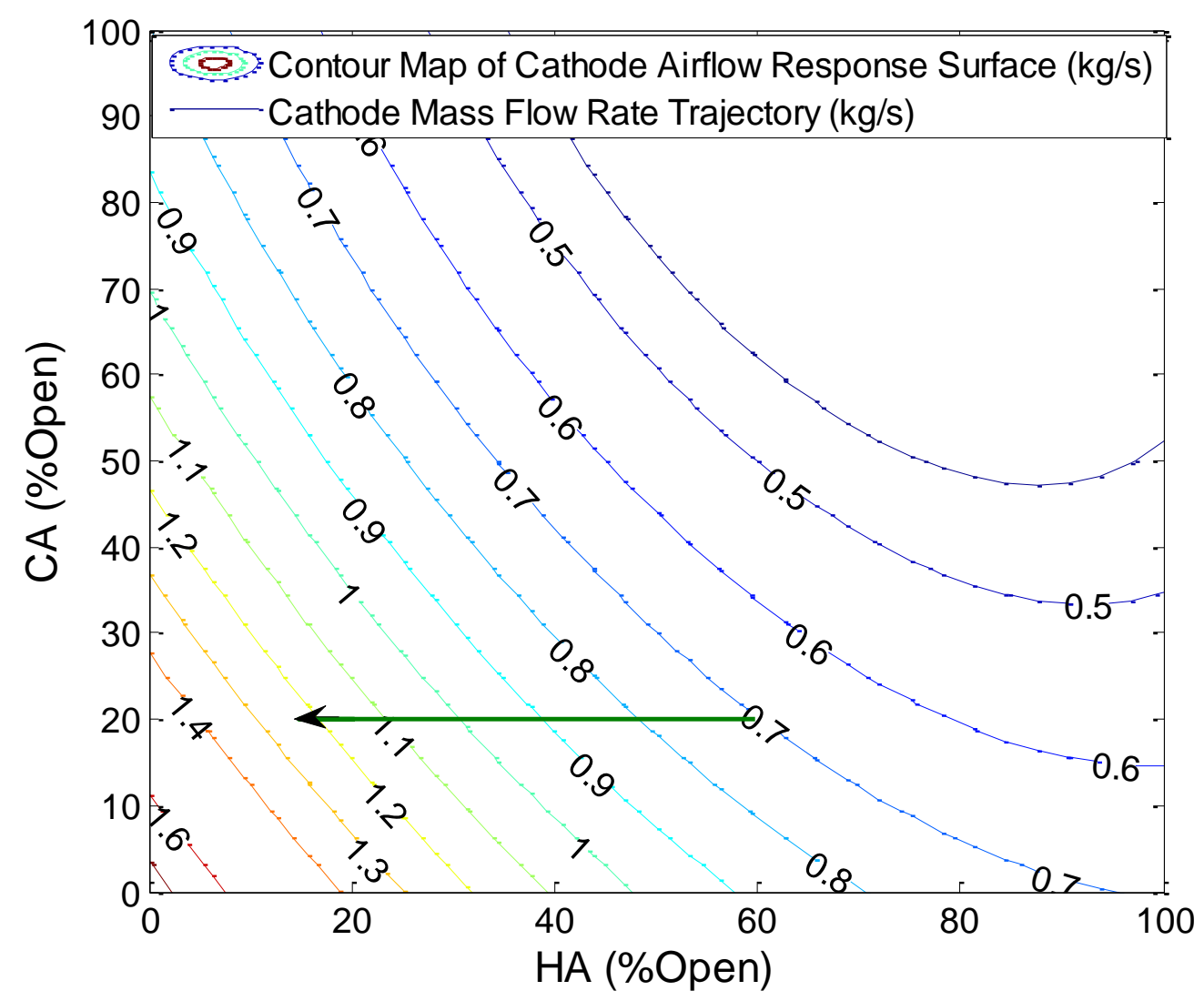

Figure 48: Cathode Airflow Trajectory along the Contour of Simplified Cathode Airflow Response Surface for a Total Load Increase from $125 \mathrm{kw}$ to $200 \mathrm{~kW}$ 


\subsubsection{Cathode Airflow Trajectory for Total System Load Increase from 100kW to $240 \mathrm{~kW}$}

The load increase of $100 \mathrm{~kW}$ to $240 \mathrm{~kW}$ represents a large load increase in this control scheme; it is limited due to system limitation in cathode mass flow rate. The load split seen in Figure 49 is very similar to the $75 \mathrm{~kW}$ load increase case. The gas turbine drops its entire load during the intermediate case and SOFC carries the full load.

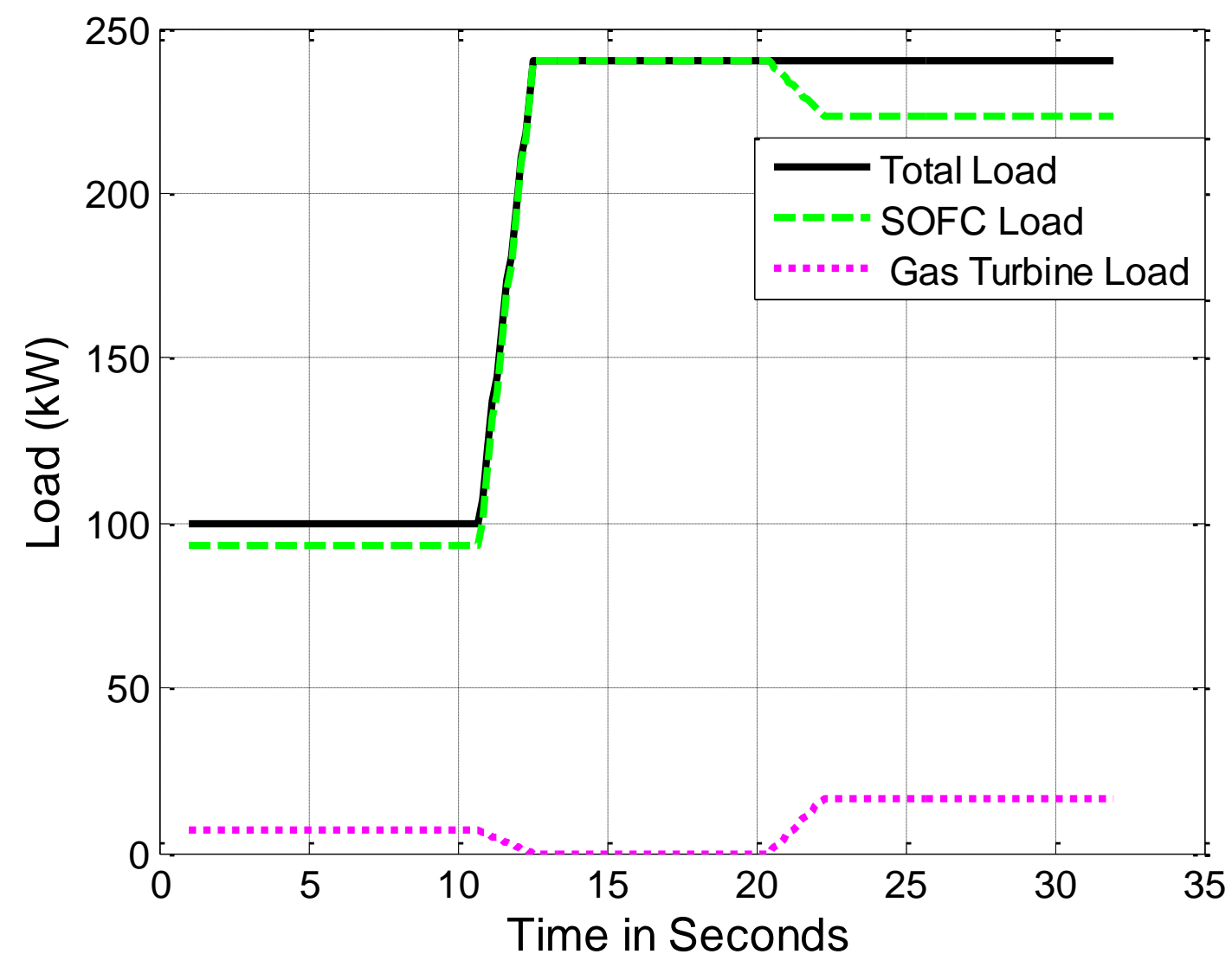

Figure 49: Load Distribution for Load Increase of $100 \mathrm{~kW}$ to $240 \mathrm{~kW}$ 
The valve positions and mass flow rates of the system parameters are illustrated below in Figure 50. HA valve again behaves in the same manner but with the large load increase is forced to decrease from fully open to almost completely closed. The CA valve must be more open at the initial load but then as the load drops it reduces to its target $20 \%$ much like before with the small load increase. The compressor flow once again decreases but this time but the final step the BA bypass is necessary. It opens slightly following the HA valve. This is as expected from Equation 13.

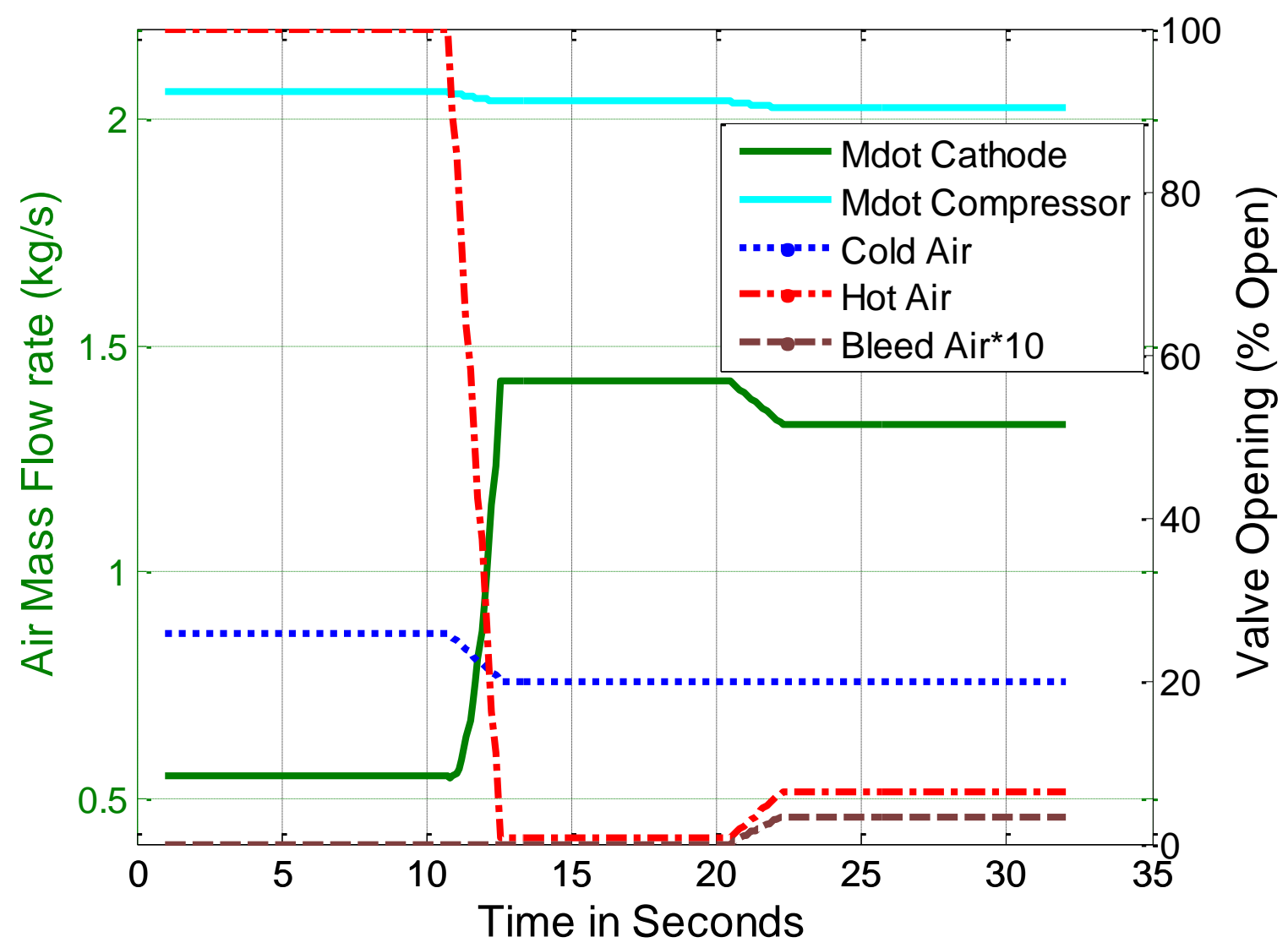

Figure 50: Cathode Mass Flow Rate and Valve Position Variation for a Total Load Increase from $100 \mathrm{~kW}$ to $240 \mathrm{~kW}$ 


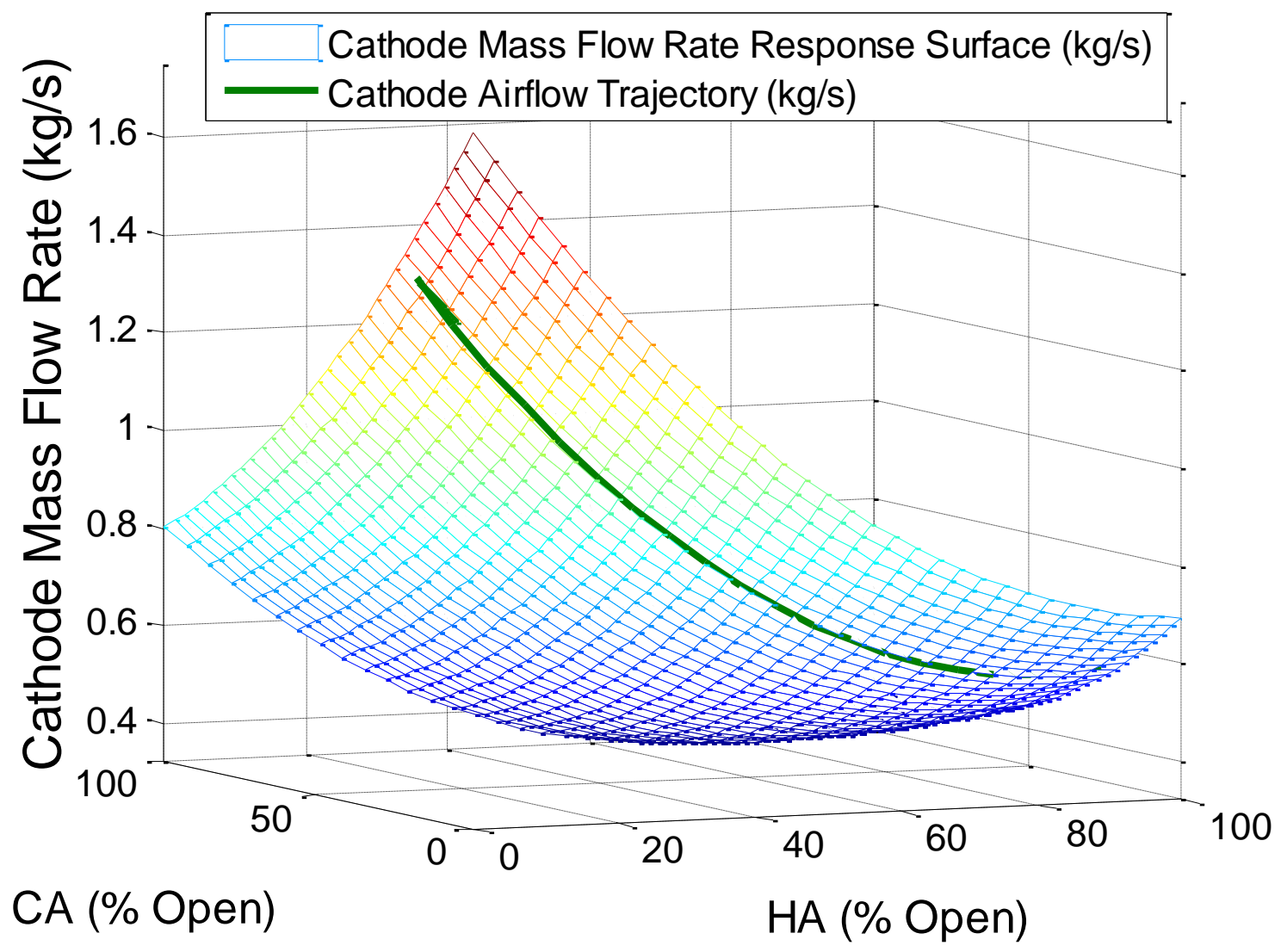

Figure 51: Cathode Airflow Trajectory on the Response Surface of Cathode Airflow for a Total Load Increase from $100 \mathrm{~kW}$ to $240 \mathrm{~kW}$

The cathode mass flow rate offers a large increase with the $140 \mathrm{~kW}$ increase in load. The trajectory essentially spans the cathode airflow limits of the system as seen in response surface in Figure 51. The contour in Figure 52 shows the cathode mass flow rate traveling diagonal along the full range of HA spectrum with CA varying only slightly above the $20 \%$ efficiency target. As with the other cases the trajectory overshoots and then decreases to achieve the desire load division between the GT and SOFC. 


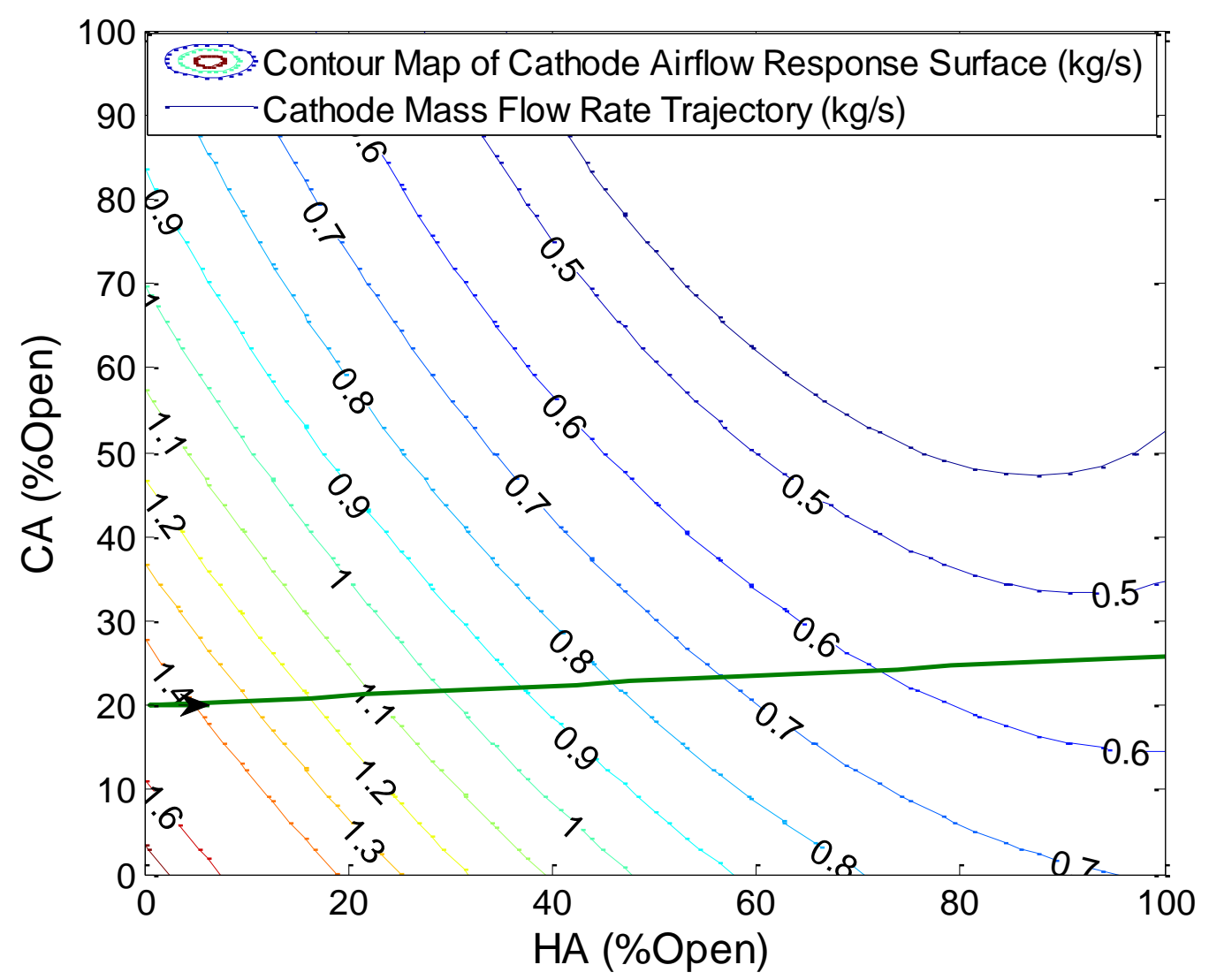

Figure 52: Cathode Airflow Trajectory along the Contour of Simplified Cathode Airflow Response Surface for a Total Load Increase from $100 \mathrm{~kW}$ to $240 \mathrm{~kW}$ 


\subsubsection{Optimal Cathode Mass Flow Rate during a Load Decrease}

It is also important to effectively control the cathode airflow during a decrease in total system load. This is necessary for periods of low electric demand. The load distributions between the gas turbine and SOFC as well as the valve positions and cathode mass flow rate variations for a given reduction in load are given in the following figures. The cathode airflow trajectories are also graphically shown with respect to the cathode airflow response surface and the contour map. This clearly depicts a strategy that decreases system load by traveling between optimal points, as much in the CA $20 \%$ region as possible, and using the path of steepest ascent/descent to travel between points while staying along the calculated response surface.

\subsubsection{Cathode Airflow Trajectory for Total System Load Decrease from 200kW to $140 \mathrm{~kW}$}

This test case represents a load drop of $60 \mathrm{~kW}$ in the middle range of load operation. This load drop should compare well to the second case in the load increase section. As seen in Figure 53 during a load decrease the fuel cell undershoots its load drop while the gas turbine overshoots and then drops to a final load smaller than the initial load. In the end the GT and SOFC achieve optimal load distributions.

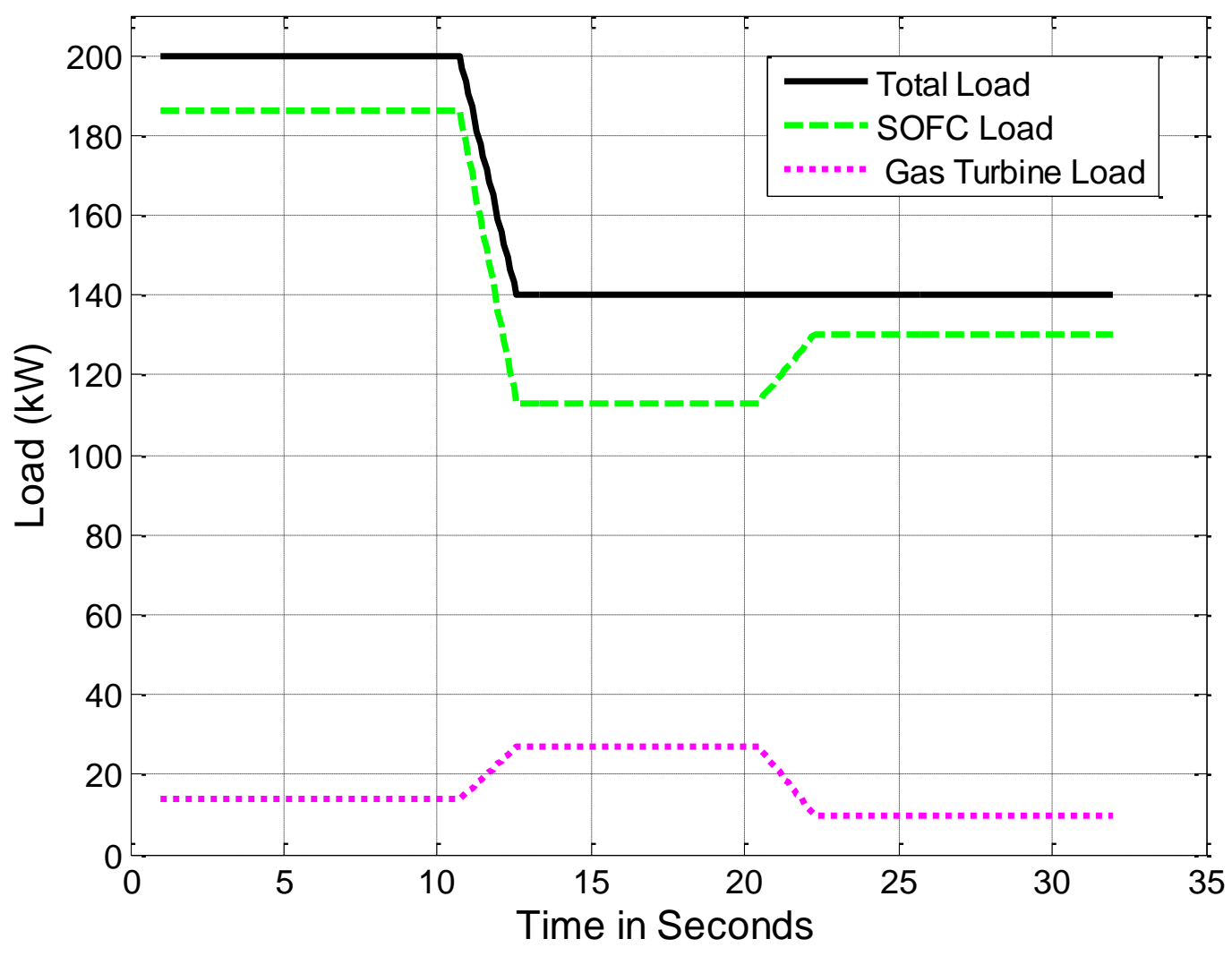

Figure 53: Load Distribution for Load Drop from 200kW to 140kW 
As expected with a load drop the HA valve is now increased and overshoots before settling to the higher valve position. The HA valve still shows an inverse relationship to the cathode mass flow rate. As seen before with the medium load increase in the interpolated range the CA valve is maintained at the efficient $20 \%$ value. This is as expected because the only difference is the direction of the load change. There is a difference seen in the behavior of the compressor flow however. In Figure 54 it is seen that the compressor flow decreases at the intermediate step but then increases to the final load distribution. This is interesting but can be easily explained. It is due to the complex interaction of the valve positions on the compressor flow exhibited in Equation 13. The compressor flow is increased with an increase in HA but decreased with an increase in GT load. The gas turbine load has much more of an effect than HA as seen by the coefficient in Equation 13. This specific case exhibits an intermediate position where the load on the turbine is relatively high at approximately $30 \mathrm{~kW}$ and the HA valve is at a value of $60 \%$. The gas turbine load is just high enough to reduce the flow through the compressor to below its minimum and causes the BA to become necessary to achieve the required flow and prevent stall. When the gas turbine load decreases to the final value the compressor flow increases to an acceptable value and BA is no longer necessary.

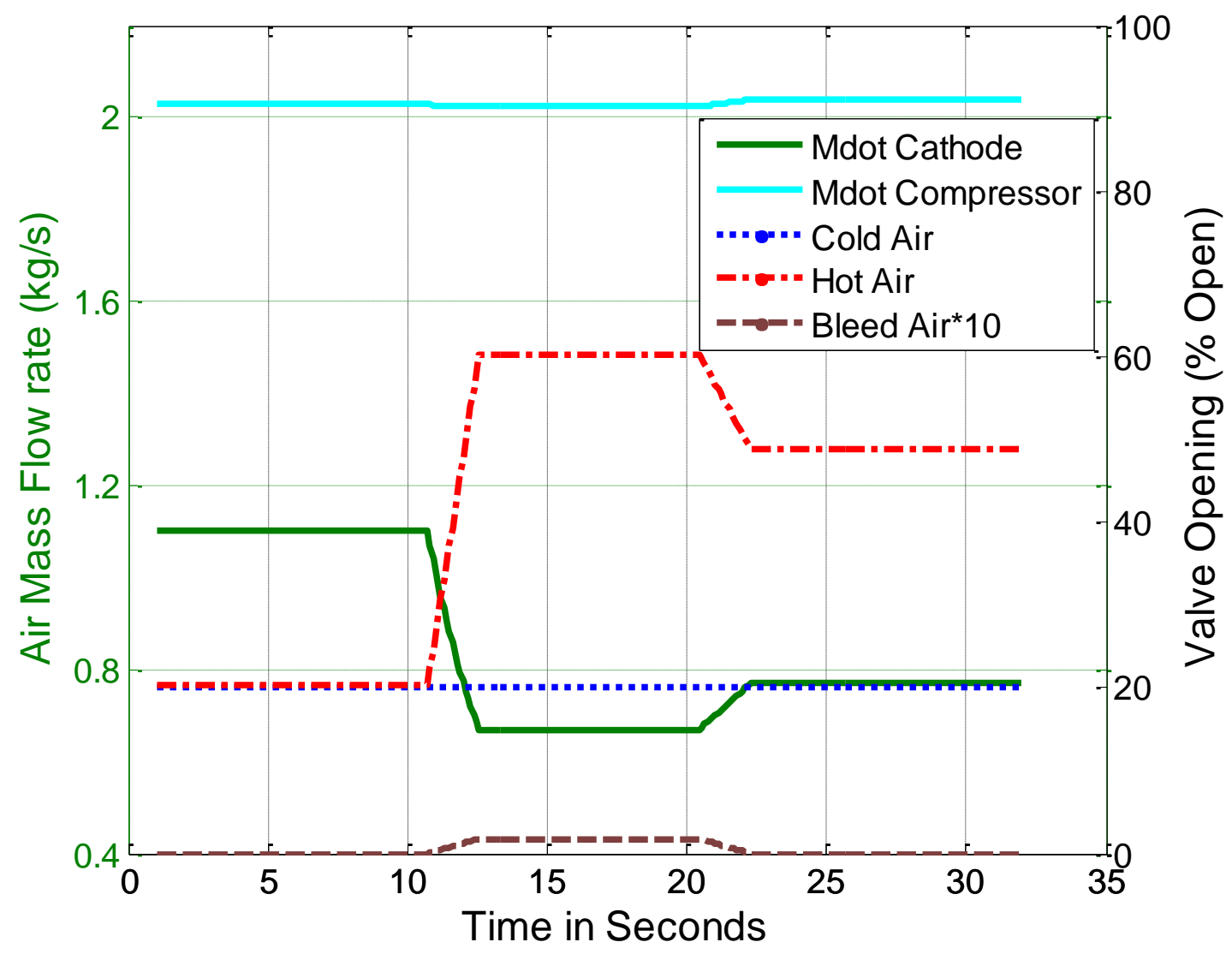

Figure 54: Cathode Mass Flow Rate and Valve Position Variation for a Total Load Drop from $200 \mathrm{~kW}$ to $140 \mathrm{~kW}$ 


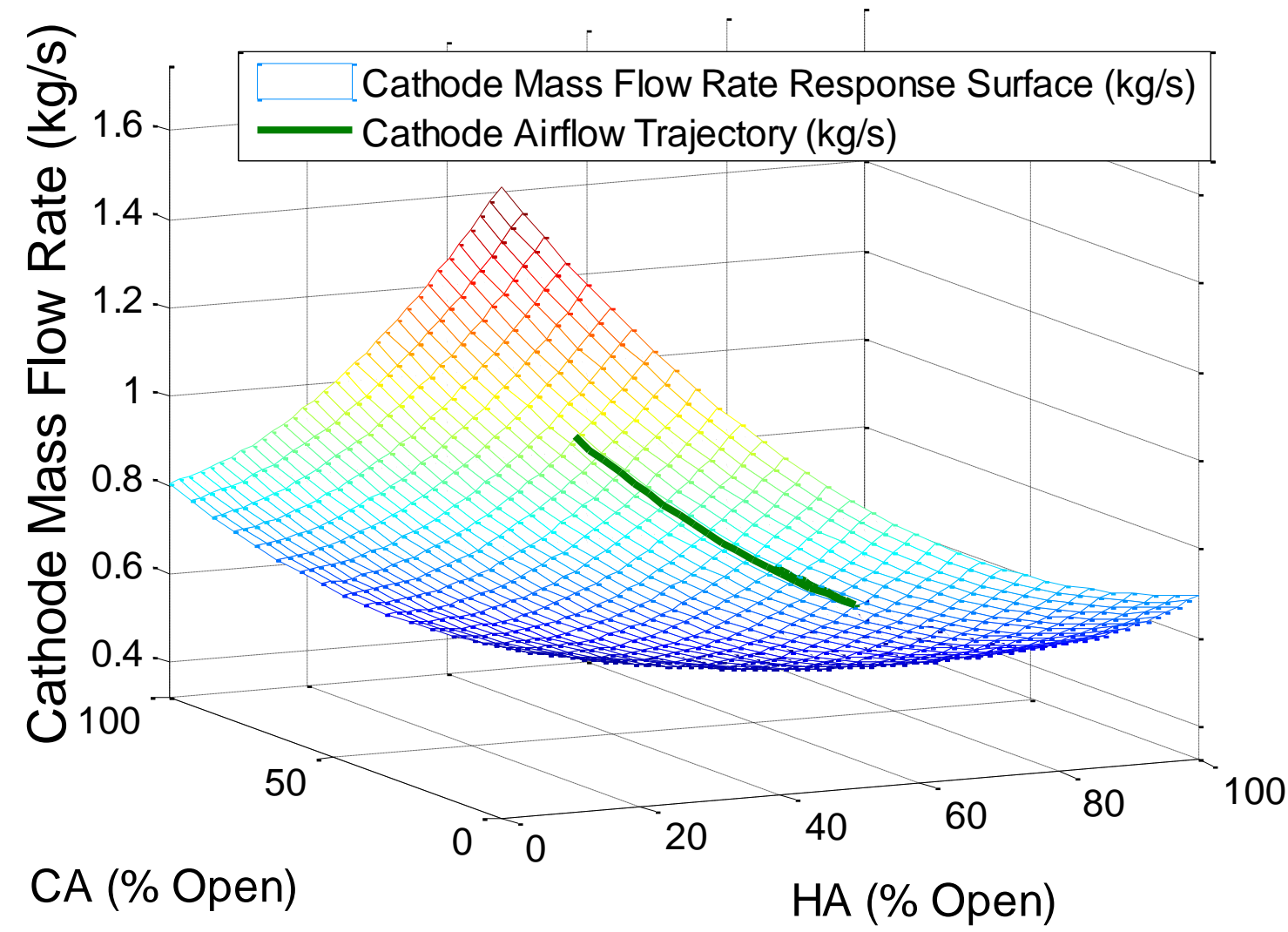

Figure 55: Cathode Airflow Trajectory on the Response Surface of Cathode Airflow for a Total Load Drop from $200 \mathrm{~kW}$ to $140 \mathrm{~kW}$

As previously stated a smooth transition with a CA bypass valve maintained at $20 \%$ opened is achieved similar to the medium load case in the load increase. Figure 55 and Figure 56 are very similar to Figure 47 Figure 48 expect that now the cathode mass flow rate is being decreased instead of increased. Once again it is important to note that the cathode airflow trajectory is undershot but cannot be easily seen due to the overlap of the trajectory. 


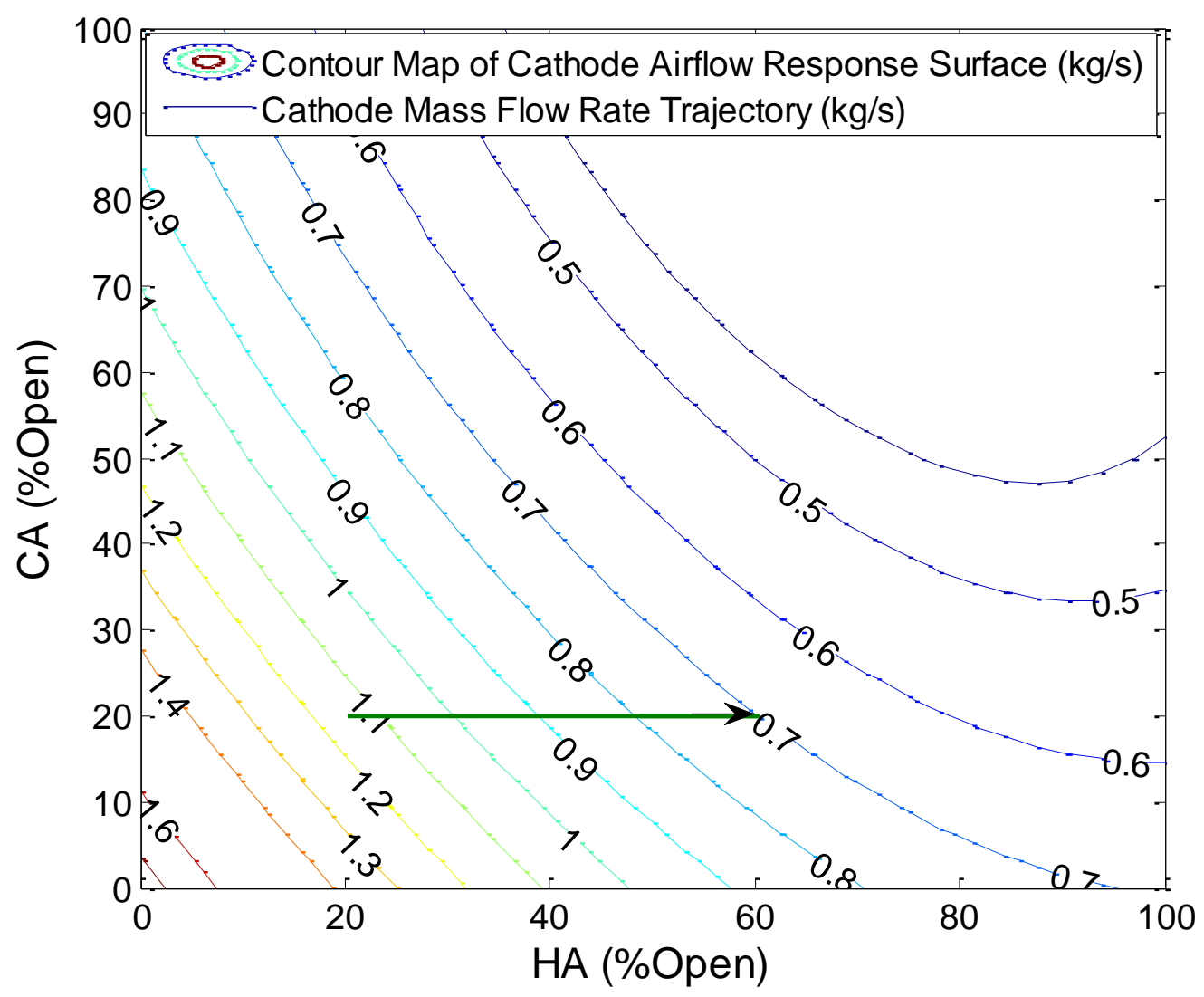

Figure 56: Cathode Airflow Trajectory along the Contour of Simplified Cathode Airflow Response Surface for a Total Load Drop from $200 \mathrm{~kW}$ to $140 \mathrm{~kW}$ 


\subsubsection{Cathode Airflow Trajectory for Total System Load Decrease from 260kW to $120 \mathrm{~kW}$}

The final test case is a large load drop of $140 \mathrm{~kW}$ from $260 \mathrm{~kW}$ to $120 \mathrm{~kW}$. Many of the same relationships are seen as with the medium load drop. This case also shows great similarities to the previous load drop and inverse of the relationships seen in the large load increase shown previously. In Figure 57 the SOFC power output undershoots and then stabilizes while the GT shoots up to a higher load and then reduces its power output to less than the original.

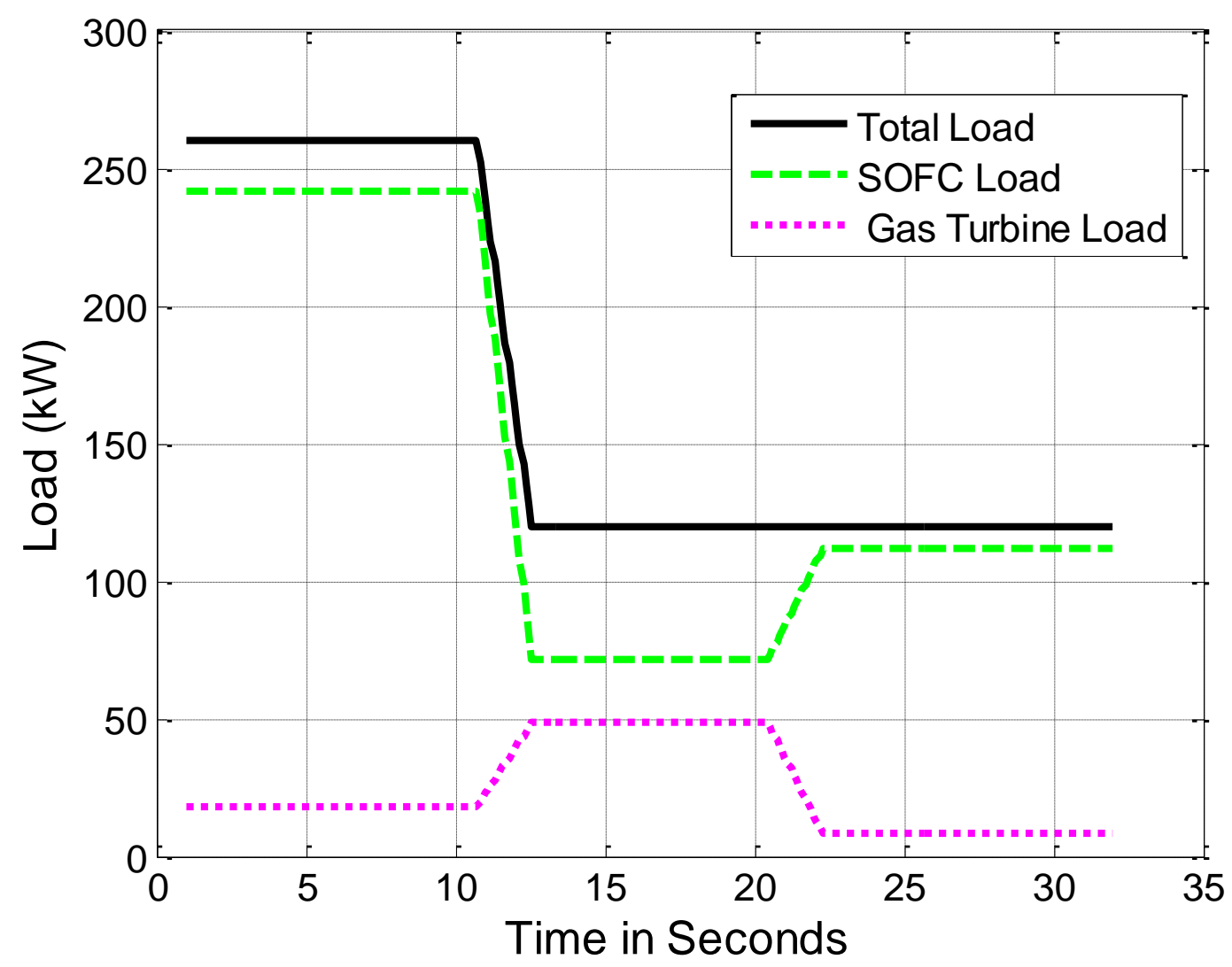

Figure 57: Load Distribution for Load Drop from 260kW to 120kW 
The valve positions act similar to those in the previous load drop however the HA bypass valve runs the full spectrum starting practically closed, opening to $100 \%$ and then settling down to the optimal load division at around $65 \%$ open. The CA bypass valve also acts in an until now unseen manner starting at the desired $20 \%$ open and opening to around $40 \%$ to reach the intermediate cathode mass flow rate and then settling back down to $20 \%$ again. The inverse behavior was not seen in the large load increase because in that case the cathode airflow was increased which would typically call for closing of the CA valve but in order to maintain stability this valve is constrained to never operate below $20 \%$ open. The compressor flow also behaves in an interesting manner; it steadily increases through the large load drop. Right from the initial load the BA bypass is needed. This can be attributed to a practically closed HA bypass valve and low CA valve position which causes a low compressor flow through Equation 13. The same basic situation with respect to valve position and mass flow rate was seen in the final load distribution of the large load increase in Figure 50.

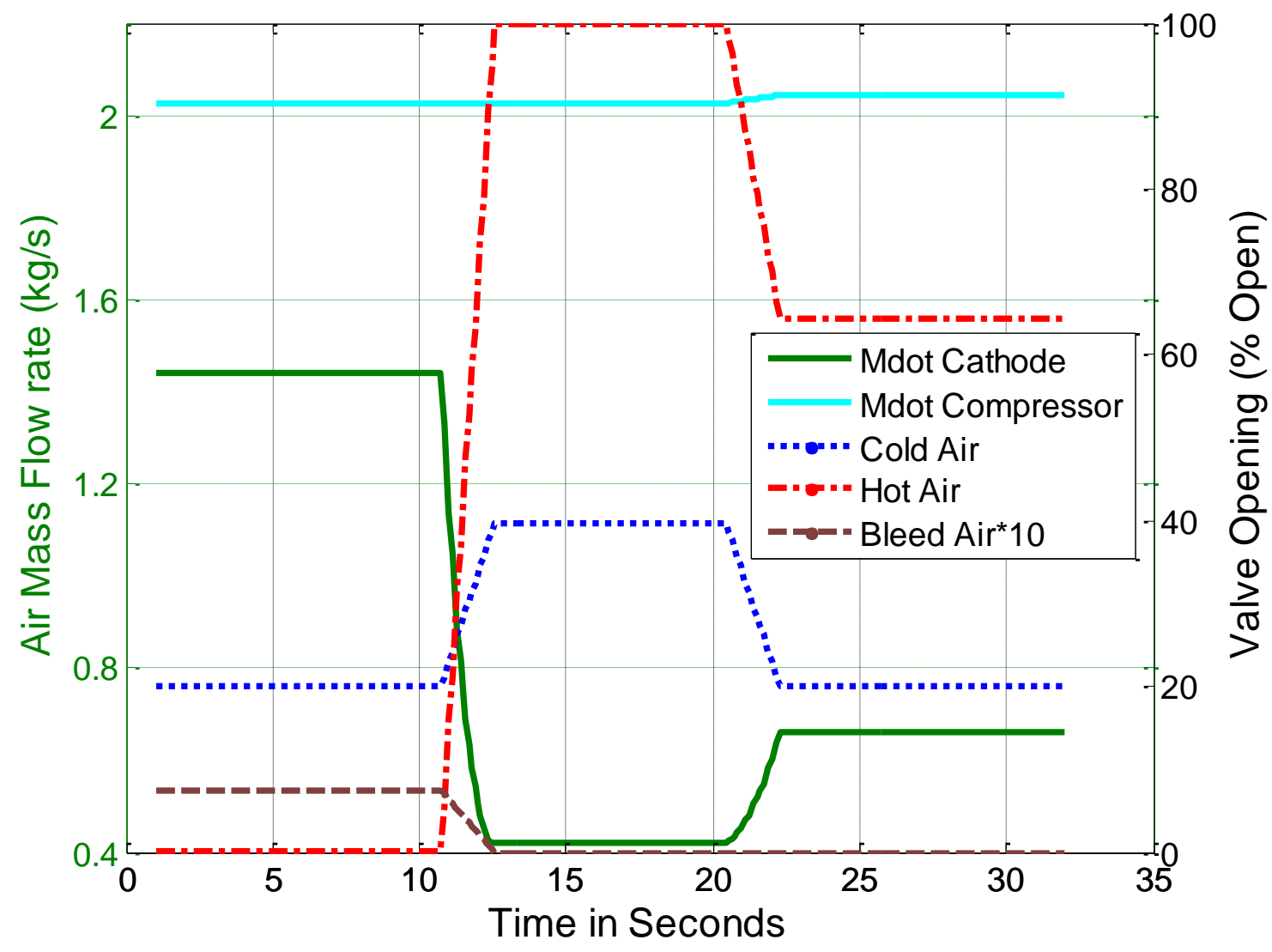

Figure 58: Cathode Mass Flow Rate and Valve Position Variation for a Total Load Drop from $260 \mathrm{~kW}$ to $120 \mathrm{~kW}$ 


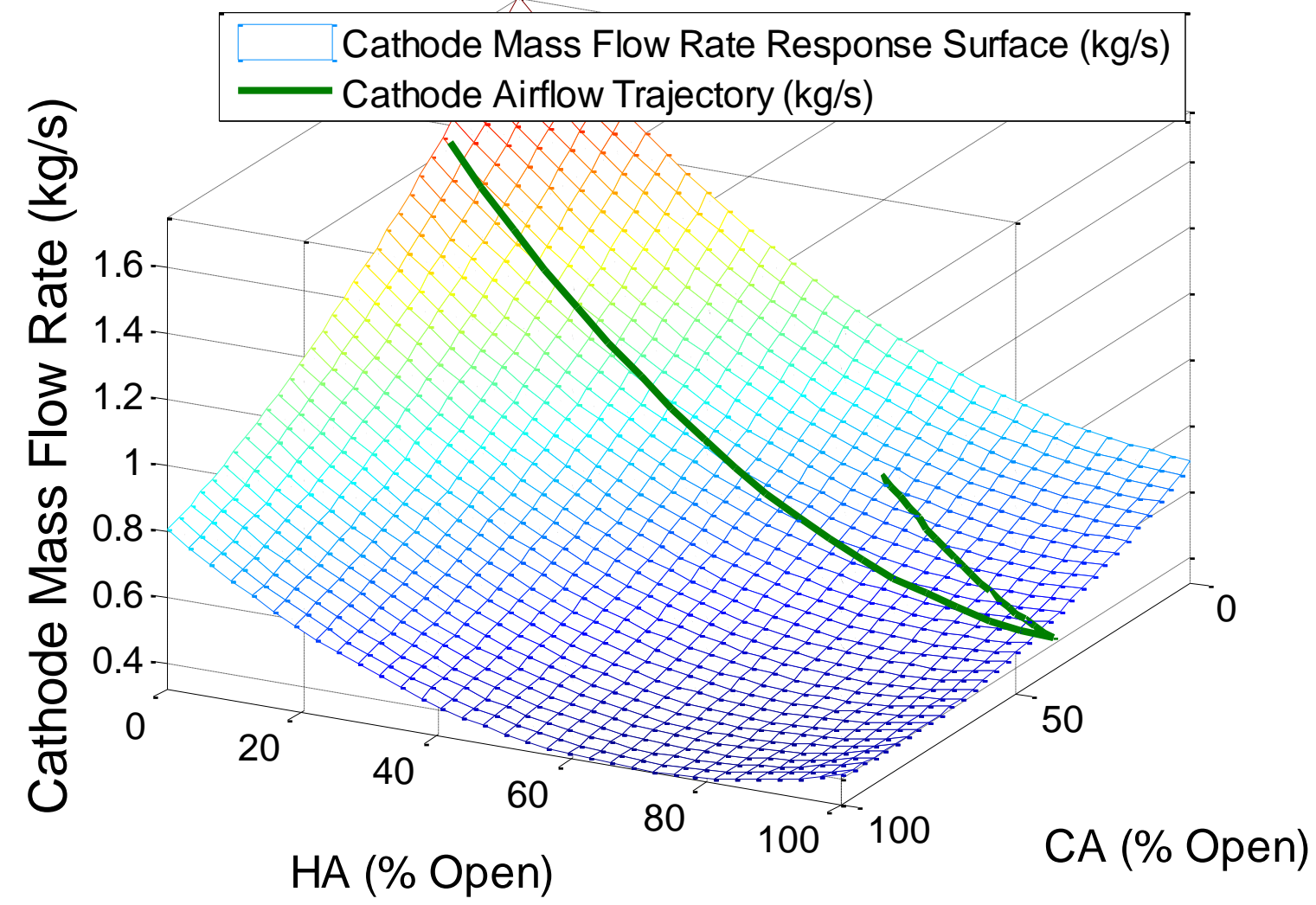

Figure 59: Cathode Airflow Trajectory on the Response Surface of Cathode Airflow for a Total Load Drop from $260 \mathrm{~kW}$ to $120 \mathrm{~kW}$

The cathode mass flow rate trajectory travels from an upper limit of $1.5 \mathrm{~kg} / \mathrm{s}$, down to around 0.5 $\mathrm{kg} / \mathrm{s}$ and then settles at an $0.65 \mathrm{~kg} / \mathrm{s}$ mass flow rate. As seen with other cases the trajectory is undershot and then returns to the desired optimal load split. Figure 59 and Figure 60 show this behavior. In this case it appears there is a larger undershoot; however this is not the case it only appears that way due to the increased separation between cathode mass flow rate lines as they decrease. Also it is seen in Figure 60 that the trajectory travel up to CA $40 \%$ but in Figure 52 the CA valve travels down form around $25 \%$. The reason for this difference is seen because of undershooting the cathode mass flow rate in the load drop and overshooting it in the load increase. Aside from this observation the load decrease and load increase trajectories are essentially the inverse of each other. 


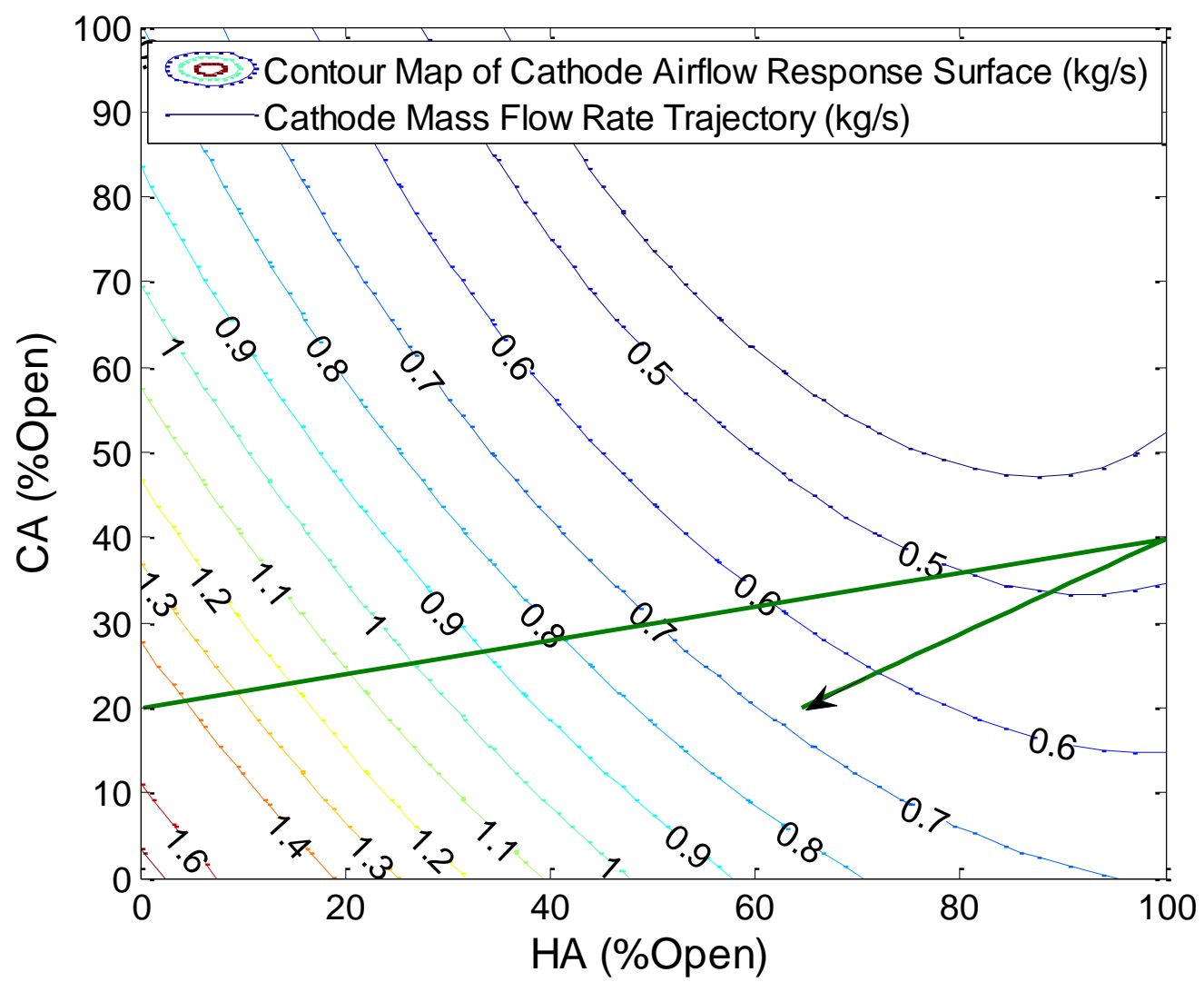

Figure 60: Cathode Airflow Trajectory along the Contour of Simplified Cathode Airflow Response Surface for a Total Load Drop from $260 \mathrm{~kW}$ to $120 \mathrm{~kW}$ 


\subsection{Summary of Results}

Many relationships occur in the various test cases presented. The HA and CA valves can be manipulated to achieve the necessary flow through the cathode. The CA valve is held constant at the optimal $20 \%$ initially and increased only when necessary. A change in load in the mid-range of operation for the HyPer exhibits a change in the HA valve alone. CA is able to be held constant at the optimal $20 \%$ valve position. When operating in lower power ranges the CA must be increased in order to achieve the necessary lower flows through the cathode.

There are some distinct differences seen in load increases and decreases. For instance when comparing large load changes it can be seen that the valve positions are not mirror images of each other for the two cases. In a large load drop the SOFC must undershoot its steady-state power production to allow the turbine to burn the unreacted fuel exiting the anode. Thus the cathode airflow must also undershoot which causes a larger increase in the CA valve position. The opposite is seen when it comes to the largest increase. The cathode airflow follows the same trajectory until it comes to overshooting for load increases. Because this requires closing of the CA valve and that is limited due to stability the CA is utilized much less with a total load increase.

The BA valve exhibits the most peculiar behavior of all the valves. It is opened only when there is a risk of stall due to low flow through the compressor. When considering the increases in load when the $B A$ is needed it tends to follow the HA valve but in the decreases in load the BA tends to oppose the HA valve. This is due to the complex interaction of the valve positions, turbine load, and ambient conditions and their effect on the flow through the compressor. The load on the gas turbine has much more of an effect on the flow through the compressor than the HA valve does as seen in Equation 13. So really what is seen in these cases is that the bleed air has an inverse relationship to the electric load on the GT. For a load increase the bleed air must be opened at the end of the transition when the load is the highest and in a load decrease the BA is opened in the beginning when the load is highest. During higher loads depending on the other interactions the BA is needed to increase the flow through the compressor and the HA just doesn't have as much of an effect as the gas turbine load. However as was previously identified the other valve positions play a part in the compressor flow and can cause a need for bleed air. In a medium load drop the BA is necessary in the intermediate step which is not seen in any other interaction. This can once again be attributed to the complex interactions of the flow through the compressor.

These examples show a wide range of the operational points for the HyPer system. They display the complex relationships that affect different aspects of the control scheme and show its corresponding reactions to various load changes. The examples requiring BA prove that the control scheme successfully recognizes a danger to stall and alters the bleed air to alleviate the risk of compressor stall. The control scheme therefore achieved its desired results. 


\section{Conclusions}

The ever decreasing supply of nonrenewable resources requires the need for innovative efficient energy production systems such as the HyPer system. Accurate control of the airflow through the cathode side of the fuel cell is of major importance in order to maintain efficient operation while protecting the fuel cell stack against temperature gradients that could cause damage. Such gradients are most likely to occur during system startup/shutdown or during large load changes. Up to this point, most of the control of the HyPer system has been done manually. This is due to the fact that the system does not yet house a "real" SOFC and is able to handle rapid changes in pressure and temperature. However, this will not always be the case it is anticipated that testing will occur with a small SOFC stack and controls are necessary to protect the future fragile stack. The controls proposed offer straightforward and optimal methods to manage the cathode airflow which is one of the most important process variables in the operation of the hybrid system.

This control requires examination of the system's characteristics. The cathode airflow was of particular concern but the effect of all control variables on the system as a whole must also be examined. The experimental data evaluated represented 81 steady state operating points. This was previously unmapped territory within the HyPer's operational envelope, and required the simultaneous manipulation of four control variables as opposed to previous "one factor at a time" experimental method. The relationships examined between control inputs and important system variables for the HyPer are universally nonlinear. But as seen from the data presented in this work, over the control variable ranges tested the relationship was found to be low order and smooth. The response surfaces shown in this work were simplifications of the least square regression correlations, due to the fact that graphical representation of all four variables in a two-dimensional figure is not possible. But by eliminating the most insignificant variables, reasonably accurate surfaces could be created. Specifically for the cathode airflow, there is a plethora of steady state operating points for each airflow value. In order to navigate through these airflow rates during load changes appropriate load division needed to be determined.

A thermodynamics analysis of the system was performed in order to find a suitable load division between the solid oxide fuel cell and the gas turbine. This load division made it possible to determine the necessary air mass flow rate through the cathode in order to achieve various load increases and decreases. However as previously stated it was still necessary to determine the optimal trajectory of the valve positions required to achieve the desired cathode air mass flow rate.

While the steepest ascent/descent criterion provides a simple and apparently effective strategy for valve manipulation, it cannot be considered optimal in any sense other than minimizing valve movement. New criteria for an "optimal" trajectory were developed considering tradeoffs between maximizing compressor surge margin by opening of the CA and BA valves, and maximizing overall system efficiency by closing the BA valve. Complex interactions between the CA, HA, BA valves and the cathode air inlet temperature and pressure all were taken into account for this trajectory. Previously 
collected data was also integrated into the optimal control scheme, due to a lack of data around the operational borders. A model was created that took into account the previous factors and determined optimal cathode airflow trajectories given an increase or decrease in the total electric load of the system.

Some unexpected behavior was found with the flow rate through the compressor and the need for $B A$ at certain operational locations. Further research is needed to explain this complex interaction. Future experimentation is also needed to validate several assumptions in the "optimal" trajectory especially for the borders of operation. Determining the exact location of compressor surge and stall considering several situations would be helpful. It will also be necessary in the end to link inputs from the anode circuit and various disturbance inputs into a comprehensive and integrated controller. Before this can occur the optimal algorithm offered here will be implemented on the HyPer system and tested under a variety of operating conditions using real-time fuel cell models and the physical machinery available at NETL.

The HyPer system shows much promise for the future. However funding concerns have limited its ability to evolve into implementation. Over my experience working with the system the progress has been halted from a lack of government interest and funding. I believe the government's perspective is that fuel cells will always be a valid option but let's ignore them for now and see what else is out there. This doesn't make much sense to me. The HyPer system is somewhat ahead of its time in the sense that there is currently not a stable SOFC which could be fully integrated into the system at the desired scale. However the "If you build it they will come" mentality is encouraging. Even though advancement of SOFC technology is needed the system can still be developed. There is no need to wait around when two problems can be solved at the same time. This type of innovation and progress is needed in this ever changing world and should not be suppressed but rewarded. 


\section{Works Cited}

1. SOFC/GT Hybrid. Siemens. [Online] http://www.energy.siemens.com/fi/en/power-generation/fuelcells/sofc-gt-hybrid.htm.

2. Determination of the Operating Envelope for a Direct Fired Fuel Cell Turbine Hybrid Using Hardware Based Simulation. Tucker, David, Liese, Eric and Gemmen, Randall. Newport Beach : National Energy Technology Laboratory, 2009. International Colloquium on Enviromentally Preferred Advanced Power Generation. pp. 1-10.

3. Characterization of Air Flow Management and Control in a Fuel Cell Turbine Hybrid. Tucker, David, Lawson, Larry and Gemmen, Randall. Chicago : ASME Power Conference, 2005. PWR200550127. pp. 1-9.

4. U.S. DOE Fossil Energy Fuel Cells Program. Williams, M. C., Strakey, J. and Surdoval, W. 2006, Journal of Power Sources, pp. 159(2), pp. 1241-1247.

5. Fuel Cell-Coal Based Systems. s.I. : U.S. Department of Energy, 2005. U.S. DOE Funding Oppurtunity Announcement, DE-PS26_05NT42346.

6. The National Energy Technology Laboratory's Hybrid Power Systems Program. Dennis, R. A., et al., et al. Amsterdam, The Netherlands : s.n., GT-2002-30668. 2002 ASME Turbo Expo.

7. Gas Turbine Assessment for Air Management of Pressurized SOFC/GT Hybrid Systems. Traverso, A., et al., et al. Rome, Italy : EFC2005-86228, 2005. First European Fuel Cell Technology and Applications Conference.

8. Control Strategy for a Solid Oxide Fuel Cell and Gas Turbine Hybrid System. Stiller, C., et al., et al. 2006, Journal of Power Sources, pp. 158,pp.305-315.

9. Lawrence Livermore National Laboratory: Energy Flow. [Online] October 2011. [Cited: February 16, 2012.] https://flowcharts.IInl.gov.

10. Spiegel, Colleen. Designing and Building Fuel Cells. s.I. : McGraw-Hill, 2007.

11. Solide Oxide Fuel Cells. s.I. : Fuel Cell and Hydrogen Energy Association. Fact Sheet.

12. Alkaline Fuel Cells. FCTec. [Online] [Cited: 01 11, 2012.] http://www.fctec.com/fctec_types_afc.asp.

13. Gurie, Eileen J. De. "Solide Oxide Fuel Cells". [Online] 2003. [Cited: September 10, 2010.] http://www.csa.com/discoveryguides/fuecel/overview.php.

14. Solid Oxide Fuel Cell. ProQuest. [Online] [Cited: July 15, 2010.] http://www.csa.com/discoveryguides/fuecel/overview.php.

15. EG\&G Technical Services. Fuel Cell Handbook, 7th ed. Morgantown, WV : US Department of Energy, 2003.

16. Combined Solid Oxide Fuel Cell and Gas Turbine Systems for Efficient Power and Heat Generation. Palsson, Jen, Selimovic, Azra and Sjunnesson, Lars. 2000, Journal of Power Sources, pp. 442-448. 
17. Control Design of an Atmospheric Solid Oxide Fuel Cell/Gas Turbine Hybrid System: Variable versus Fixed Speed Gas Turbine Operation. Roberts, R., et al., et al. 2006, J. Power Sources, pp. 484491.

18. Integrated Modelling Study of FC/GT Hybrids. [Online] [Cited: 10 15, 2010.] http://ec.europa.eu/research/energy/pdf/efchp_fuelcell3.pdf.

19. Design and Part-load Performance of a Hybrid System based on a Solid Oxide Fuel Cell Reactor and a Micro Gas Turbine. Costamagna, P., Magistri, L. and Massardo, A.F. 2001, Journal of Power Sources, pp. 352-368.

20. Analysis and optimization of a solid oxide fuel cell and intercooled gas turbine (SOFC-ICGT) hybrid cycle. Yi, Yaofan, et al., et al. 2003, Journal of Power Sources, pp. 77-85.

21. An Analysis of SOFC/GT CHP System Based on Exergetic Performance Criteria. Akkaya, A.V., Sahin, B. and Erden, H.H. 2008, Int. J Hydrogen Energy, pp. 656-664.

22. Thermodynamic Modeling of a Gas Turbine Cycle Combined with a Solide Oxide Fuel Cell. Haseli, Y., Dincer, I. and Naterer, G.F. 2008, Int. J. Hydrogen Energy, pp. 5811-5822.

23. Design and Partial Load Exergy Analysis of Hybrid SOFC-GT Power Plant. Calise, F., Palombo, A. and Vanoli, L. 2006, J. Power Source, pp. 225-244.

24. Integration of $A$ Solid Oxide Fuel Cell into a $10 \mathrm{MW}$ Gas Turbine Power Plant. Cheddie, Denver F. 2010, Energies, pp. 754-769.

25. A Methodology for Thermo-economic Modeling and Optimization of Solid Oxide Fuel Cell Systems. Palazzi, F, et al., et al. 2007, Applied Thermal Engineering, pp. 2703-2712.

26. Thermoeconomic Modeling and Parametric Study of Hybrid SOFC-Gas Turbine-Steam Turbine Power Plants Ranging from 1.5 to 10MWe. Arsalis, AM. 2008, J. Power Source, pp. 313-326.

27. Modeling and control of a SOFC-GT-based autonomous power system. Kandepu, Rambabu, et al., et al. 2007, Energy, pp. 406-417.

28. The Control Strategy for a Solid Oxide Fuel Cell Hybrid System. Milewski, Jaroslaw, et al., et al. Christchurch, New Zealand: s.n., 2009. 2009 IEE International Conference on Control and Automation. pp. 1635-1640.

29. Evaluation of Hybrid Fuel Cell Turbine System Startup with Compressor Bleed. Tucker, D.,Lawson, L. O., Gemmen, R. S. 2005 ASME Turbo Expo. pp. GT2005-68784.

30. A Real-Time Spatial SOFC Model for Hardware-Based Simulation of Hybrid Systems. Hughes, D, et al., et al. Washington D.C. : ASME 2011 5th International Conference on Energy Sustainability \& Fuel Cell Science and Technology Conference, 2011. ESFuelCells 2011-54591.

31. Magee, Mark M. Load Split Management Strategy for Hybrid System during Demand Step Changes. Honor's Thesis. Morgantown, WV : West Virginia University, 2011.

32. The Role of Solid Oxide Fuel Cells in Advanced Hybrid Power Systems of the Future. Tucker, David, Shelton, Michael and Manivannan, A,. 2009, The Electrochemical Society Interface, pp. 45-48. 
33. Dry Air Properties. The Engineering Toolbox. [Online] [Cited: March 6, 2012.] http://www.engineeringtoolbox.com/dry-air-properties-d_973.html.

34. Cathode Temperature Management During Hybrid System Startup. Banta, L., et al., et al. New York, NY: s.n., 2010. 8th ASME International Fuel Cell Science, Engineering and Technology Conference. pp. 14-16.

35. FutureGen Integrated Hydrogen, Electric Power Production and Carbon Sequestration Research Initiative. s.I. : U.S. DOE, Office of Fossil Energy, March 2004.

36. Solide Oxide Fuel Cells. Bloom Energy. [Online] [Cited: July 10, 2010.] http://www.bloomenergy.com/products/solid-oxide-fuel-cell/].

37. The Role of Solid Oxide Fuel Cells in Advanced Hybrid Power Systems of the Future. Tucker, David, Shelton, Michael and Manivannan, A. Fall 2009, The Electrochemical Society Interface, pp. 45-48. 


\section{Appendices}

\section{Appendix A. MATLAB ${ }^{\mathrm{TM}}$ Code}

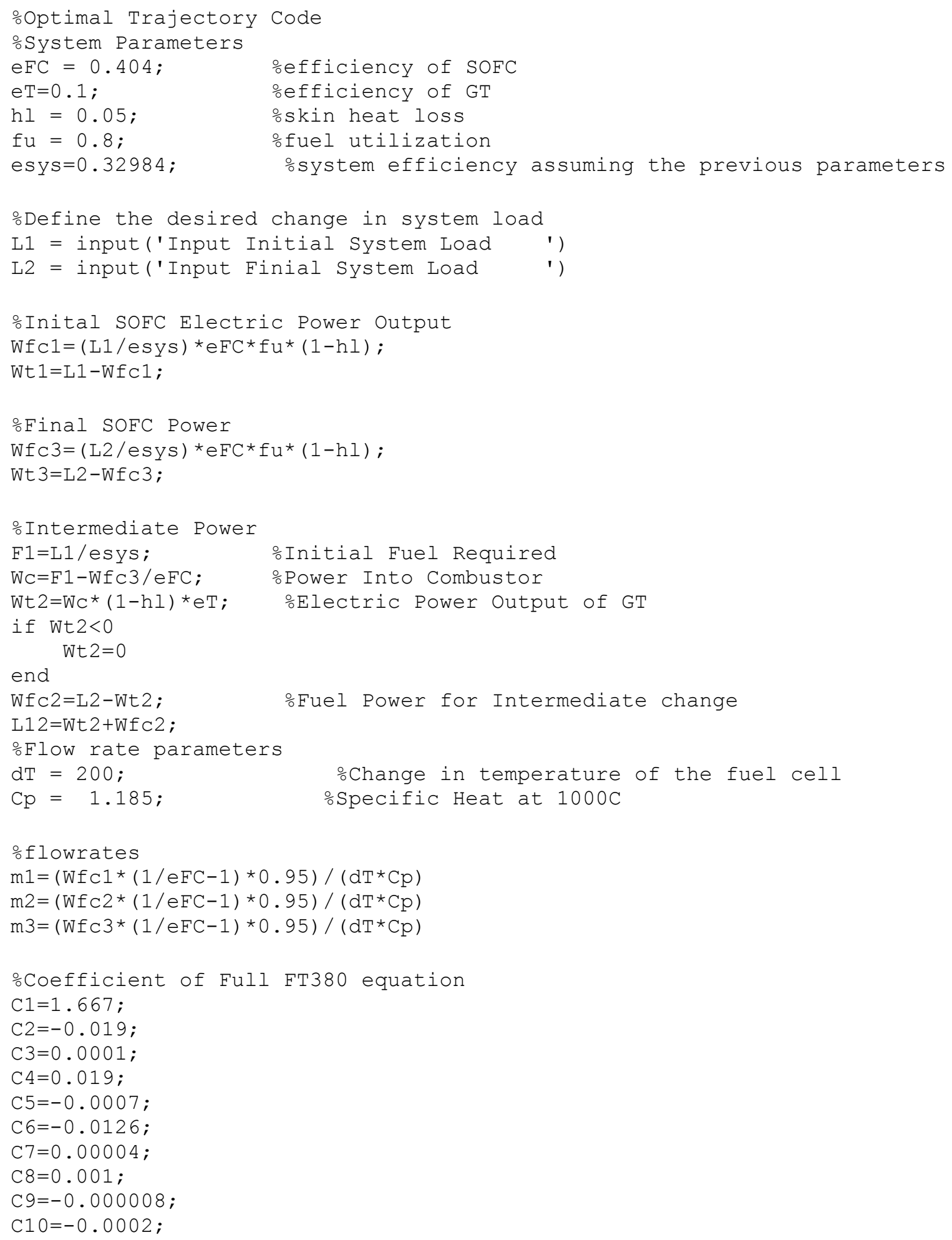




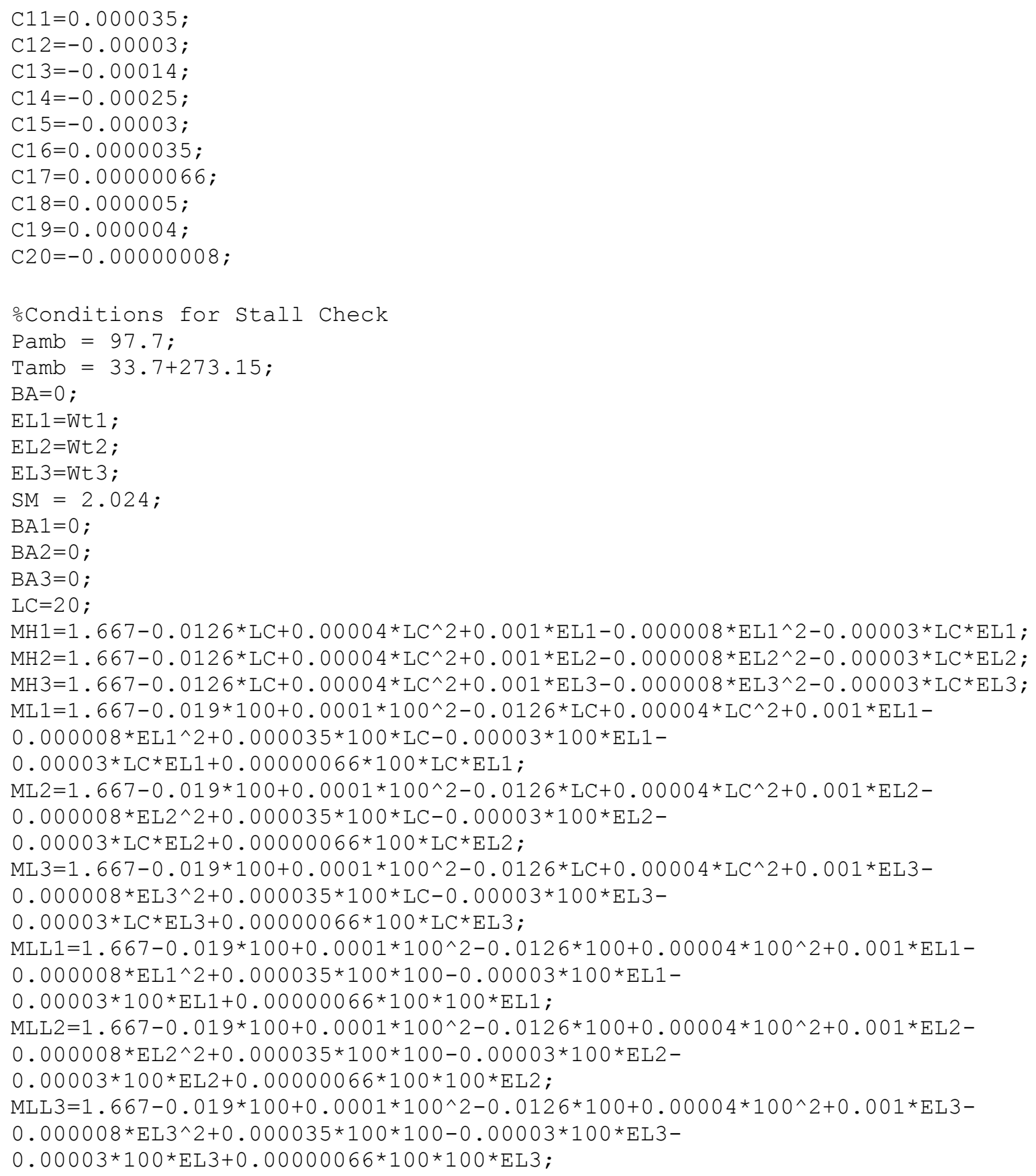




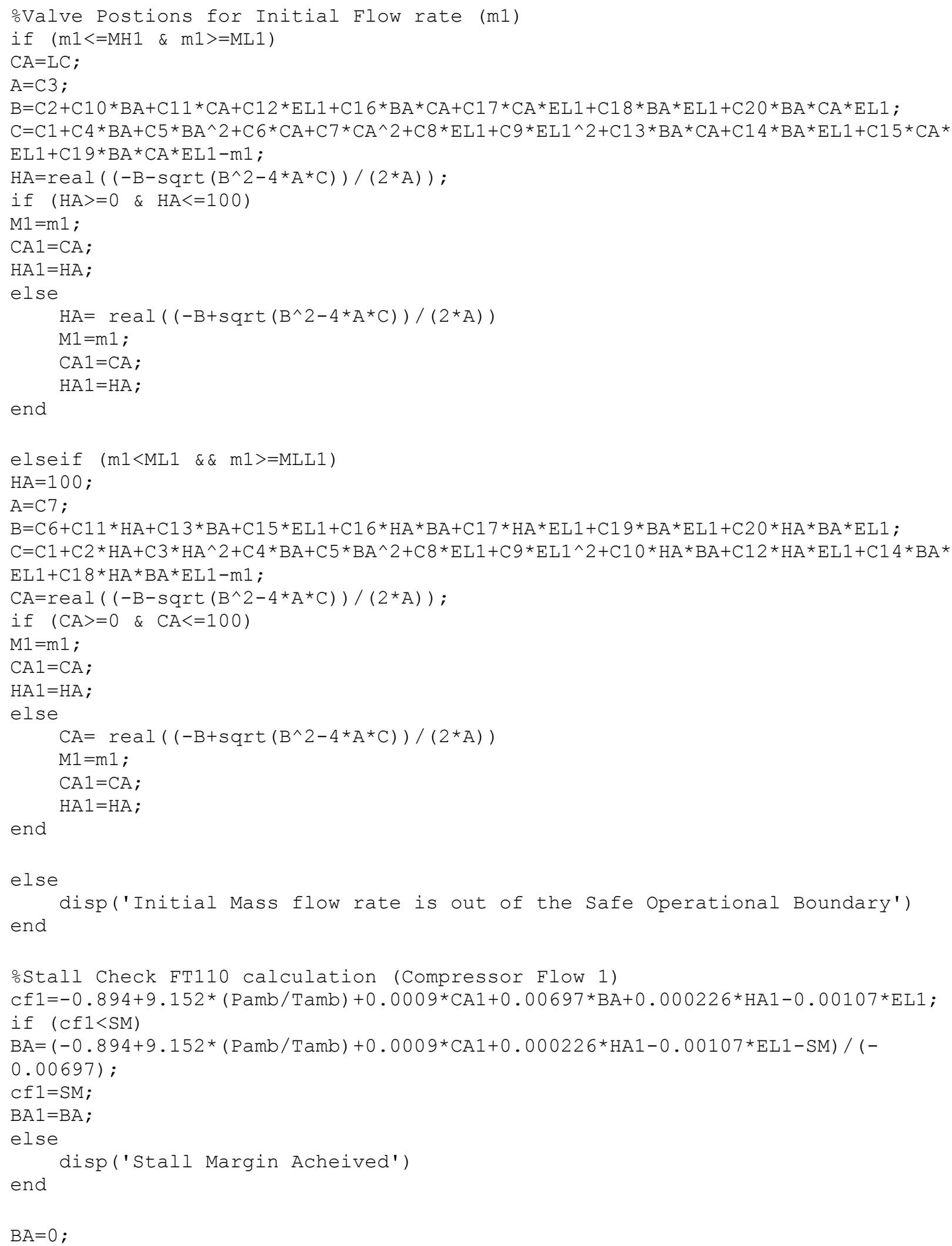




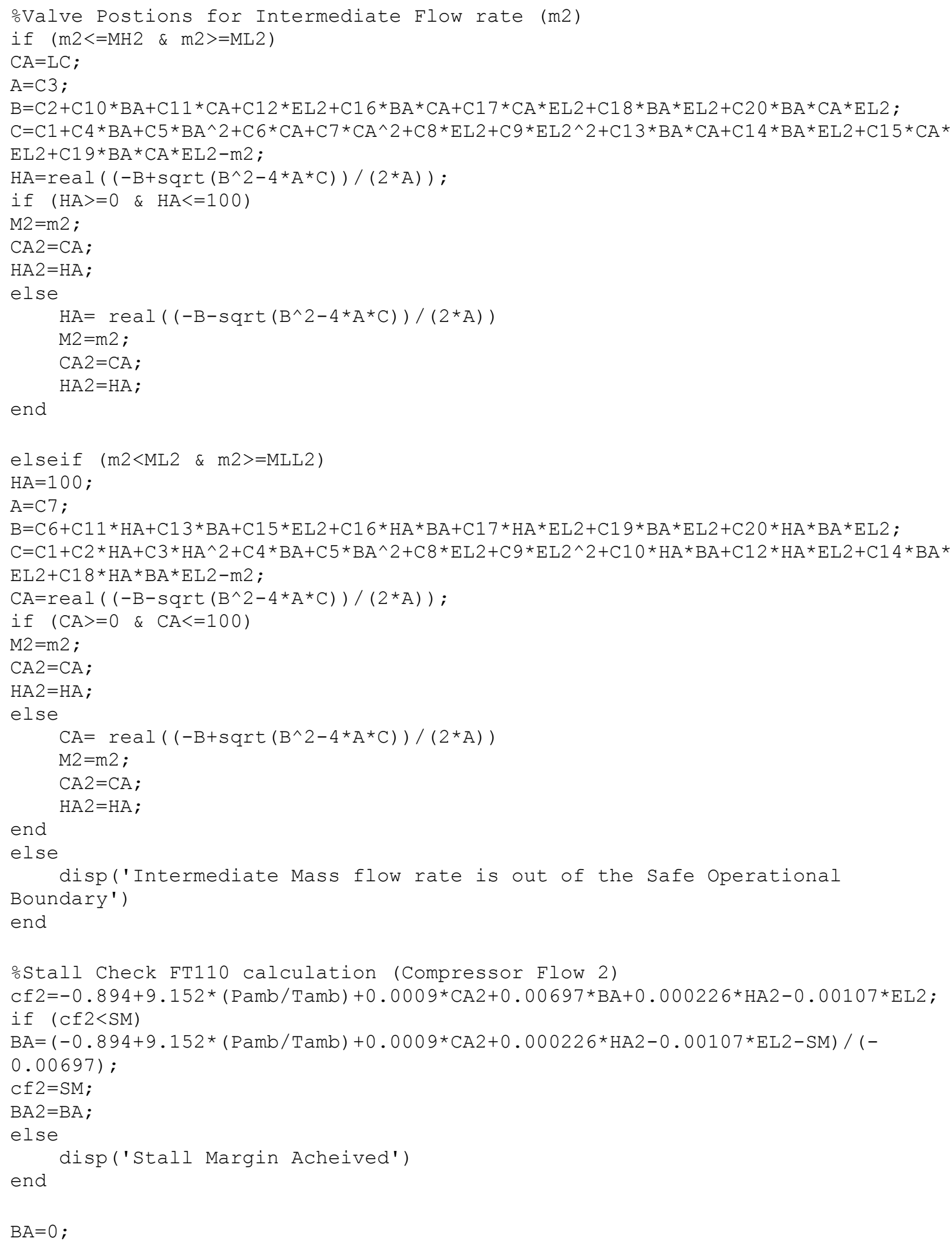




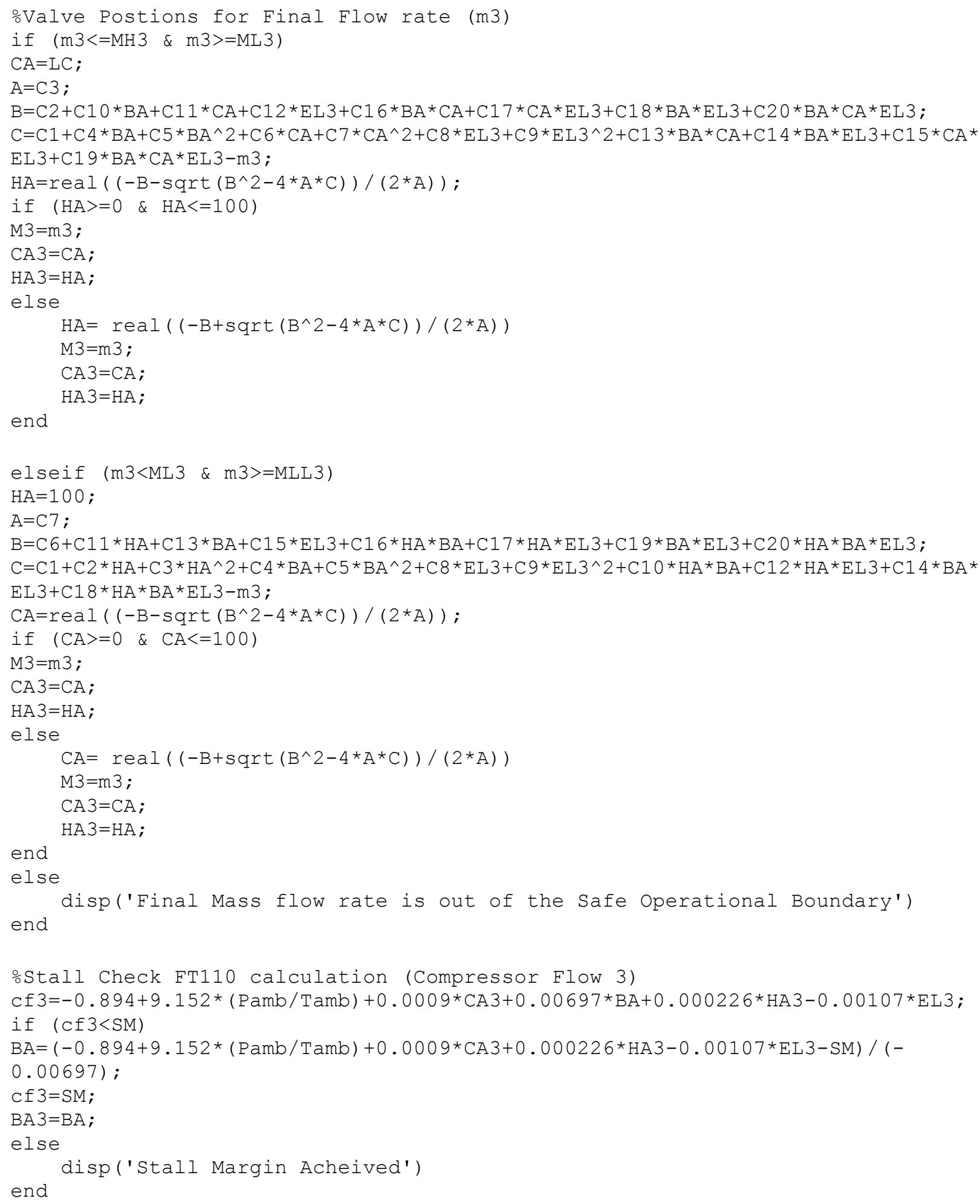




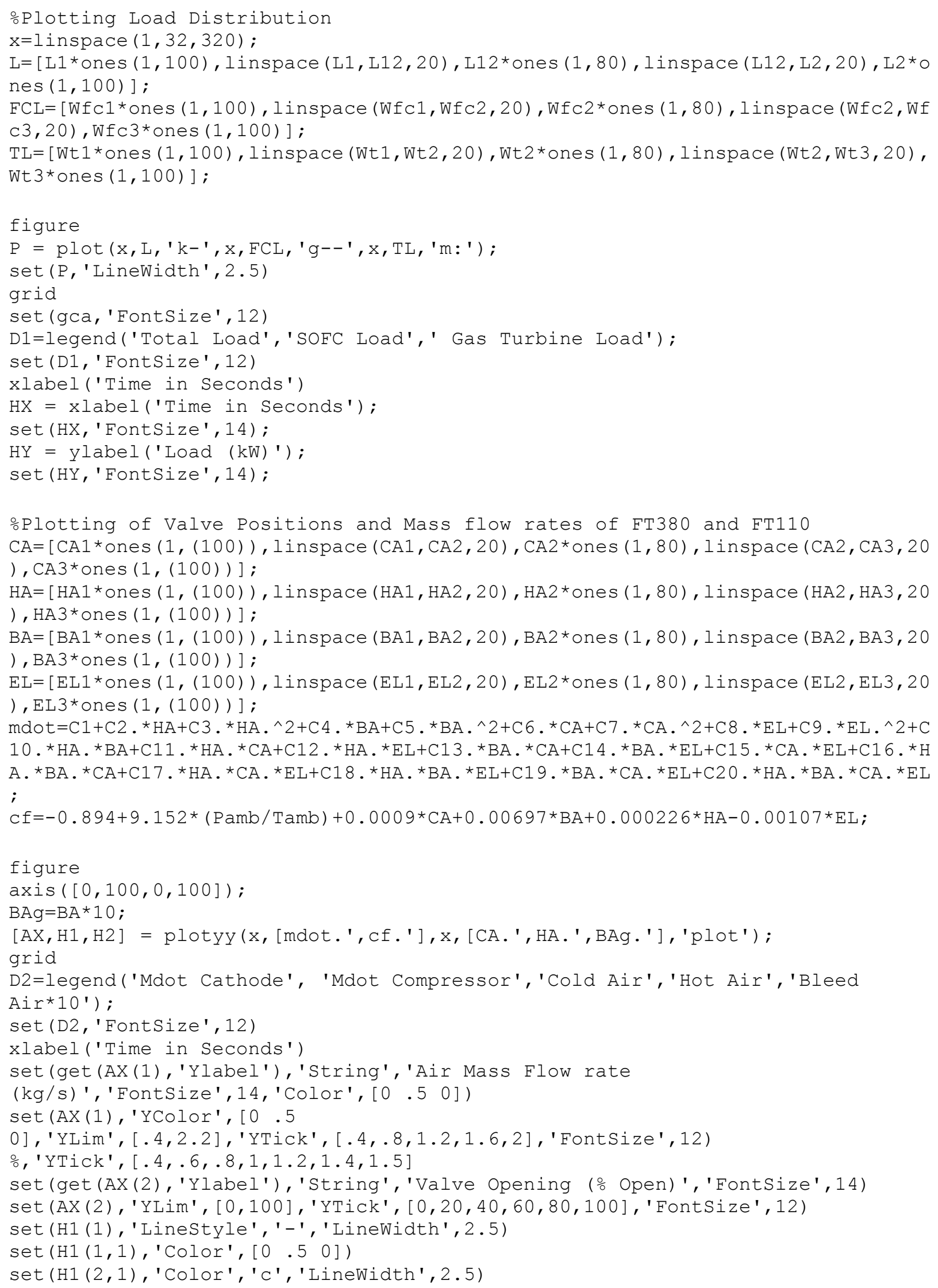




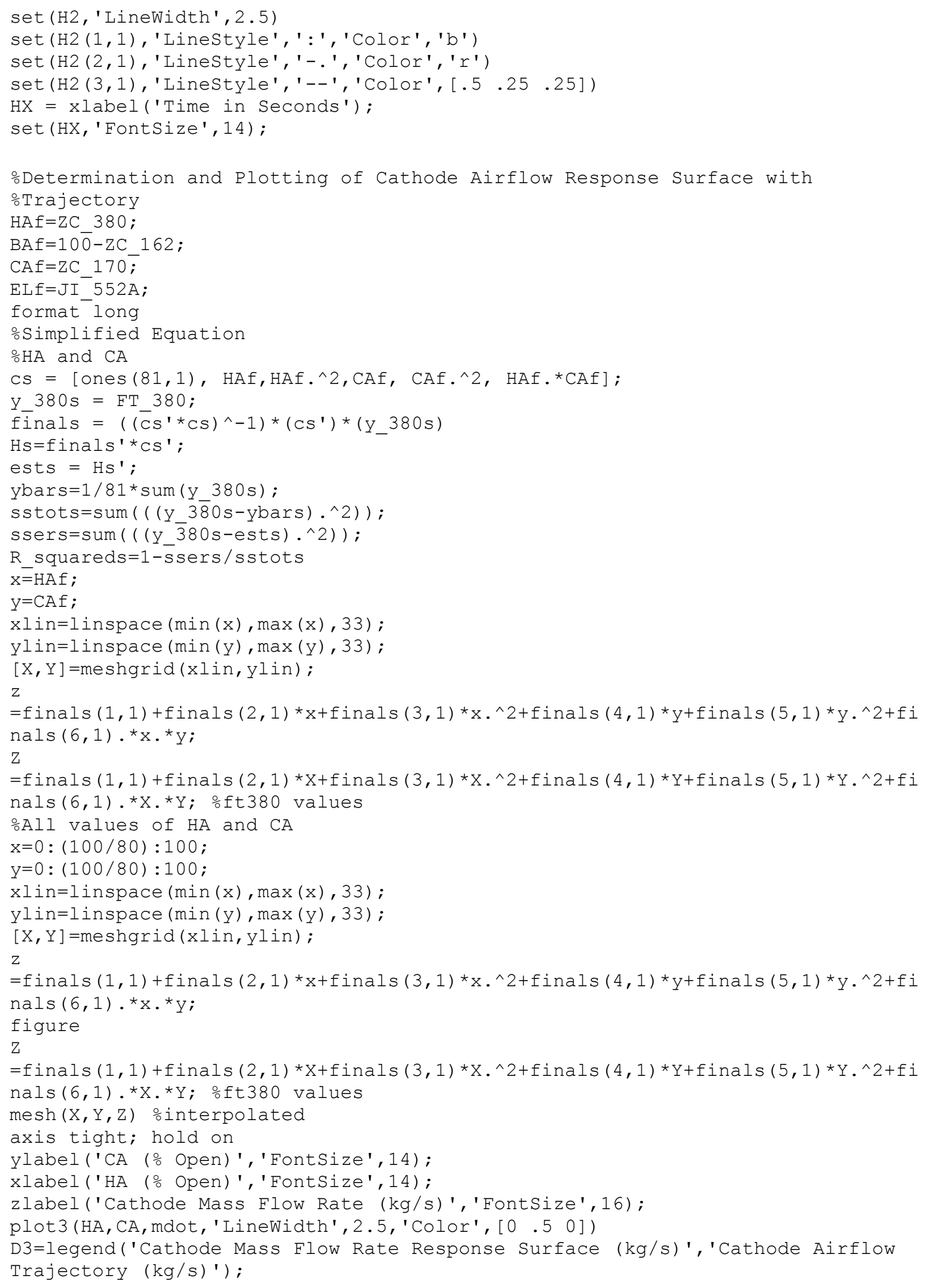




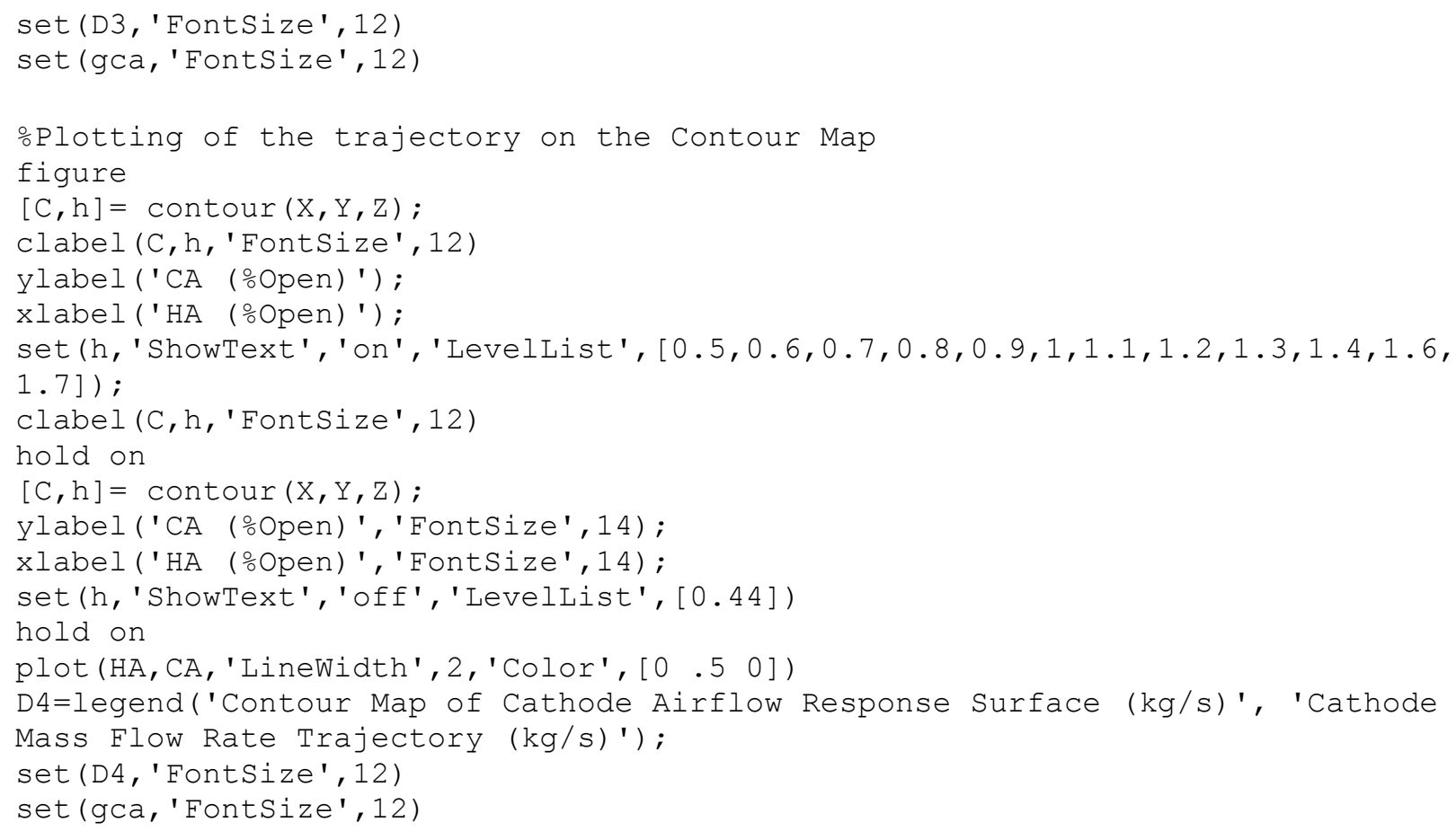




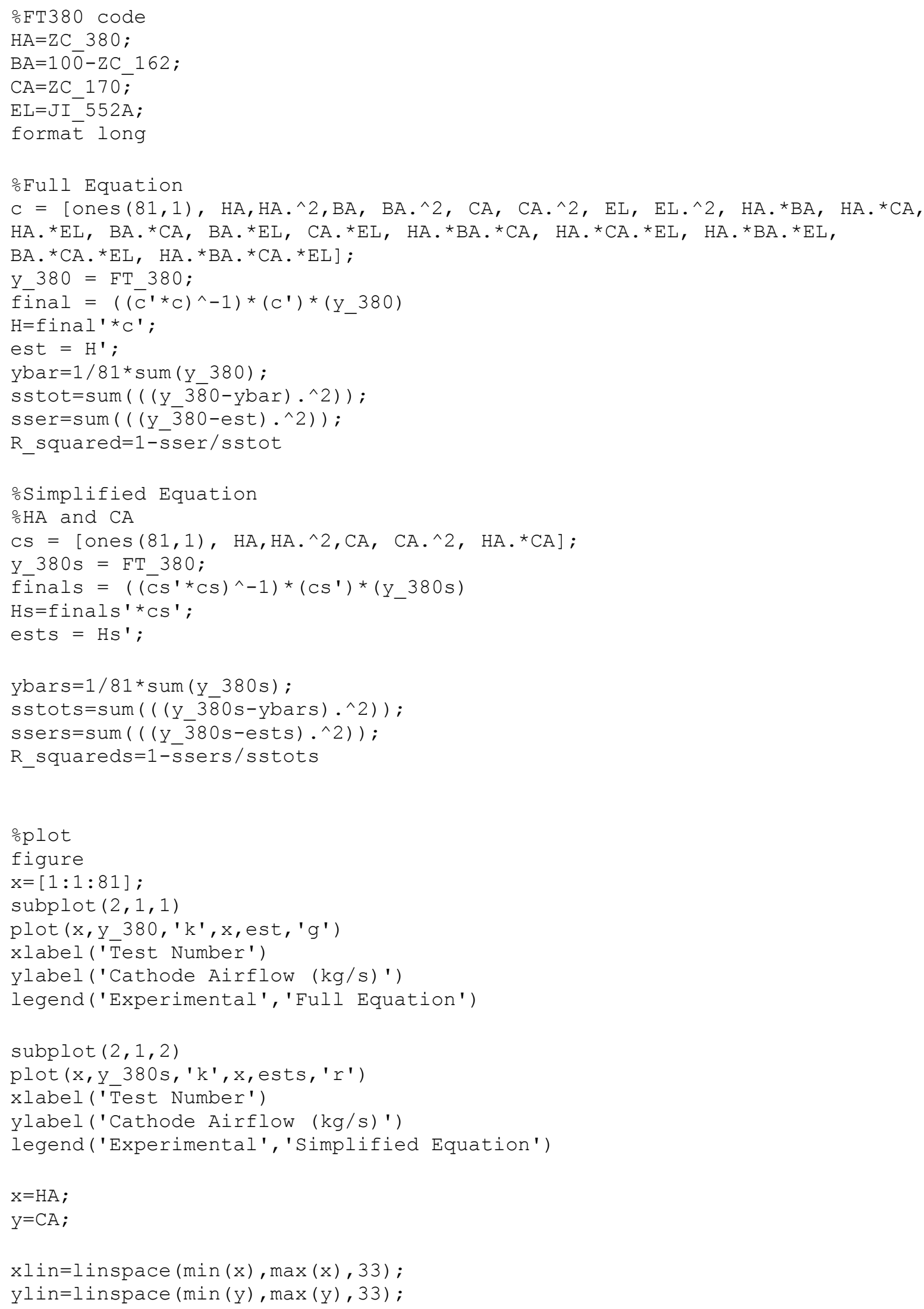




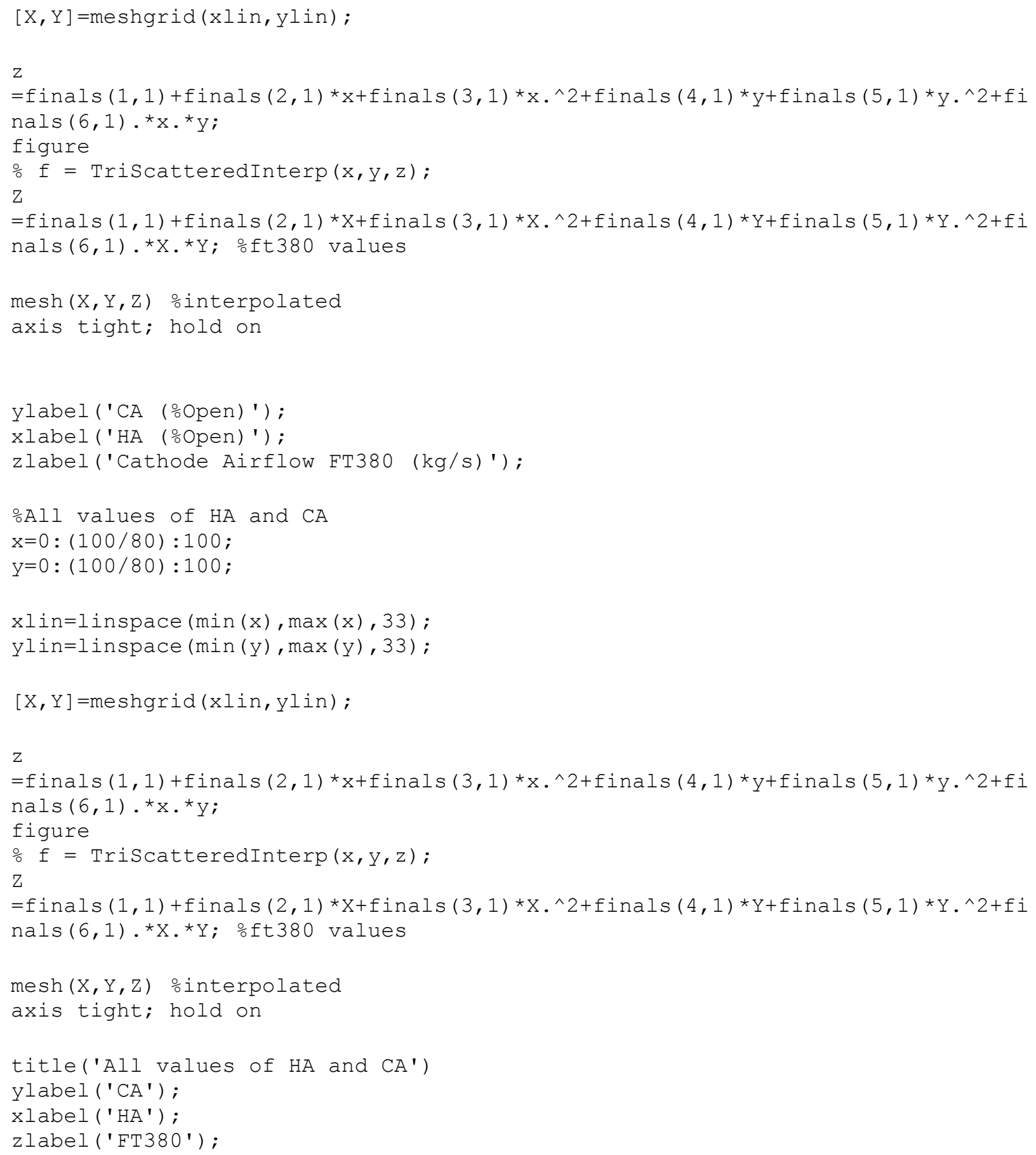




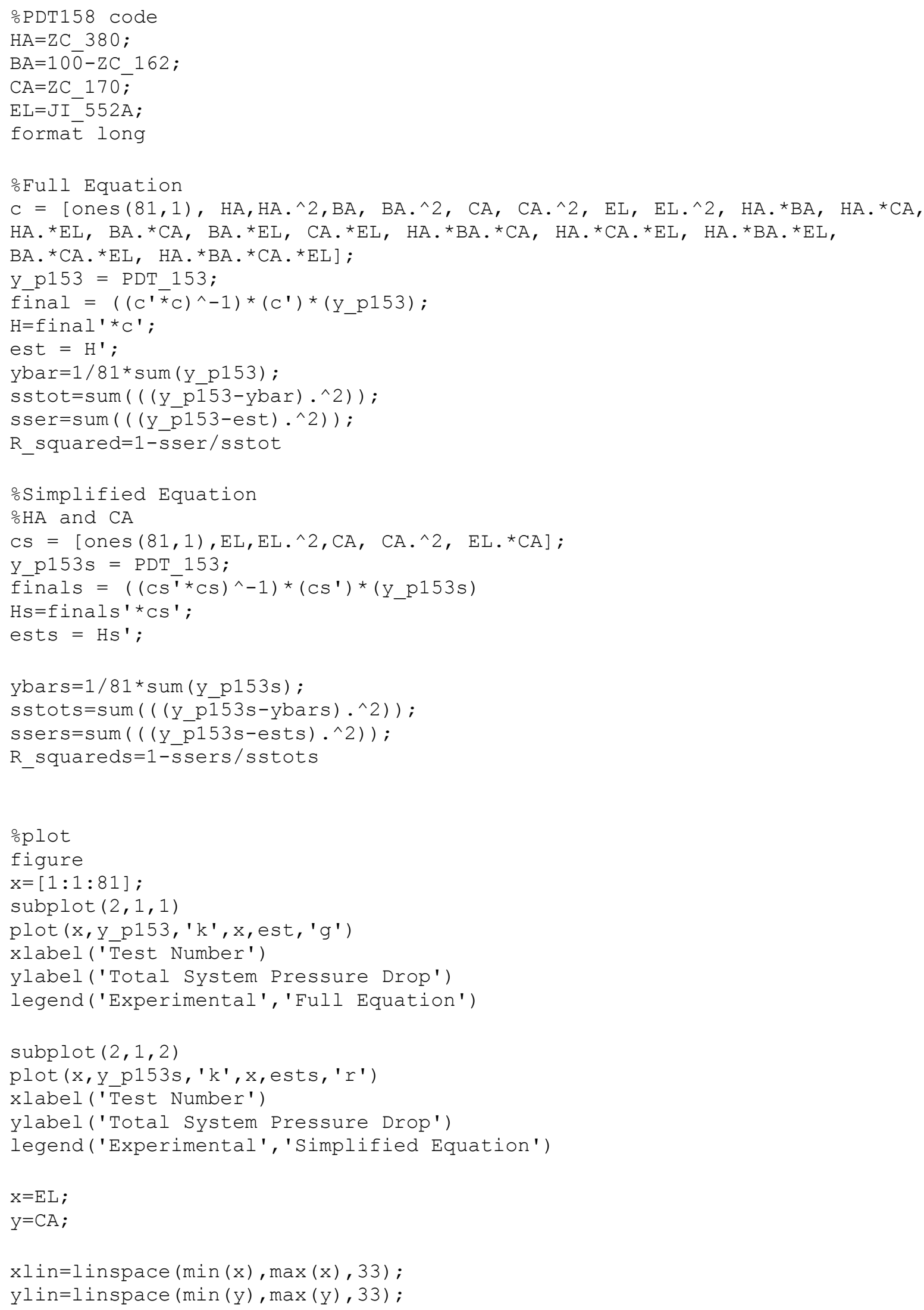




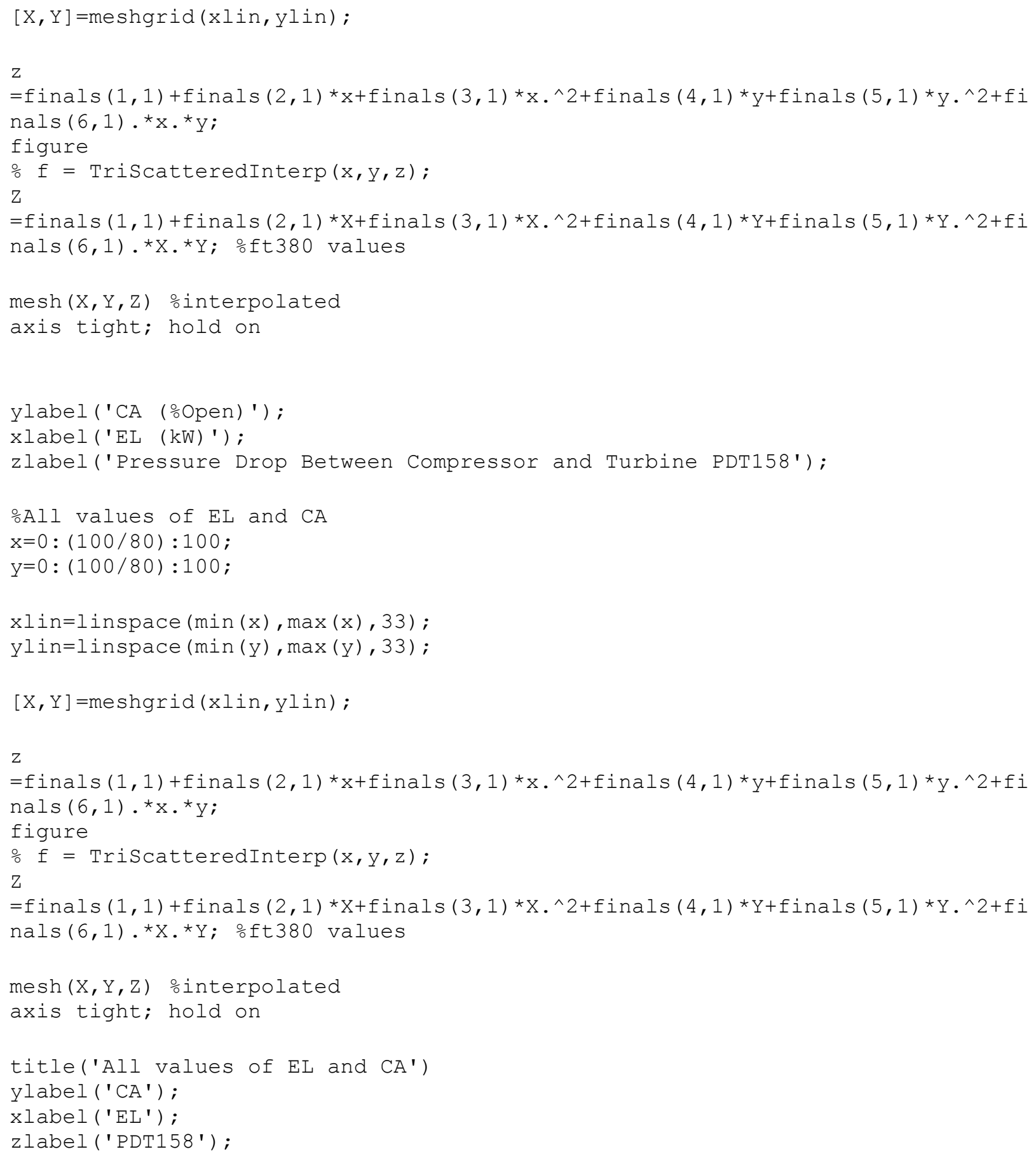




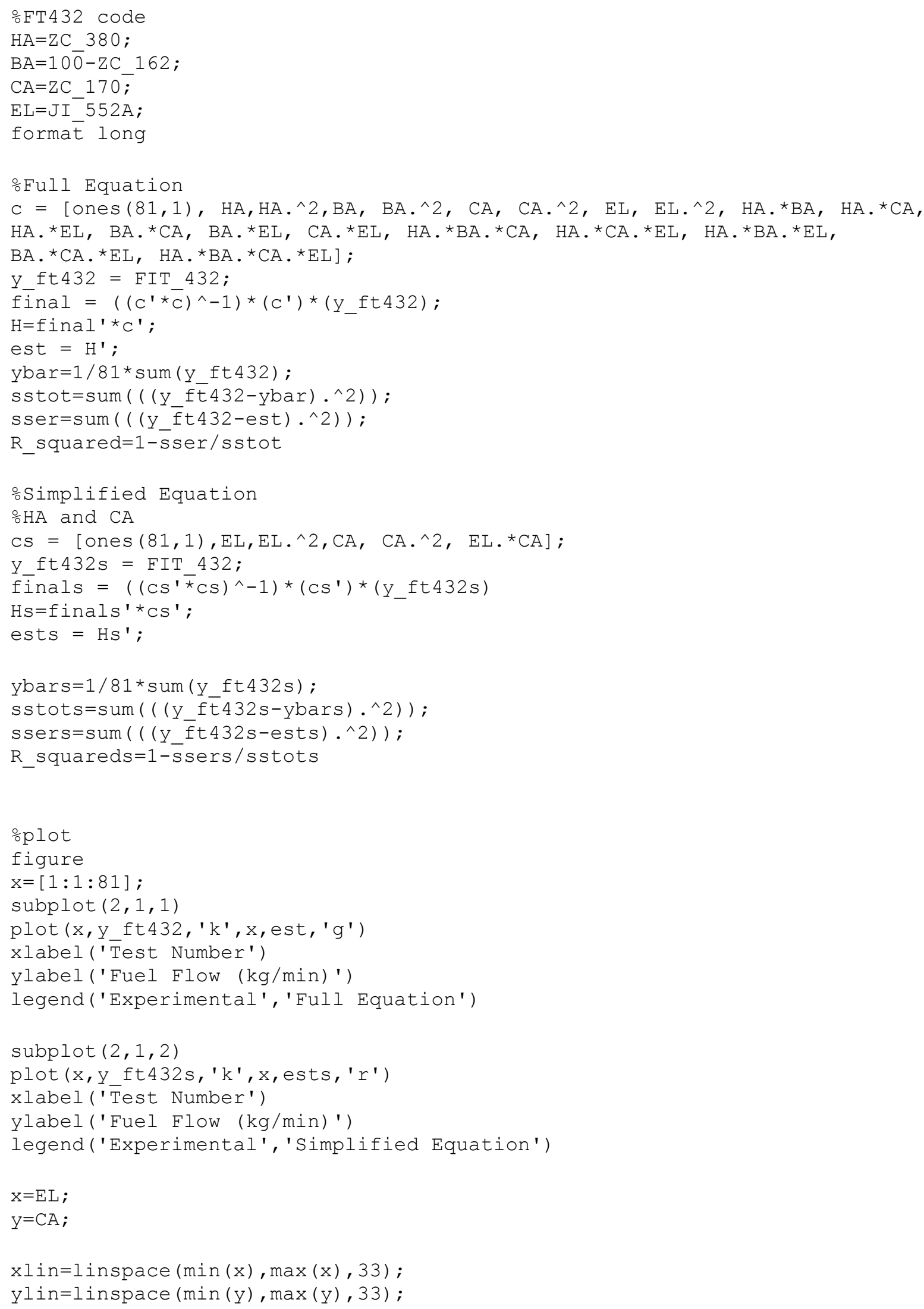




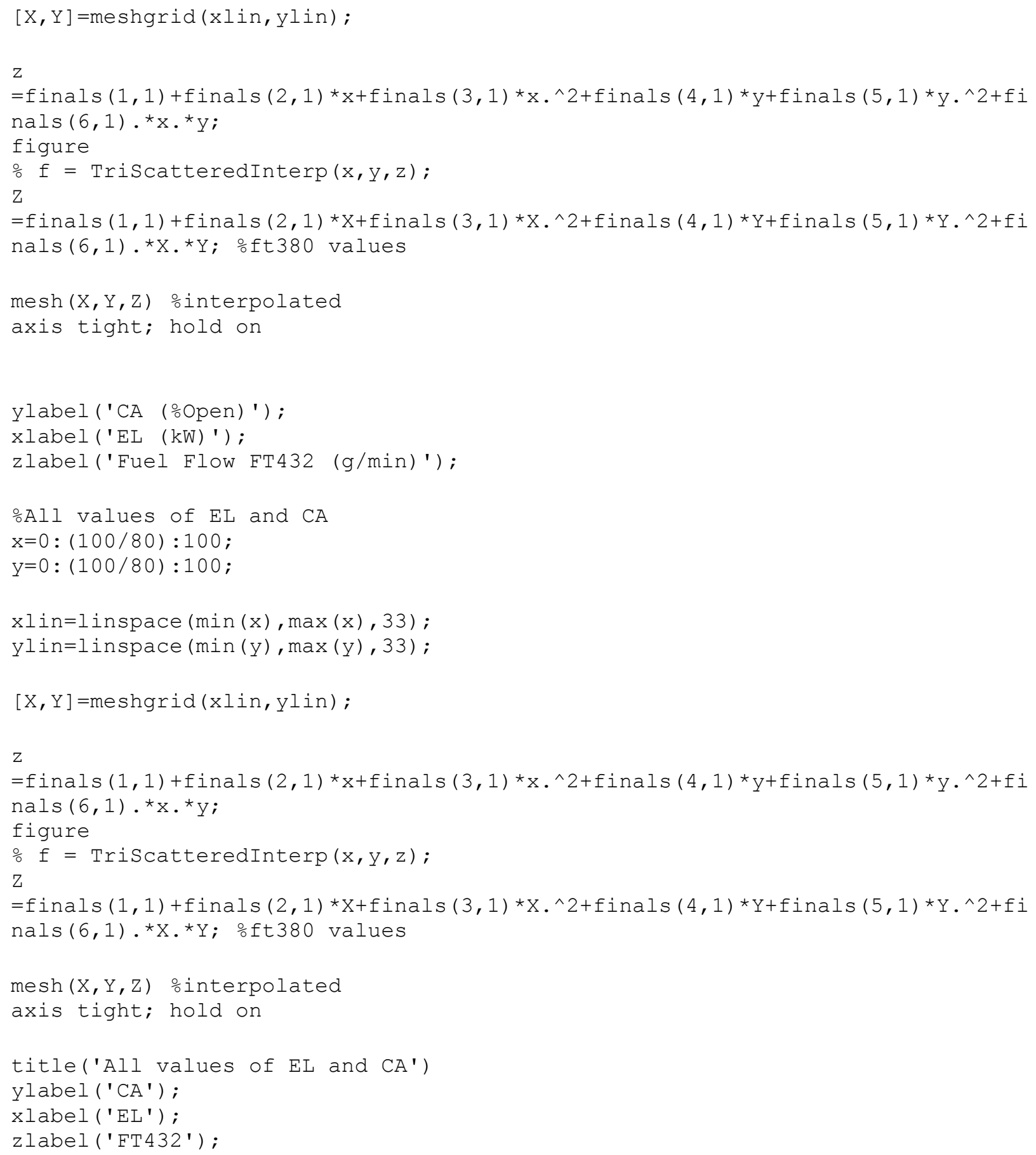




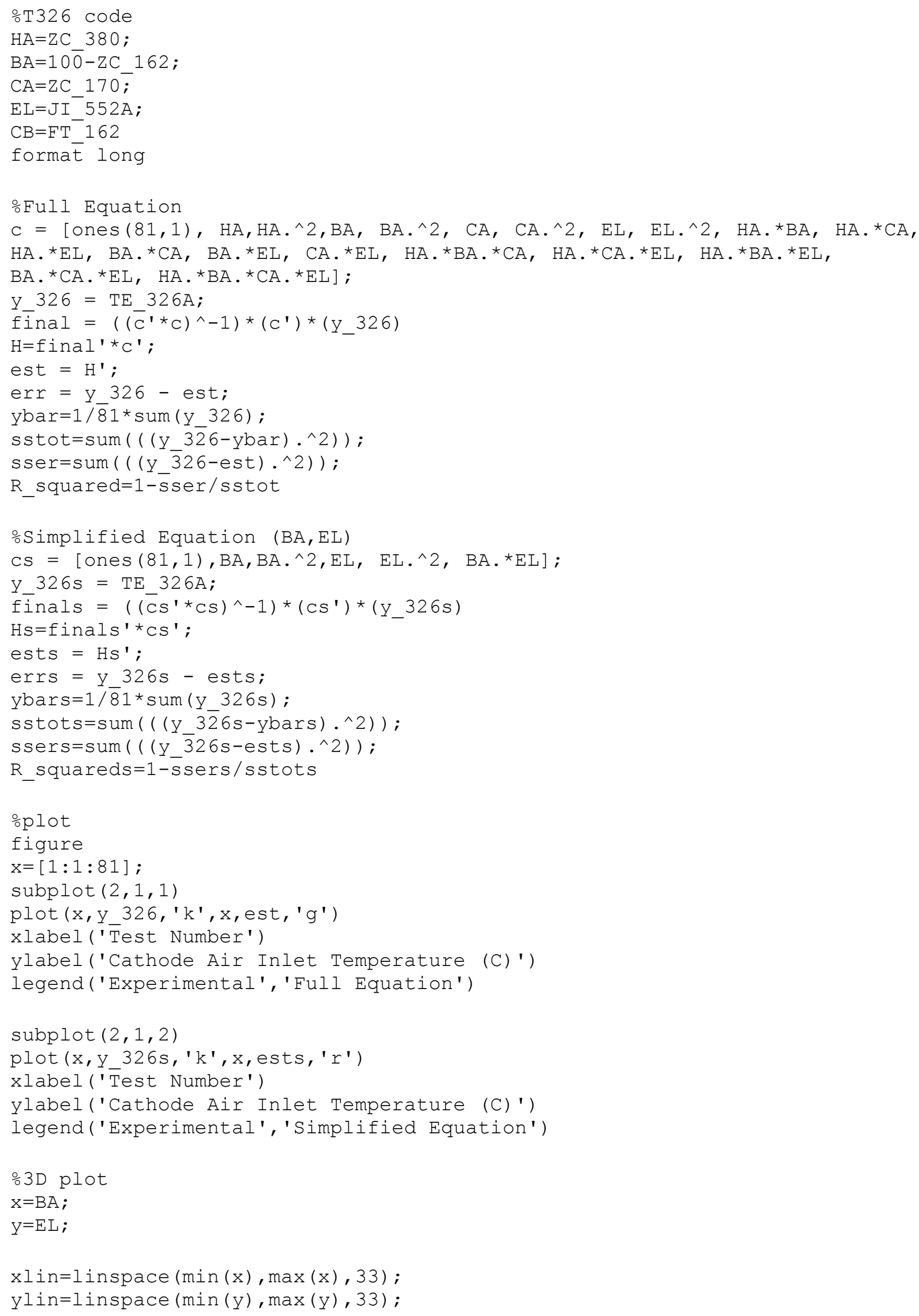




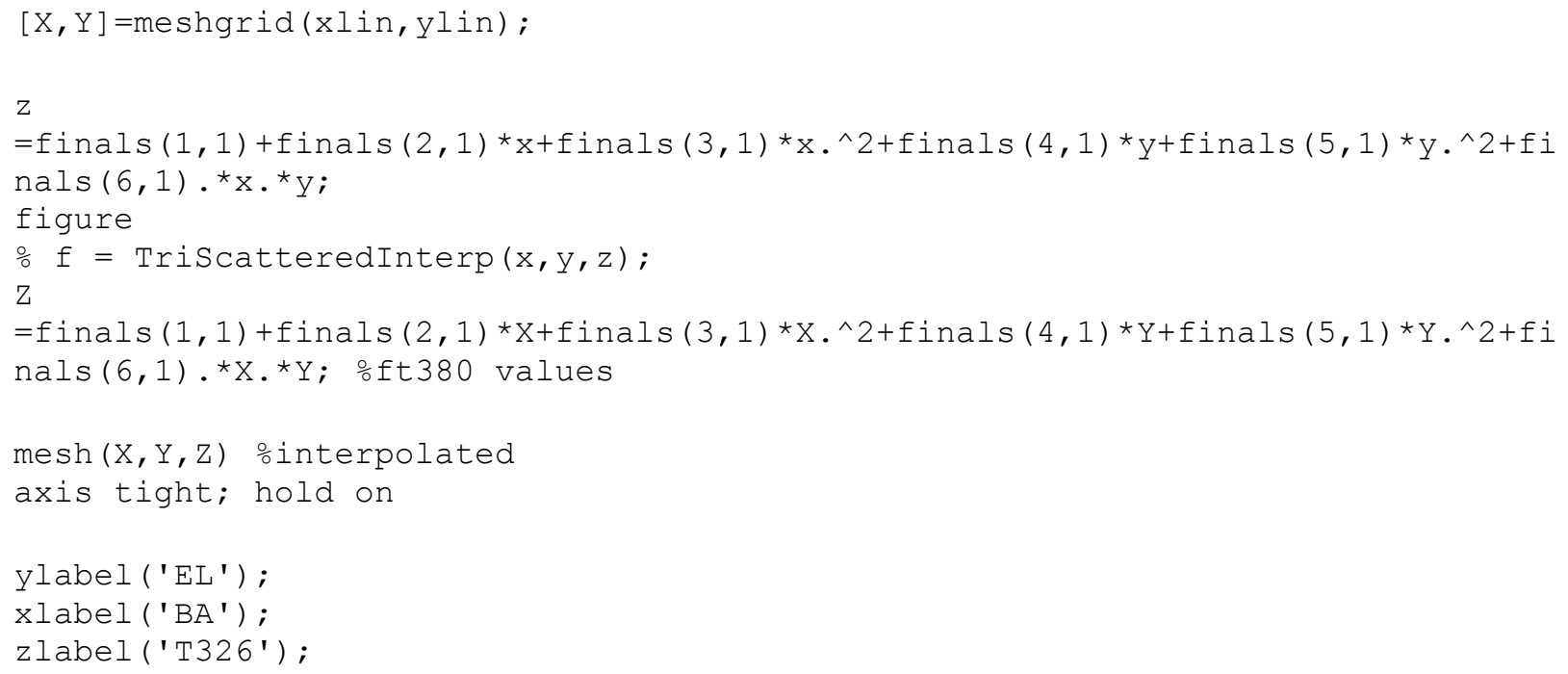




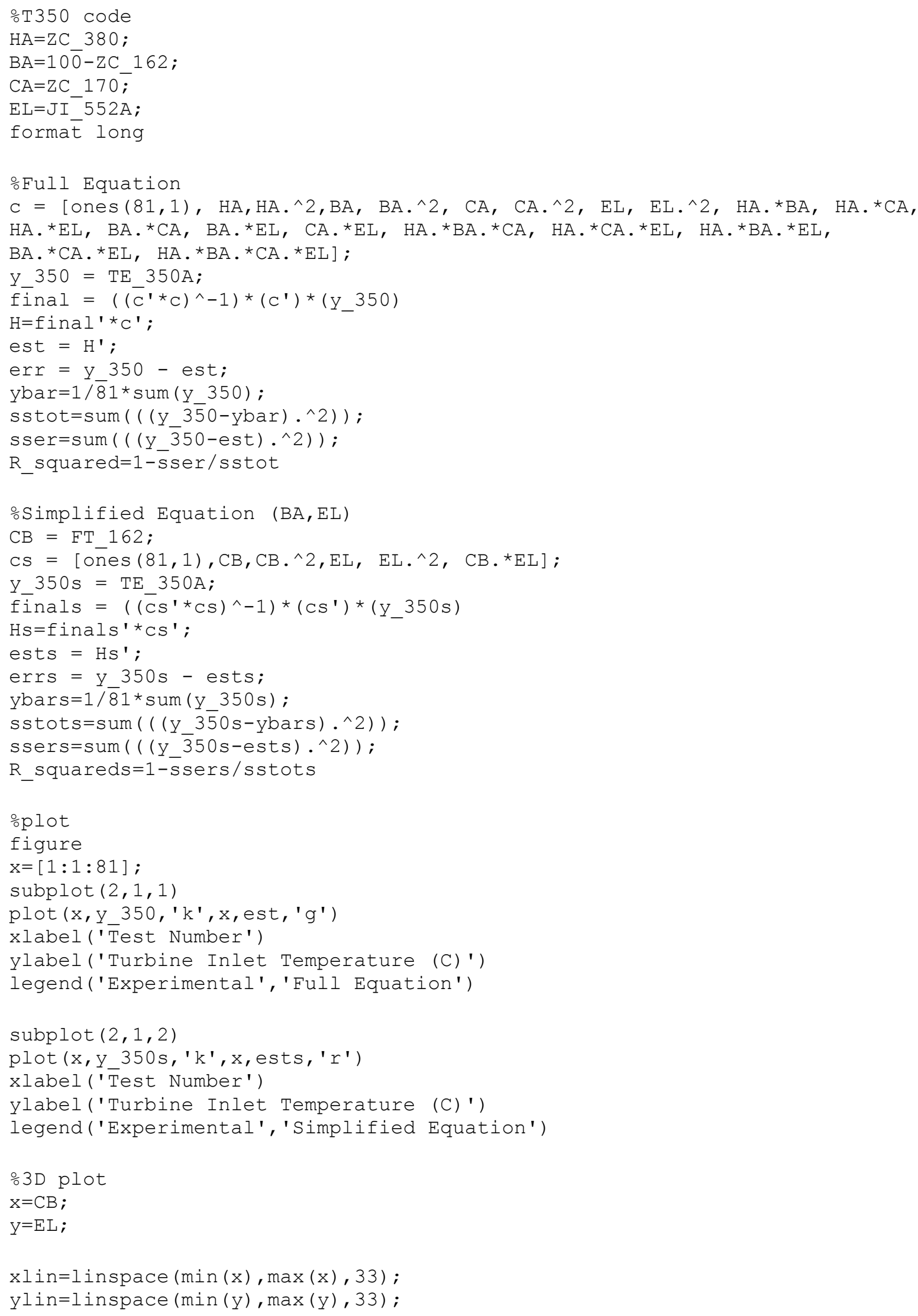




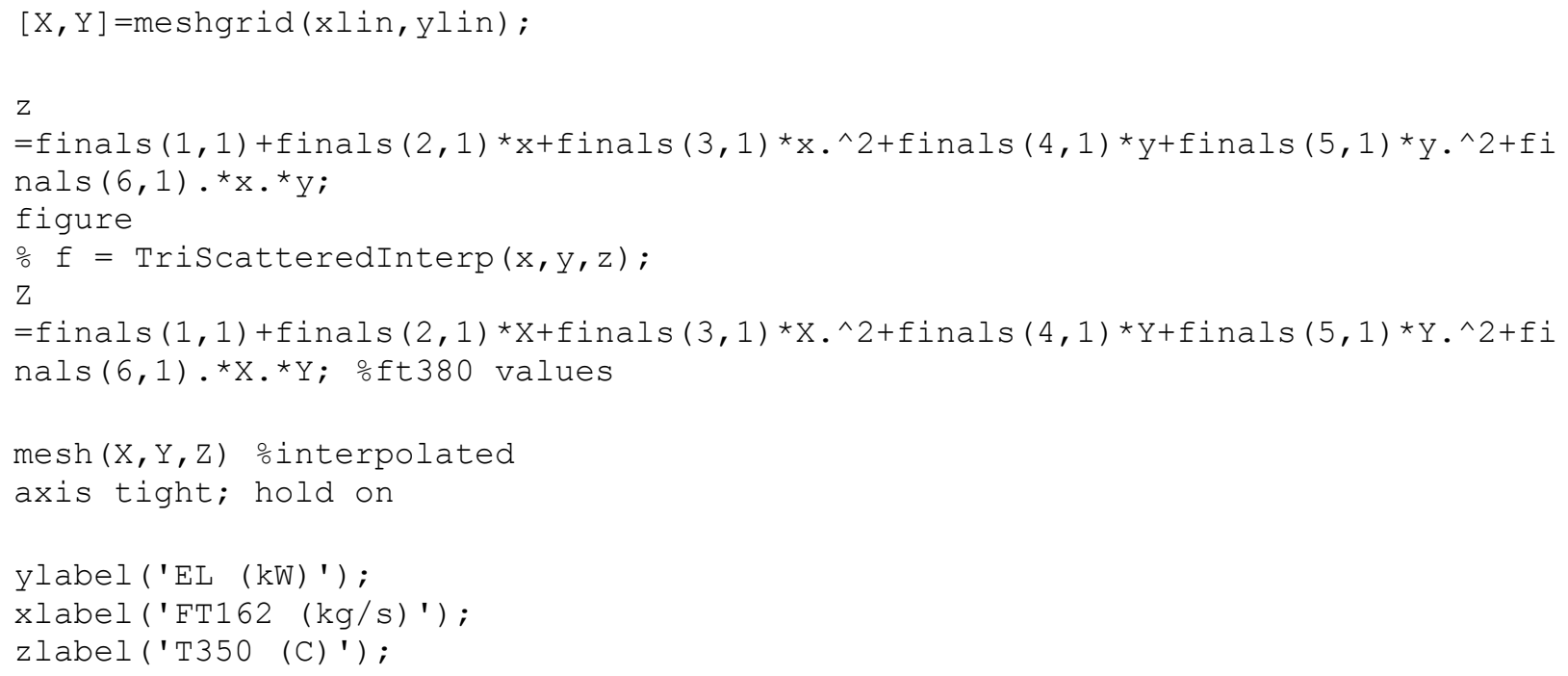




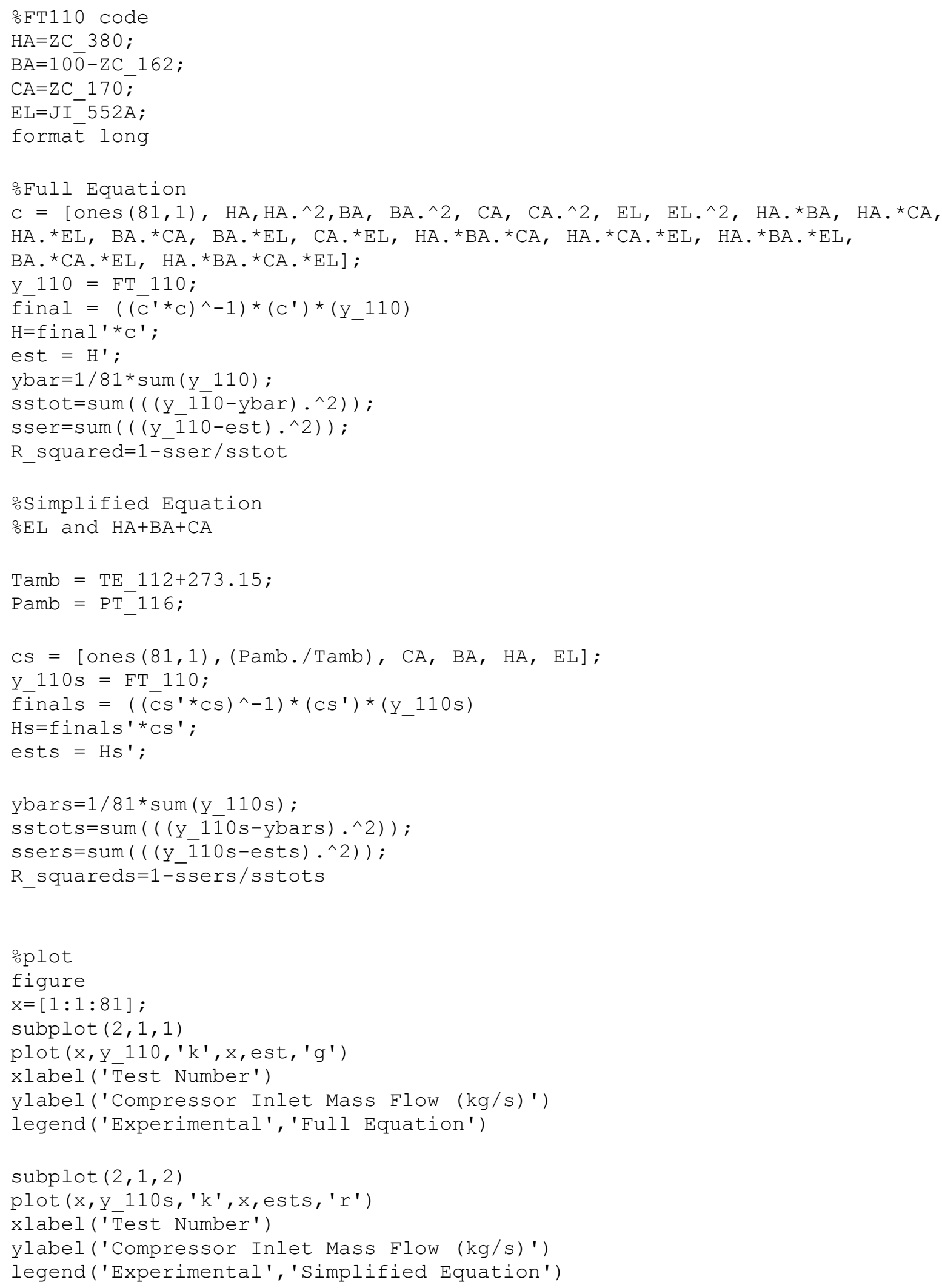


grid

legend('Mdot', 'Cold Air', 'Hot Air')

xlabel ('Time in seconds')

HX $=$ xlabel ('Time in Seconds');

set (HX, 'FontSize', 12);

ylabel ('Valve Opening/100; Air Flow in $\mathrm{kg} / \mathrm{s}$ ')

$\mathrm{HY}=$ ylabel ('Valve Opening/100; Air Flow in kg/s');

set (HY,'FontSize', 12); 


\section{Appendix B. Load Change Examples}

\begin{tabular}{|c|c|c|c|c|c|c|c|c|c|c|c|c|c|}
\hline & 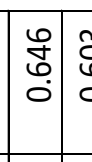 & 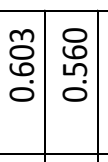 & 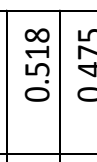 & 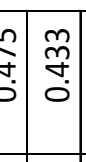 & 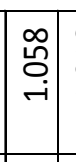 & 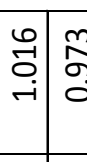 & 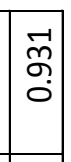 & 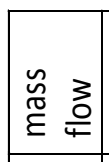 & $\left.\begin{array}{l}\infty \\
\infty \\
\infty\end{array}\right]$ & $\begin{array}{l}\text { శి } \\
\text { I }\end{array}$ & d্ & & \\
\hline 5 & 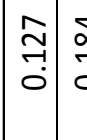 & 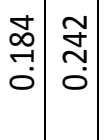 & 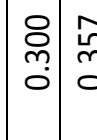 & 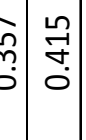 & : & \begin{tabular}{l}
7 \\
\hdashline \\
0
\end{tabular} & $\stackrel{n}{\grave{n}}$ & 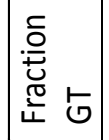 & & 总 & 总 & & \\
\hline & 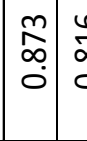 & \begin{tabular}{cc|c}
0 & $\infty$ \\
0 & 0 \\
0 & 0 \\
0 & 0 \\
0
\end{tabular} & \begin{tabular}{l|l}
0 & 9 \\
0 & 8 \\
0 & 0
\end{tabular} & 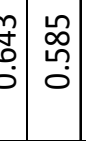 & & \begin{tabular}{l|l}
0 & $\pi$ \\
0 \\
0 \\
0
\end{tabular} & 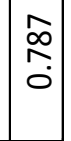 & 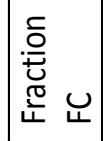 & รू & 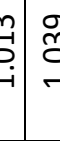 & s. & & 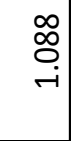 \\
\hline & 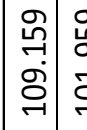 & 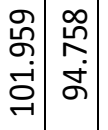 & 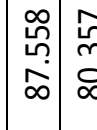 & 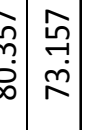 & $\mid$ & & & u & & 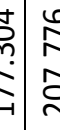 & $g$ & ֶָ. & 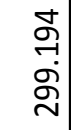 \\
\hline 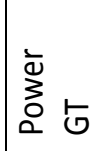 & $\begin{array}{l}\vec{f} \\
\dot{d} \\
\dot{f} \\
\vec{f}\end{array}$ & 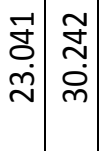 & 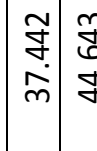 & 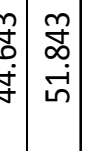 & : & 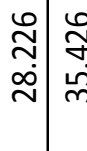 & $\left|\begin{array}{c}\tilde{\hat{\sigma}} \\
\dot{\gamma}\end{array}\right|$ & $\mid$ & : & $=$ & & ᄀ. & ఫ్ \\
\hline & 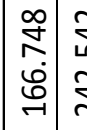 & 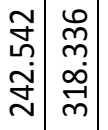 & 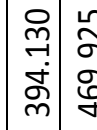 & & & 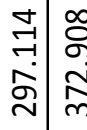 & $\left|\begin{array}{l}\tilde{o} \\
0 \\
o \\
q \\
f\end{array}\right|$ & 岶 & 品 & $f$ & 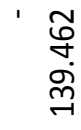 & 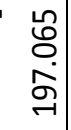 & \\
\hline يे & 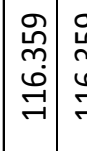 & 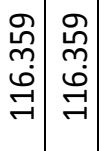 & 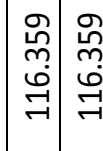 & 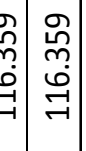 & $\mid$ & 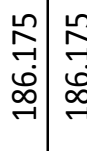 & 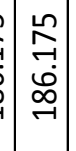 & 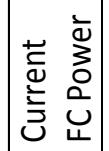 & 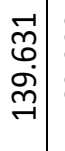 & 占 & & $\stackrel{\tilde{\sim}}{\sim}$ & \\
\hline & 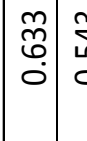 & 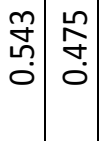 & 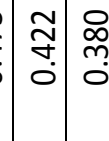 & 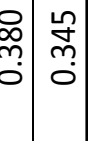 & $\mid$ & 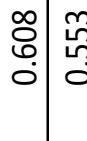 & 㤐 & 岂 & สี & 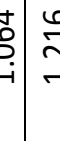 & $\stackrel{\infty}{\infty}$ & 요 & 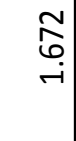 \\
\hline 资 & 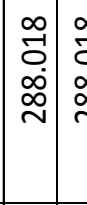 & 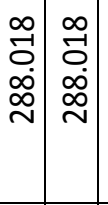 & & & 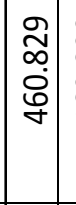 & & 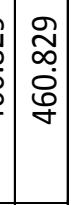 & 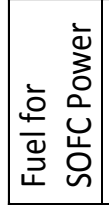 & 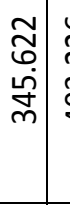 & 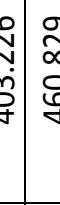 & 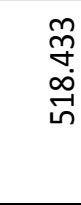 & & \\
\hline 势 & 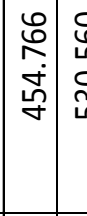 & 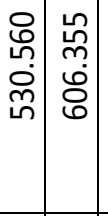 & 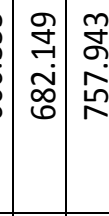 & & & 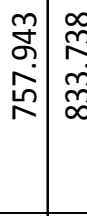 & $\tilde{\tilde{n}}$ & 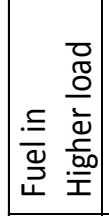 & & $\tilde{a}$ & & & $\bar{m}$ \\
\hline$\frac{\sigma}{\sigma}$ & $\stackrel{\overbrace{}}{\approx}$ & $\underset{\approx}{\approx}[\approx]$ & $\stackrel{\sim}{\approx} \stackrel{\sim}{\approx}$ & $\Xi \approx$ & 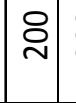 & ¿̊ & $\sim$ & 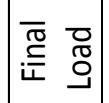 & $\vec{T}$ & & $\stackrel{\sim}{\approx}$ & $\sim$ & $\stackrel{\stackrel{n}{\sim}}{\sim}$ \\
\hline 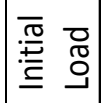 & $\stackrel{0}{\rightarrow-1}$ & 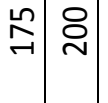 & 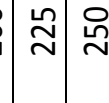 & 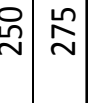 & $\stackrel{\mathscr{N}}{\sim}$ & 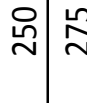 & 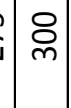 & 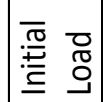 & & $\stackrel{\text { th }}{\Rightarrow}$ & $\stackrel{\sim}{\sim}$ & $\stackrel{\sim}{\Xi}$ & $\Xi$ \\
\hline 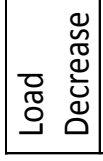 & & & & 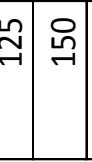 & & & : & 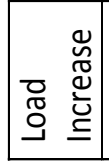 & & 是 & $\stackrel{\sigma}{-1}$ & 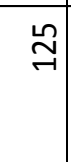 & 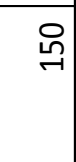 \\
\hline
\end{tabular}




\section{Appendix C. Data Points}

The data below is the measured data from multiple different parameters throughout the HyPer system.

This data was collected during the experiment and each row represents an averaged 1000 points. The

1000 points used were determined to be when the system was closest to steady state for each test point.

\begin{tabular}{|c|c|c|c|c|c|c|c|c|c|c|c|c|c|}
\hline $\begin{array}{l}\text { Test } \\
\text { Point }\end{array}$ & FIT432 & FT110 & FT162 & FT380 & JI552A & PDT158 & PT116 & TE112 & TE326A & TE350A & ZC162 & ZC170 & ZC380 \\
\hline 1 & 851.435 & 2.030 & 0.556 & 0.925 & 46 & 23.082 & 98.036 & 35.437 & 476.888 & 747.192 & 92.309 & 40.058 & 21.362 \\
\hline 2 & 579.303 & 2.127 & 0.849 & 0.790 & 0 & 16.887 & 97.877 & 34.579 & 366.725 & 594.723 & 92.507 & 60.634 & 21.384 \\
\hline 3 & 699.595 & 2.111 & 0.894 & 0.335 & 25 & 12.348 & 97.898 & 36.095 & 403.659 & 655.536 & & 80.672 & 81.123 \\
\hline 4 & 682.557 & 2.103 & 892 & 0.335 & 25 & 12.323 & 97.900 & 36.432 & 404.180 & 654.664 & 92.490 & 80.636 & 1.119 \\
\hline 5 & 681.029 & 2.034 & 448 & 0.573 & 45 & 19.359 & 97.952 & 37.416 & 459.119 & 726.758 & 92.499 & 40.073 & 1.479 \\
\hline 6 & 638.665 & 2.090 & 654 & 0.385 & 25 & 14.278 & 97.922 & 37.293 & 409.380 & 663.324 & 92.532 & 0.638 & 1.219 \\
\hline 7 & 536.917 & 2.088 & 543 & 0.959 & 0 & 22.446 & 97.894 & 36.386 & 74.226 & 179 & 91.263 & 102 & .262 \\
\hline 8 & 696.494 & 2.034 & 536 & 0.914 & 45 & 23.120 & 97.859 & 37.998 & 469.933 & 741.045 & 91.226 & 40.588 & 21.651 \\
\hline 9 & 690.634 & 2.135 & 0.917 & 0.336 & 25 & 12.459 & 97.914 & 37.064 & 19.084 & 670.972 & 89.227 & 80.608 & 81.361 \\
\hline 10 & 560.913 & 2.129 & 0.553 & 0.959 & 0 & 22.975 & 97.954 & 34.382 & 382.139 & 619.624 & 89.303 & 40.136 & 21.596 \\
\hline 11 & 554.055 & 2.157 & 0.526 & 0.485 & 0 & 18.649 & 97.958 & 33.862 & 370.562 & 603.851 & 89.285 & 40.134 & 81.228 \\
\hline 12 & 599.269 & 2.098 & 0.430 & 0.484 & 24 & 18.775 & 98.005 & 35.283 & 395.731 & 641 & 92.975 & 40.164 & 81.239 \\
\hline 13 & 609.410 & 2.073 & 0.528 & 0.946 & 24 & & & & .094 & & 92.956 & & .637 \\
\hline 14 & 573 & 2.143 & 84 & 94 & 0 & & & & 659 & & 66 & & .783 \\
\hline 15 & 70 & 2.128 & 3 & 0 & 24 & & & & 39 & & & & 847 \\
\hline 16 & 692 & 2.092 & 30 & 38 & 45 & & 97.778 & 93 & 474 & & 61 & & 789 \\
\hline 17 & 530 & 2.147 & 53 & 92 & 0 & & 28 & & 942 & & 51 & & 277 \\
\hline 18 & 729.246 & 2.099 & 686 & 0.474 & 45 & 55 & 97.849 & 35.205 & 518 & 92 & 549 & 732 & 845 \\
\hline 19 & 550.425 & 2.167 & 532 & 0.603 & 1 & 29 & 98.066 & 31.744 & 198 & 119 & 89.227 & 173 & .850 \\
\hline 20 & 645.609 & 2.117 & 555 & 0.935 & 24 & 23.106 & 98.026 & 33.394 & 422.488 & 933 & 90.650 & .178 & 2.163 \\
\hline 21 & 627.851 & 2.145 & 538 & 0.607 & 24 & 38 & 97.991 & 31.664 & 954 & 794 & 90.703 & 181 & 1.883 \\
\hline 22 & 678.657 & 2.153 & 0.864 & 0.757 & 24 & 17.197 & 97.911 & 32.196 & 415.238 & 041 & 90.714 & 745 & 22.019 \\
\hline 23 & 668.078 & 2.148 & 0.723 & 0.493 & 24 & 15.367 & 98.030 & 33.390 & 038 & 370 & 90.633 & 60.746 & 51.799 \\
\hline 24 & 713. & 2.149 & 1.060 & 0.631 & 24 & & & & 014 & & 89.319 & .770 & .585 \\
\hline 25 & 654. & 2.054 & & & 45 & & & & & & 30 & & 844 \\
\hline 26 & 647 & 2.113 & & & 24 & & & & & & & & \\
\hline 27 & 604.184 & 2.181 & 8 & 0 & 0 & & 97. & & 996 & & 29 & 33 & 354 \\
\hline 28 & 601 & 2.173 & 1 & 26 & 0 & & 51 & 40 & 07 & & 90 & 51 & 825 \\
\hline 29 & 729.291 & 2.065 & 770 & 0.740 & 45 & 17.325 & 98.001 & 36.594 & 301 & 010 & 92.743 & 168 & .950 \\
\hline 30 & 713.185 & 2.055 & 0.549 & 0.893 & 45 & 23.051 & 98.017 & 37.451 & 488.241 & 765.102 & 89.007 & 0.075 & 2.010 \\
\hline 31 & 551.911 & 2.144 & 0.879 & 46 & 0 & 39 & 97.924 & 36.478 & .714 & 939 & 92.445 & 696 & 0.745 \\
\hline 32 & 613.563 & 2.105 & 0.514 & 0.474 & 24 & 18.689 & 97.978 & 36.701 & 418.458 & 671.726 & 89.089 & 0.106 & .483 \\
\hline 33 & 774.915 & 2.086 & 09 & 0 & 46 & 12.981 & 97.886 & 37.453 & 916 & 187 & 92.472 & .705 & 1.879 \\
\hline 34 & 600.597 & 2.139 & 1.020 & 0.647 & 0 & 324 & 97.851 & 35.715 & .894 & 574.193 & 92.487 & 30.751 & 21.935 \\
\hline 35 & 779.779 & 2.097 & 0.942 & 0.402 & 45 & & 97.767 & 92 & 452 & 022 & 88.989 & 668 & 51.872 \\
\hline 36 & & 2.150 & & & 0 & & & & & & & & 875 \\
\hline 37 & 586.491 & 2.173 & & & 0 & & & & 304 & & 244 & & 854 \\
\hline 38 & 759. & & & & 40 & & & & & & & & 917 \\
\hline 39 & 672.245 & & & & 25 & & & & & & 599 & & 904 \\
\hline 40 & 588.757 & & 694 & & 0 & & 97. & & 88 & & 90.594 & & .931 \\
\hline 41 & 670.095 & 2.164 & 0.698 & 0.398 & 4 & 14.919 & 97.789 & 32.110 & 411.233 & 233 & 89.292 & 60.225 & 80.951 \\
\hline 42 & 803.582 & 2.138 & 1.066 & 0.616 & 45 & 382 & 97.579 & 32.564 & 463.828 & 717.404 & 89.295 & 80.693 & 21.906 \\
\hline 43 & 715.968 & 2.118 & 0.665 & 0.395 & 5 & 119 & 97.626 & 32.217 & 438.993 & 707.074 & 92.635 & 60.254 & 80.742 \\
\hline 44 & 597.326 & 2.137 & 0.477 & 0.603 & 25 & 19.875 & 97.638 & 30.828 & 394.744 & 642.183 & 92.625 & 40.172 & 51.982 \\
\hline 45 & 599.897 & 2.141 & 0.456 & 0.492 & 25 & 19.046 & 97.652 & 30.505 & 392.420 & 640.592 & 91.413 & 40.179 & 80.865 \\
\hline 46 & 751.839 & 2.135 & 0.892 & 0.344 & 46 & 12.980 & 97.588 & 31.286 & 435.393 & 695.194 & 91.407 & 80.795 & 80.900 \\
\hline 47 & 694.833 & 2.166 & 1.037 & 0.650 & 25 & 14.384 & 97.658 & 29.611 & 394.285 & 626.420 & 91.441 & 80.806 & 22.035 \\
\hline
\end{tabular}




\begin{tabular}{|c|c|c|c|c|c|c|c|c|c|c|c|c|c|}
\hline $\begin{array}{r}\text { Test } \\
\text { Point } \\
\end{array}$ & FIT432 & FT110 & FT162 & FT380 & JI552A & PDT158 & PT116 & TE112 & TE326A & TE350A & ZC162 & ZC170 & ZC380 \\
\hline 48 & 734.112 & 2.124 & 0.691 & 0.497 & 45 & 15.805 & 97.611 & 30.684 & 438.651 & 717.233 & 91.450 & 60.209 & 51.678 \\
\hline 49 & 644.099 & 2.155 & 0.690 & 0.508 & 25 & 15.678 & 97.721 & 29.866 & 391.880 & 650.141 & 92.741 & 60.215 & 51.536 \\
\hline 50 & 682.140 & 2.173 & 0.736 & 0.504 & 25 & 15.732 & 97.767 & 30.213 & 412.737 & 679.312 & 89.145 & 60.221 & 51.623 \\
\hline 51 & 627.542 & 2.205 & 1.058 & 0.659 & 1 & 14.174 & 97.697 & 29.405 & 363.747 & 585.764 & 90.707 & 80.808 & 22.248 \\
\hline 52 & 600.224 & 2.196 & 0.722 & 0.511 & 1 & 15.404 & 97.742 & 30.387 & 365.479 & 610.374 & 89.359 & 60.157 & 51.880 \\
\hline 53 & 693.768 & 2.095 & 0.519 & 0.471 & 46 & 18.971 & 97.855 & 33.395 & 458.754 & 730.112 & 90.626 & 40.147 & 81.042 \\
\hline 54 & 603.797 & 2.186 & 0.905 & 0.355 & 0 & 12.862 & 97.697 & 32.477 & 365.488 & 595.029 & 90.643 & 80.720 & 81.035 \\
\hline 55 & 708.206 & 2.148 & 0.956 & 0.413 & 24 & 12.963 & 97.708 & 33.633 & 411.571 & 665.567 & 90.642 & 80.716 & 51.919 \\
\hline 56 & 564.241 & 2.155 & 0.676 & 0.495 & 0 & 15.142 & 97.750 & 32.959 & 356.000 & 594.018 & 92.469 & 60.206 & 51.897 \\
\hline 57 & 548.193 & 2.118 & 0.526 & 0.950 & 0 & 22.556 & 97.715 & 33.103 & 365.134 & 600.469 & 92.470 & 40.169 & 22.188 \\
\hline 58 & 597.096 & 2.158 & 0.842 & 0.762 & 0 & 16.799 & 97.666 & 33.315 & 374.549 & 610.669 & 89.144 & 60.744 & 22.190 \\
\hline 59 & 624.242 & 2.111 & 0.530 & 0.596 & 24 & 19.540 & 97.597 & 35.070 & 419.824 & 674.945 & 89.040 & 40.168 & 51.699 \\
\hline 60 & 618.480 & 2.157 & 1.040 & 0.637 & 0 & 13.863 & 97.532 & 34.763 & 374.500 & 595.599 & 89.092 & 80.730 & 22.097 \\
\hline 61 & 661.154 & 2.098 & 0.788 & 0.753 & 24 & 16.895 & 97.545 & 35.550 & 407.335 & 661.114 & 92.511 & 60.129 & 22.114 \\
\hline 62 & 535.833 & 2.113 & 0.477 & 0.612 & 0 & 19.302 & 97.518 & 35.228 & 361.560 & 590.281 & 92.500 & 40.119 & 51.777 \\
\hline 63 & 775.378 & 2.089 & 0.911 & 0.328 & 45 & 12.538 & 97.562 & & 469.371 & 740.659 & 89.095 & 80.715 & 80.888 \\
\hline 64 & 773.308 & 2.089 & 0.934 & 0.394 & 45 & 12.816 & 97.569 & 37.899 & 470.760 & 744.589 & 90.512 & 80.703 & 51.707 \\
\hline 65 & 584.277 & 2.151 & 0.913 & 0.424 & 0 & 12.790 & 97.466 & 34.562 & 357.563 & 588.787 & 92.340 & 80.745 & 51.710 \\
\hline 66 & 748.974 & 2.069 & 0.786 & 0.722 & 48 & 17.275 & 97.489 & 35.698 & 466.594 & 738.107 & 91.221 & 60.195 & 22.665 \\
\hline 67 & 733.115 & 2.089 & 0.655 & 0.385 & 48 & 14.866 & 97.415 & 35.506 & 457.806 & 734.133 & 91.176 & 60.185 & 80.697 \\
\hline 68 & 688.368 & 2.084 & 0.509 & 0.467 & 48 & 19.009 & 97.422 & 35.135 & 473.247 & 747.325 & 89.188 & 40.115 & 80.821 \\
\hline 69 & 753.903 & 2.097 & 0.890 & 0.333 & 48 & 12.723 & 97.382 & 34.776 & 452.810 & 713.742 & 92.677 & 80.708 & 80.788 \\
\hline 70 & 703.244 & 2.171 & 0.975 & 0.426 & 23 & 13.186 & 97.278 & 30.456 & 413.357 & 664.355 & 89.289 & 80.814 & 51.734 \\
\hline 71 & 546.163 & 2.170 & 0.533 & 0.623 & 0 & 19.665 & 97.305 & 29.514 & 364.971 & 596.691 & 90.874 & 40.197 & 51.708 \\
\hline 72 & 570.852 & 2.173 & 0.671 & 0.412 & 0 & 14.706 & 97.395 & 29.086 & 349.909 & 580.651 & 92.770 & 60.792 & 80.487 \\
\hline 73 & 648.555 & 2.126 & 0.579 & 0.949 & 24 & 23.253 & 97.286 & 29.761 & 424.177 & 683.071 & 89.321 & 40.198 & 21.910 \\
\hline 74 & 785.202 & 2.116 & 1.032 & 0.622 & 45 & 14.150 & 97.224 & 30.170 & 442.828 & 688.000 & 92.754 & 80.734 & 21.910 \\
\hline 75 & 741.535 & 2.122 & 0.753 & 0.493 & 45 & 15.582 & 97.333 & 30.502 & 459.421 & 741.618 & 89.342 & 60.196 & 51.398 \\
\hline 76 & 545.243 & 2.176 & 0.512 & 0.496 & 0 & 18.666 & 97.376 & 29.110 & 362.756 & 595.300 & 90.822 & 40.184 & 80.566 \\
\hline 77 & 613.194 & 2.196 & 0.949 & 0.429 & 0 & 12.906 & 97.359 & 28.934 & 361.909 & 597.131 & 90.826 & 80.782 & 51.971 \\
\hline 78 & 745.182 & 2.116 & 0.718 & 0.391 & 46 & 14.840 & 97.326 & 31.602 & 461.634 & 739.678 & 89.378 & 60.215 & 80.732 \\
\hline 79 & 795.344 & 2.109 & 1.049 & 0.604 & 46 & 14.044 & 97.166 & 32.584 & 467.900 & 717.268 & 90.636 & 80.734 & 22.099 \\
\hline 80 & 654.300 & 2.132 & 0.688 & 0.395 & 25 & 14.789 & 97.399 & 31.897 & 414.196 & 673.258 & 90.631 & 60.185 & 80.900 \\
\hline 81 & 691.893 & 2.075 & 0.522 & 0.571 & 45 & 19.371 & 97.388 & 33.000 & 465.644 & 738.734 & 90.624 & 40.156 & 51.988 \\
\hline
\end{tabular}

